\title{
Island questions: the chronology of the Brochtorff Circle at Xaghra, Gozo, and its significance for the Neolithic sequence on Malta
}

\author{
Caroline Malone ${ }^{1} \cdot$ Nathaniel Cutajar ${ }^{2} \cdot$ T. Rowan McLaughlin ${ }^{1} \cdot$ Bernardette Mercieca-Spiteri ${ }^{3} \cdot$ Anthony Pace $^{4}$. \\ Ronika K. Power ${ }^{5}$. Simon Stoddart ${ }^{6}$. Sharon Sultana ${ }^{2}$. Christopher Bronk Ramsey ${ }^{7}$. Elaine Dunbar ${ }^{8}$. \\ Alex Bayliss ${ }^{9,10} \cdot$ Frances Healy ${ }^{11}$ - Alasdair Whittle ${ }^{11}$
}

Received: 30 July 2018 / Accepted: 22 January 2019 / Published online: 20 February 2019

(C) The Author(s) 2019

\begin{abstract}
Bayesian chronological modelling of radiocarbon dates from the Brochtorff Circle at Xaghra, Gozo, Malta (achieved through the ToTL and FRAGSUS projects), provides a more precise chronology for the sequence of development and use of a cave complex. Artefacts show that the site was in use from the Żebbug period of the late 5th/early 4th millennium cal BC to the Tarxien Cemetery phase of the later 3rd/early 2nd millennia cal BC. Absolutely dated funerary activity, however, starts with a small rockcut tomb, probably in use in the mid to late fourth millennium cal BC, in the Ggantija period. After an interval of centuries, burial resumed on a larger scale, probably in the thirtieth century cal BC, associated with Tarxien cultural material, with the use of the cave for collective burial and other depositions, with a series of structures, most notably altar-like settings built from massive stone slabs, which served to monumentalise the space. This process continued at intervals until the deposition of the last burials, probably in the twenty-fourth century cal BC; ceremonial activity may have ended at this time or a little later, to be followed by occupation in the Tarxien Cemetery period. The implications for the development of Neolithic society on Malta are discussed, as well as the changing character of Neolithic Malta in comparison to contemporary communities in Sicily, peninsular Italy and southern Iberia. It is argued that underground settings and temples on Malta may have served to reinforce locally important values of cooperation and consensus, against a wider tide of differentiation and accumulation, but that there could also have been increasing control of the treatment of the dead through time. The end of the Maltese Neolithic is also briefly discussed.
\end{abstract}

Keywords Malta $\cdot$ Neolithic $\cdot$ Radiocarbon $\cdot$ Bayesian chronological modelling $\cdot$ Monumentalised cave $\cdot$ Collective burials

\section{Island questions}

Superficially, early Maltese prehistory may appear straightforward. After initial colonisation in the sixth millennium cal BC,

Alasdair Whittle

whittle@cardiff.ac.uk

1 School of Natural and Built Environment, Queen's University Belfast, Belfast BT7 1NN, UK

2 The National Museum of Archaeology, Auberge de Provence, Republic Street, Valletta VLT 1112, Malta

3 The Superintendence of Cultural Heritage, 173 St Christopher Street, Valletta VLT 2000, Malta

4 University of Malta (Valletta Campus), Old University Building, St Paul Street, Valletta VLT 1216, Malta

5 Department of Ancient History, Macquarie University, Sydney, NSW 2109, Australia settlement was established and developed over subsequent generations. In the conventional chronological scheme, these are the Ghar Dalam, Grey Skorba and Red Skorba phases (Evans 1971; Trump 2002). The succeeding Żebbug phase,
6 Department of Archaeology, Cambridge University, Downing Street, Cambridge CB2 3DZ, UK

7 Oxford Radiocarbon Accelerator Unit, Research Laboratory for Archaeology and the History of Art, Dyson Perrins Building, University of Oxford, Oxford OX1 3QY, UK

8 SUERC Radiocarbon Dating Laboratory, Scottish Enterprise Technology Park, Rankine Avenue, East Kilbride G75 0QF, UK

9 Historic England, 4th Floor Cannon Bridge House, 25 Dowgate Hill, London EC4R 2YA, UK

${ }^{10}$ Biological and Environmental Sciences, University of Stirling, Stirling FK9 4LA, UK

11 Department of Archaeology and Conservation, John Percival Building, Cardiff University, Colum Drive, Cardiff CF10 3EU, UK 
conventionally assigned to the latest fifth and earliest fourth millennium cal BC, represents the emergence of more complex social organisation on Malta, associated with characteristic rock-cut tombs containing collective burials, imported axes and obsidian and distinctive pottery (Malone et al. 1995; Trump 2002). The development of this cultural phase gradually leads into what is known as the Temple culture or period (Pace 2000; Skeates 2010, 24) (Table 1). The Temple period is renowned for its megalithic architecture, which created large stone structures designed around subcircular internal rooms, enclosed by high stone walls (conventionally known as temples). Traditionally, these have been associated with cults and religion (Malone and Stoddart 2011) and interpreted as representing a chiefly social structure (Renfrew 1973). Numerous clusters of temples are known in Malta, many broadly dated to the later fourth and first half of the third millennia cal BC, starting in the Ġantija phase (Trump 2002), but with indications now of construction as far back as the Żebbug phase. This phase of activity was evidently not short-lived, and individual temples and temple complexes can yield clear evidence of repeated rebuildings. At the close of the Tarxien phase, conventionally estimated at c. $2500 \mathrm{cal} \mathrm{BC}$, temple building and use came to an end, in circumstances that are still not well understood. Explanations have ranged from collapse, migration or simply culture change with the onset of Bronze Age settlers (Trump 1976; Stoddart et al. 1993; Pace 2002; Cazzella and Moscoloni 2004-2005; Cazzella and Recchia 2006, 2015).

This apparently simple sequence of establishment, growth, peak and decline, nonetheless, sets a series of challenging research questions. What were the conditions in which island communities developed mortuary and communal ritual? How did these communities sustain themselves? Why were the Maltese temples and related structures unique in the Mediterranean, beyond mere isolation or insularity (Grima 2001; Robb 2001)? Does the trajectory of monumentality, however supported, reflect increasingly competitive social

Table 1 Cultural/ceramic phases defined for prehistoric Malta, with their informally estimated date ranges (Pace 2000; cf. Trump 2002, 55, for slight variations)

\begin{tabular}{ll}
\hline Phase & Estimated date range \\
\hline Ghar Dalam & c. $5200-4500 \mathrm{cal} \mathrm{BC}$ \\
Grey Skorba & c. $4500-4400 \mathrm{cal} \mathrm{BC}$ \\
Red Skorba & c. $4400-4100 \mathrm{cal} \mathrm{BC}$ \\
Żebbug & c. $4100-3800 \mathrm{cal} \mathrm{BC}$ \\
Mgarr & c. $3800-3600 \mathrm{cal} \mathrm{BC}$ \\
Ġgantija & c. $3600-3000 \mathrm{cal} \mathrm{BC}$ \\
Saflieni & c. $3300-3000 \mathrm{cal} \mathrm{BC}$ \\
Tarxien & c. $3000-2500 \mathrm{cal} \mathrm{BC}$ \\
Tarxien Cemetery & c. $2500-1500 \mathrm{cal} \mathrm{BC}$ \\
\hline
\end{tabular}

relations, and, if so, what was the scale of this? Are we to envisage an overarching polity, with figures akin, say, to paramount chiefs, or a series of small-scale chiefdoms or other forms of social organisation (Renfrew 1973; Grima 2008)? Or, by contrast, have the possibilities of cooperation and consensus been underplayed (Vella 2016)? How does the sequence and character of change in Malta compare with those on Sicily, Sardinia, Corsica and elsewhere in the central Mediterranean (Robb 2007)? Were the distinctive templebuilding communities on Malta inward-looking (Grima 2001, 2003; Robb 2001), or part of wider networks (Vella 2016) or indeed both? And what were the circumstances, finally, in which the social order was no longer able to-or no longer saw fit to - maintain the temples (Cazzella and Recchia 2015)? Does this ending relate to environmental degradation, for example, or social exhaustion or to changes in the networks beyond Malta?

All such questions have a temporal dimension. Were the conventionally identified cultural phases really of such neat and more or less equal duration? How quickly or slowly did monumentality emerge, especially that of the temples and major hypogea or underground settings, such as Hal Saflieni and Xaghra? How long were individual monuments in use, and how long or short were their individual phases of construction and activity? Were there neighbouring sites in constant contemporary use across the archipelago, or did places come and go, as it were, across the generations? How quickly or slowly did decline set in and lead to the abandonment of the use of temples and related structures? At present, it is not possible to answer most of these questions with any robustness or precision. The treatment of chronology has not matched the increasingly sophisticated literature.

Both temples and occupations alike, when they can be located, have been difficult to date precisely. Most structures were cleared of their stratified contents long before scientific fieldwork attempted to establish chronological phases for the structures. Plastered floors do provide sealed levels, however, and both Evans $(1953,1971)$ and Trump $(1966,2000,2002$, 2004) attempted to extract dateable materials from pre-floor levels almost 60 years ago. No attempts have been made subsequently, however, to refine this or to exploit the evidence of earlier investigations; the human bone from the Hal Saflieni hypogeum was long since discarded (Pace 2000), and the archives from temple research are now widely scattered. So, all the dates - only some 15 in number (see for example, Skeates 2010, fig. 1) - published for the Maltese Neolithic sequence before analysis of the 1987-94 excavations at Xaghra relied on potentially residual samples of unidentified charcoal from very small sondages beneath stone structures (see Malone et al. 2009, 342). Nevertheless, in tandem with a very detailed pottery typology developed also by Evans and Trump, there was some correspondence with changing ceramic styles and broad chronological phases. The most significant 
contribution of this pioneering work was the excavation of Skorba by Trump (1959-1963), which established the earliest phases of Maltese occupation and the sub-phases of the emerging Temple culture (Trump 1966; Table 1). Trump combined the other temple dating work with Skorba to produce what has become a rather rigid and potentially very simplified series of cultural phases (see Trump 2000, 2002) largely based on matching pottery style to informal interpretation of the small number of available radiocarbon dates.

After that pioneering effort, there followed a lull of two and a half decades. The Gozo project then focused on a number of questions relating specifically to the Żebbug and the main Temple periods. The 1987-1994 work at the BrochtorffXaghra Circle provided both the first AMS dates for Malta and, also, the first sequence of dates based on human bone, rather than on large bulk samples of potentially residual charcoal (Malone et al. 2009). Nineteen AMS dates were obtained from the initial dating campaign (Table 2). Of these measurements, five were from a small rock-cut tomb within the circle, 12 from Tarxien contexts and two (one of which proved to have been measured on a recent sample) from Tarxien Cemetery Bronze Age levels. On this basis, in 2009, the small rock-cut tomb at Xaghra seemed to be of Żebbug date, in use from c. 4350 to c. 3510 cal BC (Malone et al. 2009, 345), and the Tarxien phase at the site seemed to run from c. 3000 to c. 2400 cal BC, possibly to c. 2200 cal BC (Malone et al. 2009, 345-6).

No other systematic dating programme on archaeological phases had been undertaken on the Maltese material, although an unsuccessful attempt was made to identify a Palaeolithic phase (Mifsud and Mifsud 1997). The 2013-2017 programme of further dating reported here has focused on the detail of the burial sequence at Xaghra in order to establish the chronology of the site more robustly and to assess the significance of outcomes for better understanding of the cultural dynamics of Neolithic Malta. Almost no other prehistoric burial site in the southern Mediterranean region has been subjected to comparable intense scrutiny through radiocarbon dating and modelling, making this site a particularly rich subject for ongoing debate on the Maltese prehistoric sequence. This work will be complemented by further dating and Bayesian analysis undertaken as part of the FRAGSUS project and by on-going post-excavation analysis and radiocarbon dating for two small Tarxien period rock-cut tombs excavated at Kercem on Gozo in 2008 (The Times of Malta 2009).

\section{The Brochtorff Circle at Xaghra, Gozo}

A stone circle at Xagћra, on Gozo (Fig. 1), was recognised by eighteenth-century antiquaries, and, in the $1820 \mathrm{~s}$, excavations were conducted at its centre by Otto Bayer, LieutenantGovernor of Gozo. Sketches and watercolours by Charles de Brocktorff of this otherwise unpublished fieldwork show a megalithic circle surrounding a cave containing further megalithic settings and human remains (Malone et al. 2009, figs. 1.5-1.9). Traditionally, the site came to be known as the Brochtorff Circle, but is predominantly referred to here as the Xaghra Circle. Bayer's excavation was backfilled, and the circle was largely levelled in the course of the nineteenth century, to be re-identified only in the twentieth.

Fieldwork led by Caroline Malone, Simon Stoddart and David Trump in 1987-1994 (Malone et al. 2009) was undertaken in the context of a growing recognition of the exceptional character and early date (from the fourth millennium cal BC onwards) of the monumental stone architecture of the Maltese islands. This prompted questions as to the nature of the society that had created the monuments, the interplay between insularity and external contacts and the relative fragility of insular ecology and demography, as noted previously. The project's main aims were the elucidation of two then little-understood aspects of this period: the mortuary practices associated with the monuments and the contemporary settlement record.

The excavation of the Xaghra Circle was the main focus of the investigation. By the end of this campaign, it was clear that the circle surrounded an entrance to a system of natural limestone caves which had been modified and monumentalised.

Table 2 Number of radiocarbon measurements made on different sample materials, by phase of research and laboratory

\begin{tabular}{|c|c|c|c|c|c|c|}
\hline Research phase & Laboratory code & Year & $\begin{array}{l}\text { Articulated human bone/teeth } \\
\text { from articulated human remains }\end{array}$ & $\begin{array}{l}\text { Disarticulated or unspecified } \\
\text { human bone/loose human teeth }\end{array}$ & $\begin{array}{l}\text { Disarticulated } \\
\text { animal bone }\end{array}$ & $\begin{array}{l}\text { Articulated } \\
\text { animal bone }\end{array}$ \\
\hline \multirow[t]{4}{*}{ Excavation/post-excavation } & OxA & 1992 & 2 & 8 & 2 & \\
\hline & OxA & 1994 & & 2 & & \\
\hline & SUERC & 2004 & 2 & 1 & & \\
\hline & UBA & 2009 & & 2 & & \\
\hline \multirow[t]{3}{*}{ ToTL } & SUERC & 2013 & 7 & & & \\
\hline & OxA & 2013 & 11 & & & 1 \\
\hline & OxA & 2016 & 8 & 2 & & \\
\hline FRAGSUS & UBA & 2016 & & 55 & & \\
\hline Totals & & & 4 & 68 & 2 & 1 \\
\hline
\end{tabular}


Fig. 1 Location of the Maltese islands and of the Brochtorff Circle at Xaghra and other sites mentioned in the text. Based on Malone et al. (2009, figs. 1.1 and 1.2). (C) McDonald Institute for Archaeological Research

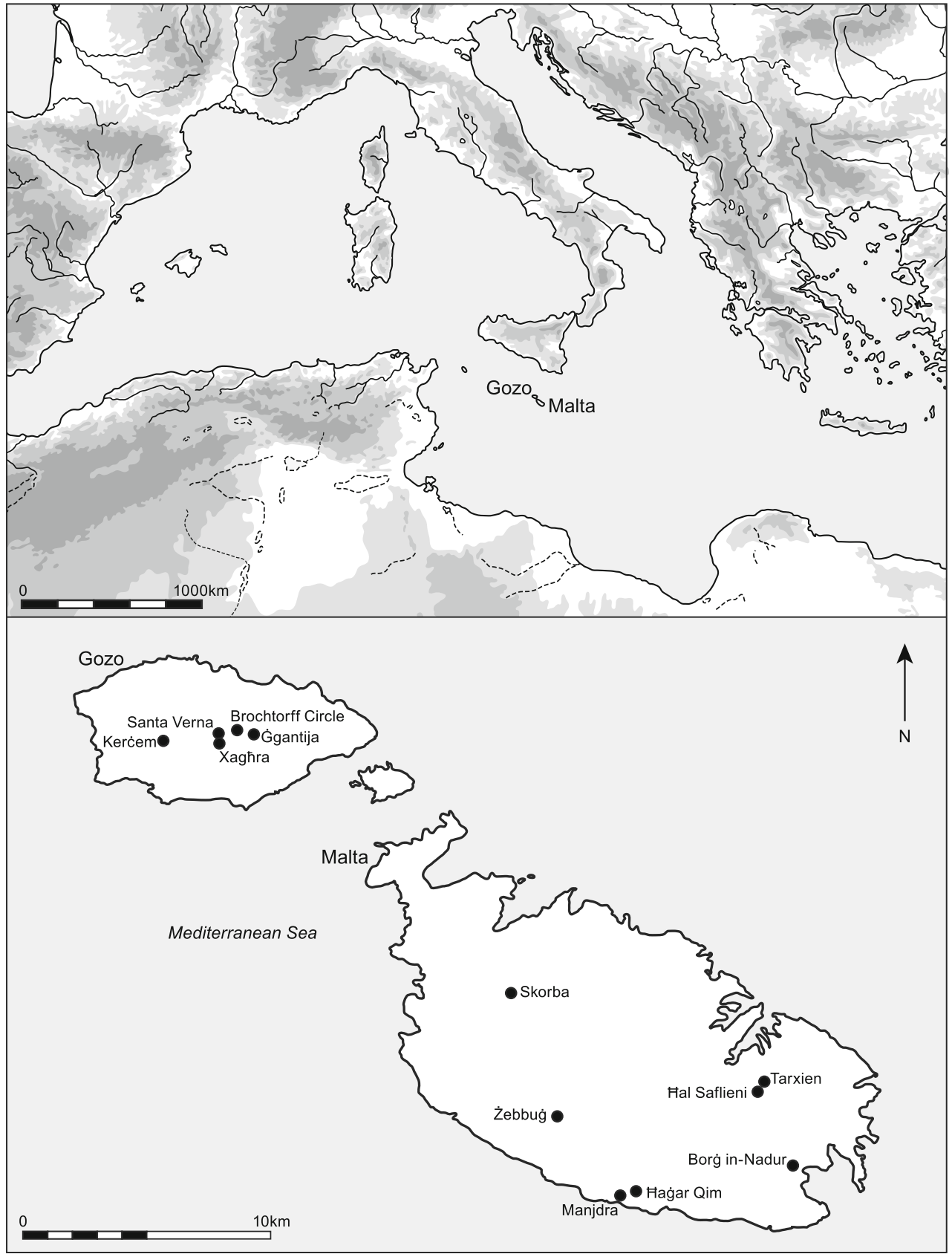

These became an underground collective tomb, the excavated parts of which yielded the remains of hundreds of individuals, mainly disarticulated, the minimum number varying from 341 to 1001 according to the method of calculation applied (Malone et al. 2009, 320-1). They were accompanied by a wealth of artefacts, including sculptures, figurines, pendants and beads, some objects being made of exotic stone, as well as large quantities of pottery. Successive megalithic architectural features had been built within the caves as repeatedly manipulated human remains accumulated (Fig. 2). At an early stage, a small, separate tomb was cut into the rock to the south-east of the entrance area. On the evidence of artefacts, use of the complex started in the Żebbug phase of the Maltese Neolithic, with a lull, although not a cessation, in the Mgarr and Gंgantija phases. Pottery of all three styles was generally redeposited, found mingled with the far more abundant Tarxien pottery of the flamboyantly monumental floruit of the site as a funerary monument (Malone et al. 2009, 82-7). There was subsequent non-funerary Bronze Age activity, in the Tarxien Cemetery and Borg in-Nadur phases. The main spatial divisions of the excavated parts of the cave complex are shown in Fig. 3.

The present analysis, undertaken as part of the project The Times of Their Lives (ToTL; see the "Acknowledgements" section), builds on dating done during the excavation and post- 
Fig. 2 Reconstruction of the west and east caves of the circle and its entry (Malone et al. 2009, fig. 14.12). By Libby Mulqueeney after originals by Caroline Malone and Steven Ashley. The solid black line defines the area that would probably have been open to the sky. () McDonald Institute for Archaeological Research

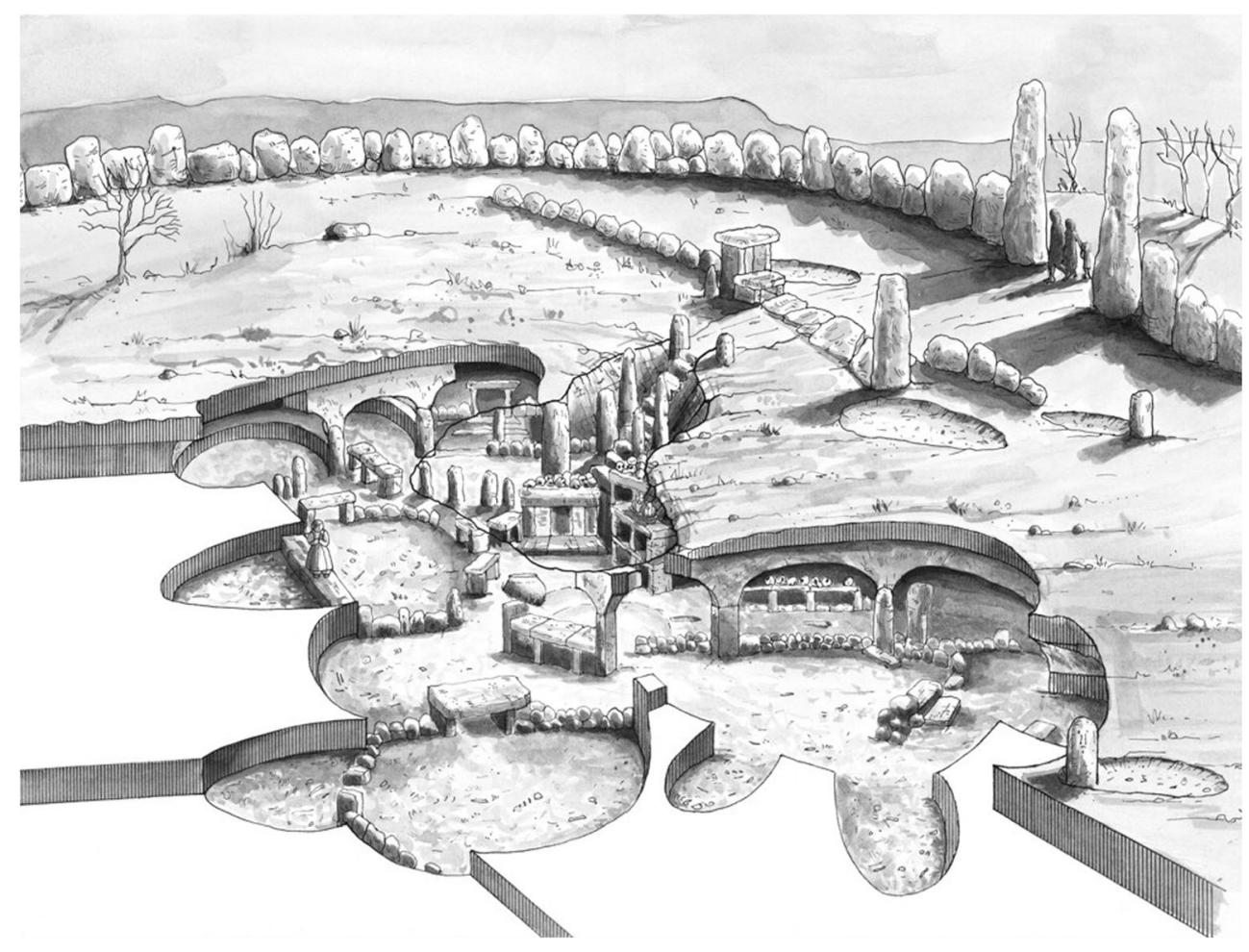

excavation analysis of the tomb (Malone et al. 2009, 341-6) and incorporates the initial programme of new dating done in the course of the FRAGSUS project: Fragility and Sustainability in Restricted Island Environments (see the "Acknowledgements" section). The ToTL project has aimed to establish more precise chronologies than have so far been obtained for selected sites and aspects of the European Neolithic, by the application of
Bayesian chronological modelling to radiocarbon dates measured on samples chosen by rigorous criteria. By increasing chronological precision, this approach makes it possible to view many questions in a fresh light, such as those concerning the timing and rhythm of use of individual sites, the duration of monuments or traditions or phenomena of continuity and disruption (Bayliss and Whittle 2015). The involvement of the
Fig. 3 Plan of the circle, showing the nomenclature of major archaeological features on the site (Malone et al. 2009, fig. 5.11). () McDonald Institute for Archaeological Research

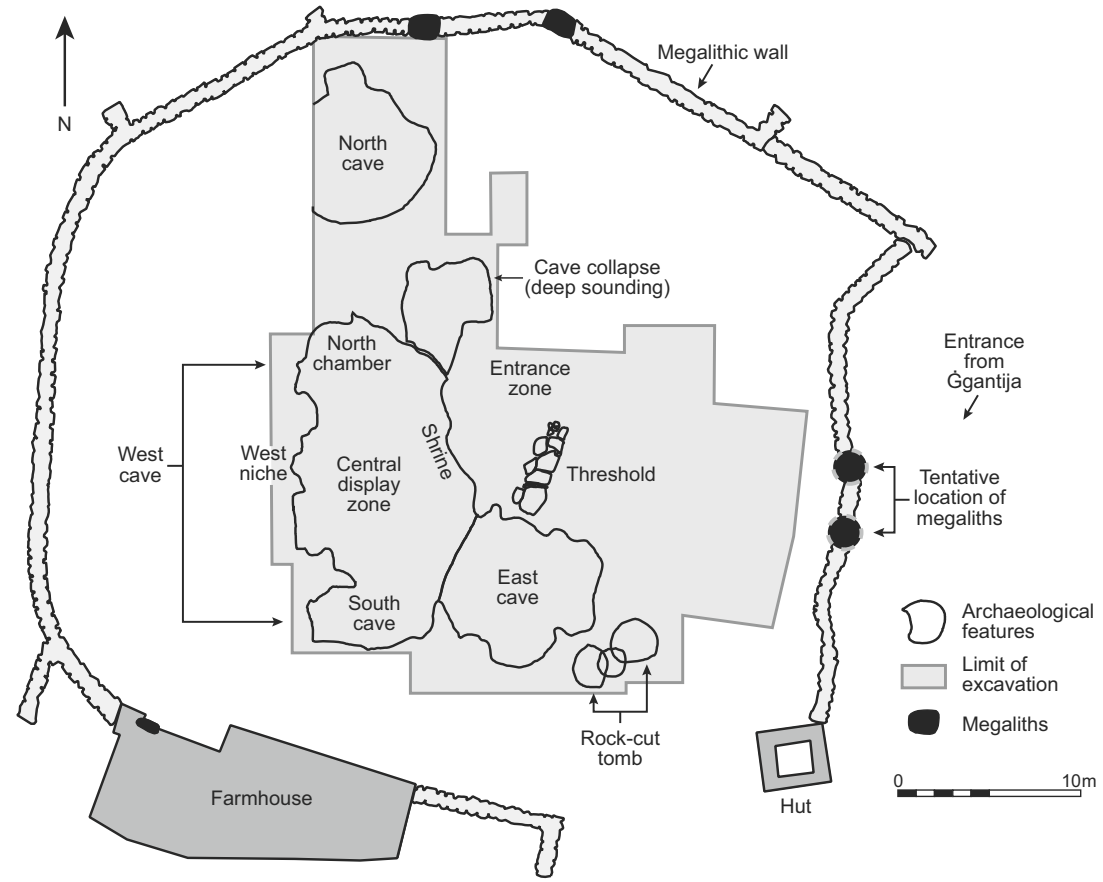


ToTL project sprang from an interest in past and recent research on monumentality and collective burials and from a desire eventually to compare the results with informal and formally modelled date estimates for other monuments and collective deposits elsewhere in Europe. Xaghra was chosen for analysis because it is a recent excavation with detailed stratigraphic and osteological analysis, the latter continuing as part of the FRAGSUS project. The overall aim was to contribute chronological precision to the understanding of the history of the monument, as a first step towards the wider, collective effort of establishing a more precise chronology for the monumental and cultural sequence of Neolithic Malta and to offer a provisional assessment of the implications of a more robustly established timeframe. In practical terms at Xaghra, this entailed estimating the dates and durations of the funerary use of different components of the monument.

Additional dating that will complement this analysis is underway as part of the FRAGSUS project, including samples spanning a range of site types, from sediment cores from across the landscape that capture vegetation and environmental change, to individual temple and settlement sites. Significantly, work on two temple sites, Skorba and Santa Verna, which overlie earlier Neolithic settlement, has revealed levels relating to the much earlier pre-temple cultural phases, which will provide firmer evidence for the earliest history of human occupation on the islands (McLaughlin et al. in prep). All the FRAGSUS analysis is coupled with palaeoecological and isotopic studies that will expand understanding of dietary, climatic and other factors within a robust chronological framework (Malone et al. 2016; Malone et al. in press).

\section{Methods}

\section{Radiocarbon dating}

A total of 101 radiocarbon results and associated stable isotopic measurements have been obtained from funerary contexts at Xaghra, with a further two from non-funerary Bronze Age contexts. They are summarised in Table 2 and detailed in Table 3. Thirty-three human and animal bone samples were submitted during the excavation and post-excavation programmes, of which 19 yielded sufficient carbon for dating and $15(45 \%)$ failed (Malone et al. 2009, 341). Forty-two bone and tooth samples were submitted by the ToTL project, of which 29 were dated successfully and $13(31 \%)$ failed. The ToTL measurements include one pair of replicates (i.e. independent determinations on two samples from the same individual; Table 3: OxA-27834, -33925). A further 60 tooth samples were submitted by the FRAGSUS project, of which 55 were dated successfully and five $(8 \%)$ failed. All radiocarbon results are conventional radiocarbon ages, corrected for fractionation (Stuiver and Polach 1977).
The failure rates for the first two sets of samples submitted from Xaghra are not unusual for bone samples from around the Mediterranean, where collagen preservation is worse than in cooler climates. The level of failure in the first round of ToTL submissions prompted a change of approach in the second round, when almost all the samples submitted were of dentine, where collagen is often better preserved because it is protected by the overlying enamel. All the dentine samples were dated satisfactorily. The lower failure rate of the FRAGSUS samples reflects the fact that they were all of dentine.

\section{Sample preparation and measurement}

At the Oxford Radiocarbon Accelerator Unit (OxA), the samples measured in 1992-1994 were pretreated as described by Hedges et al. (1989) and the extracted protein purified using the ion exchange protocol outlined by Hedges and Law (1989) and Law and Hedges (1989; pretreatment code AI). They were, then, combusted to carbon dioxide as described by Hedges et al. (1992) and measured by Accelerator Mass Spectrometry (AMS) using the carbon dioxide ion source (Gillespie et al. 1983; Hedges 1981). The samples measured in 2013-2016 underwent acid-base-acid treatment, gelatinisation and ultrafiltration as described by Brock et al. (2007, 106-7: pre-treatment code AF). They were, then, combusted and graphitised as described by Brock et al. (2010, 110) and Dee and Bronk Ramsey (2000) and dated by AMS (Bronk Ramsey et al. 2004). $\delta^{13} \mathrm{C}$ and $\delta^{15} \mathrm{~N}$ values were measured by Isotope Ratio Mass Spectrometry (IRMS) as described by Brock et al. (2010, 110).

At the ${ }^{14} \mathrm{CHRONO}$ Centre, the Queen's University, Belfast (UBA), the samples submitted in 2009 and 2016 were prepared and measured as described by Reimer et al. (2015) with graphitisation by zinc reduction.

At the Scottish Universities Environmental Research Centre, East Kilbride (SUERC), the samples measured in 2004 were pre-treated as described by Longin (1971), before being converted to carbon dioxide in pre-cleaned sealed quartz tubes (Vandeputte et al. 1996), graphitised as described by Slota Jr et al. (1987) and dated by AMS as described by Xu et al. (2004). From those measured in 2013, gelatin was extracted and ultrafiltered, before combustion, graphitisation and dating by Accelerator Mass Spectrometry (Dunbar et al. 2016). $\delta^{13} \mathrm{C}$ and $\delta^{15} \mathrm{~N}$ values were measured independently by Isotope Ratio Mass Spectrometry (IRMS) as described by Sayle et al. (2014).

\section{Quality control}

All three laboratories maintain continuous programmes of internal quality control. They also take part in international intercomparisons (Scott 2003; Scott et al. 2007, 2010). In the quarter-century since the first Xaghra bone samples were dated at Oxford, however, significant improvements have been 


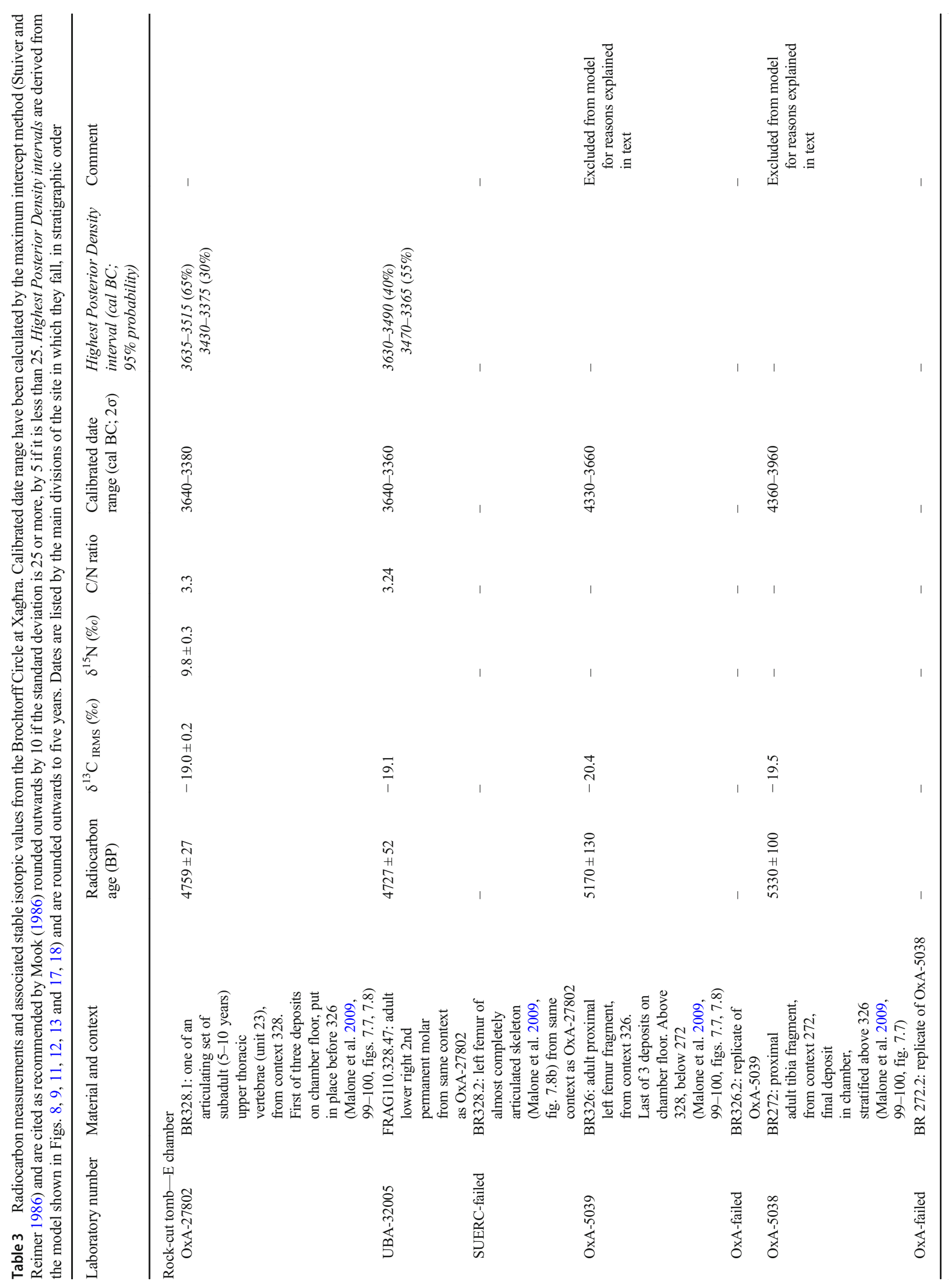




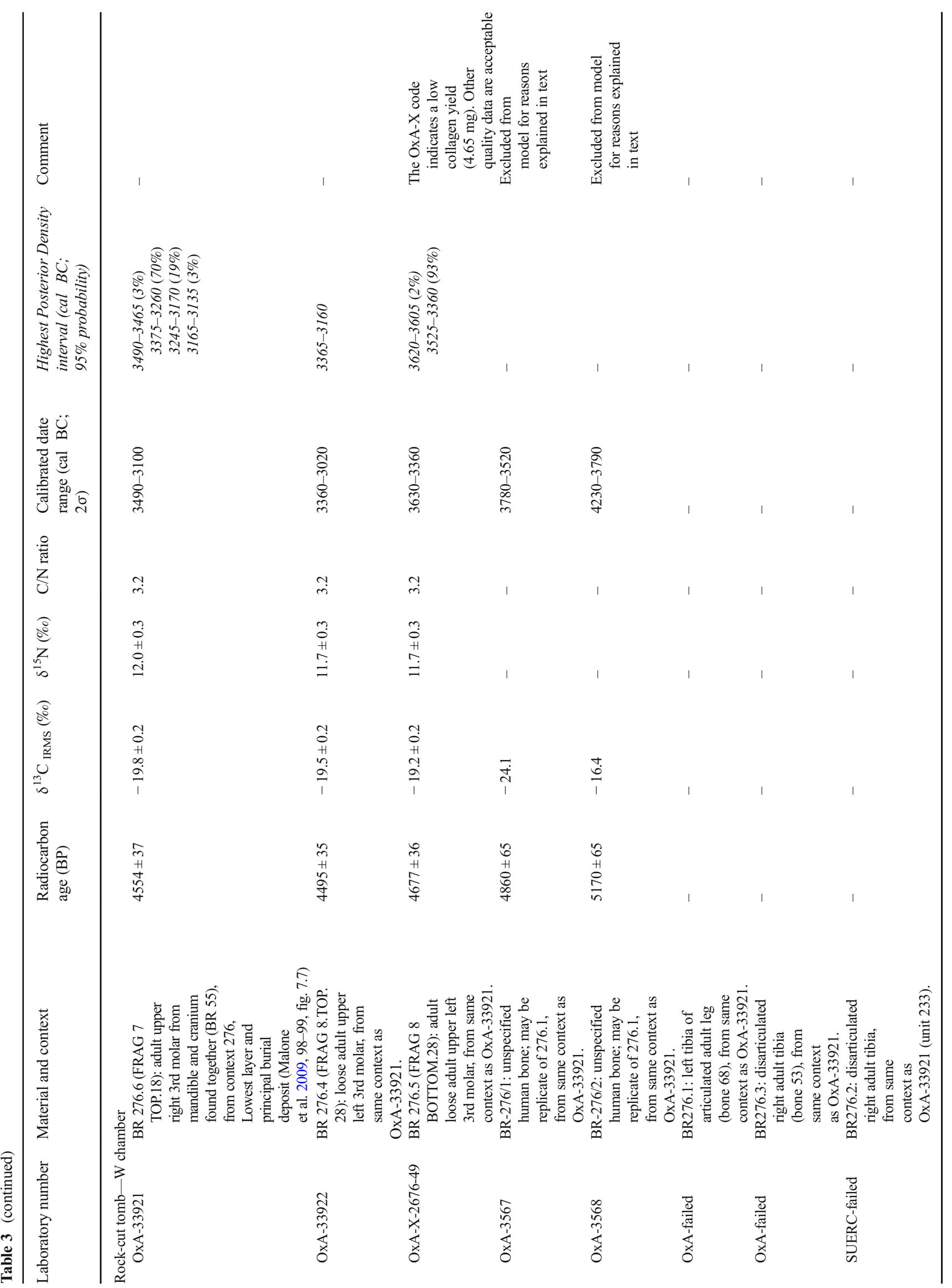




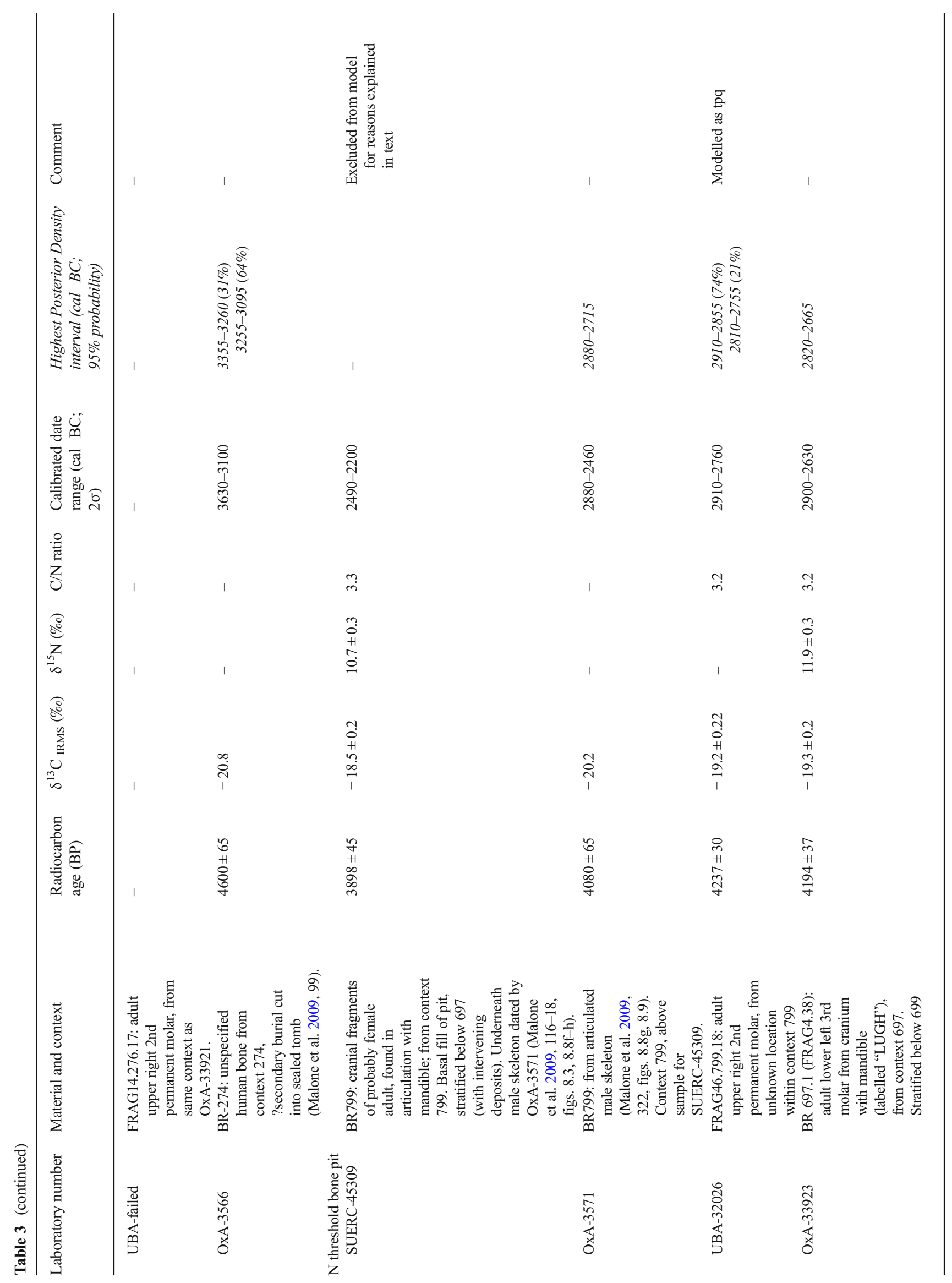




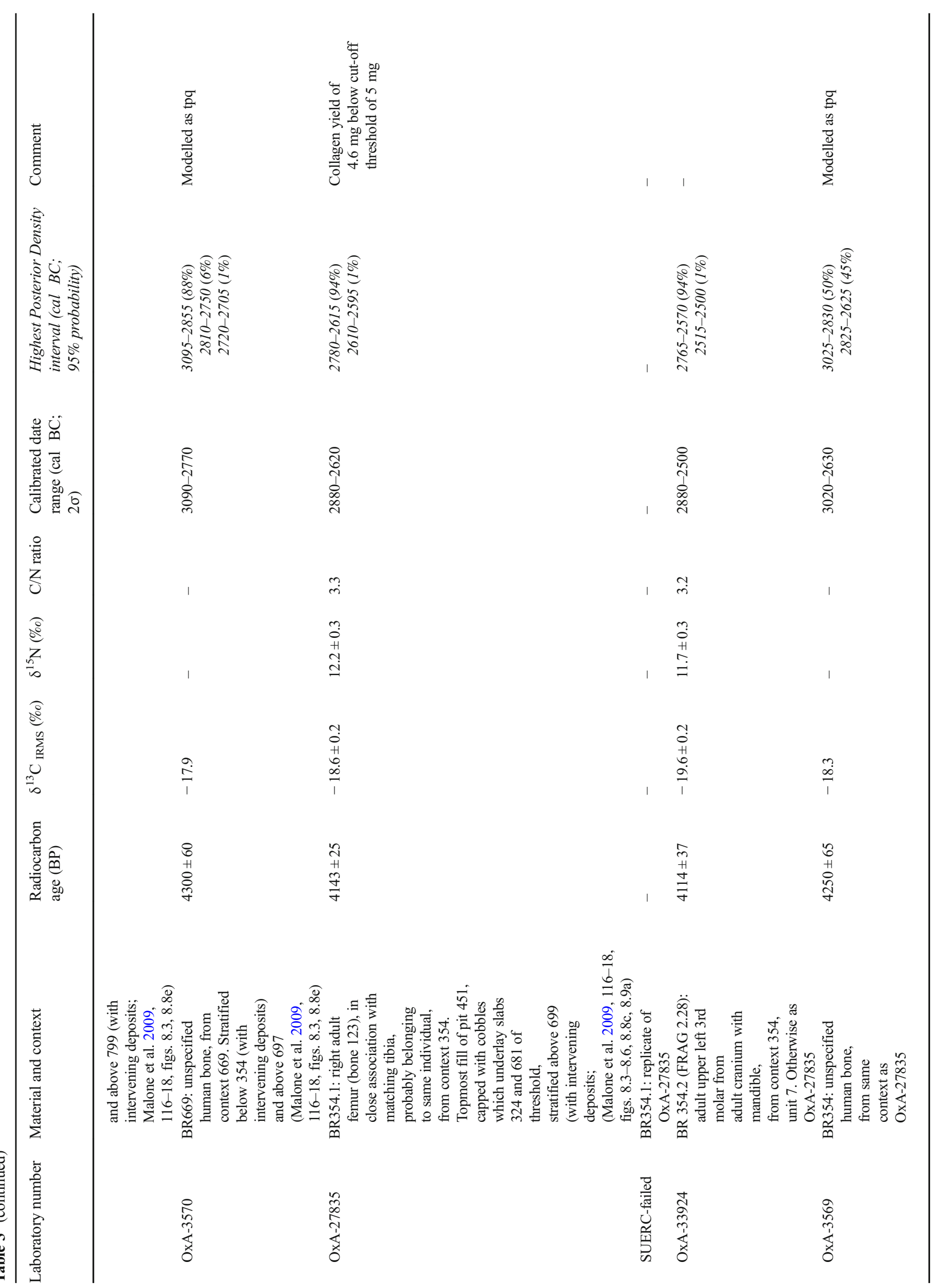




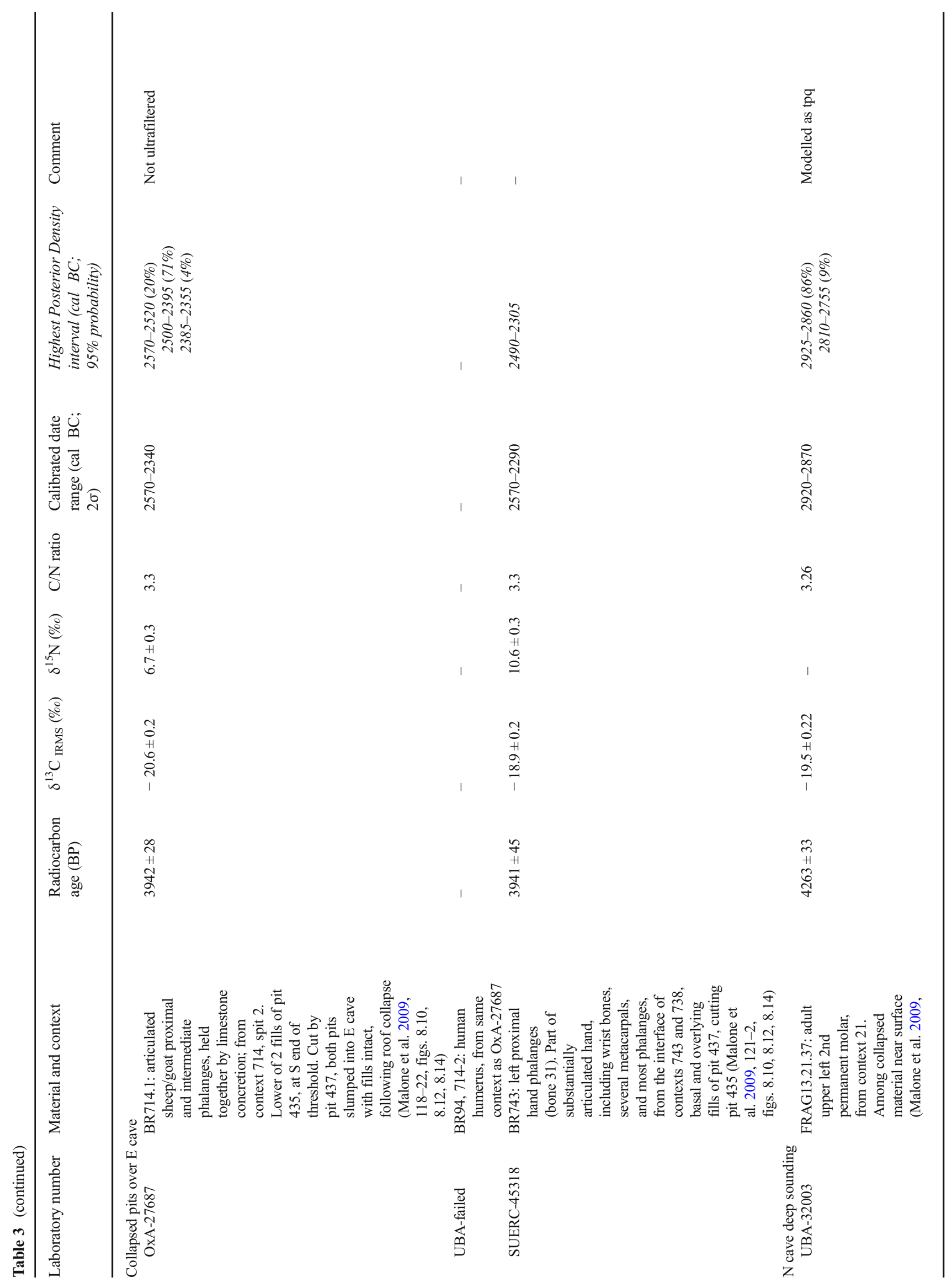




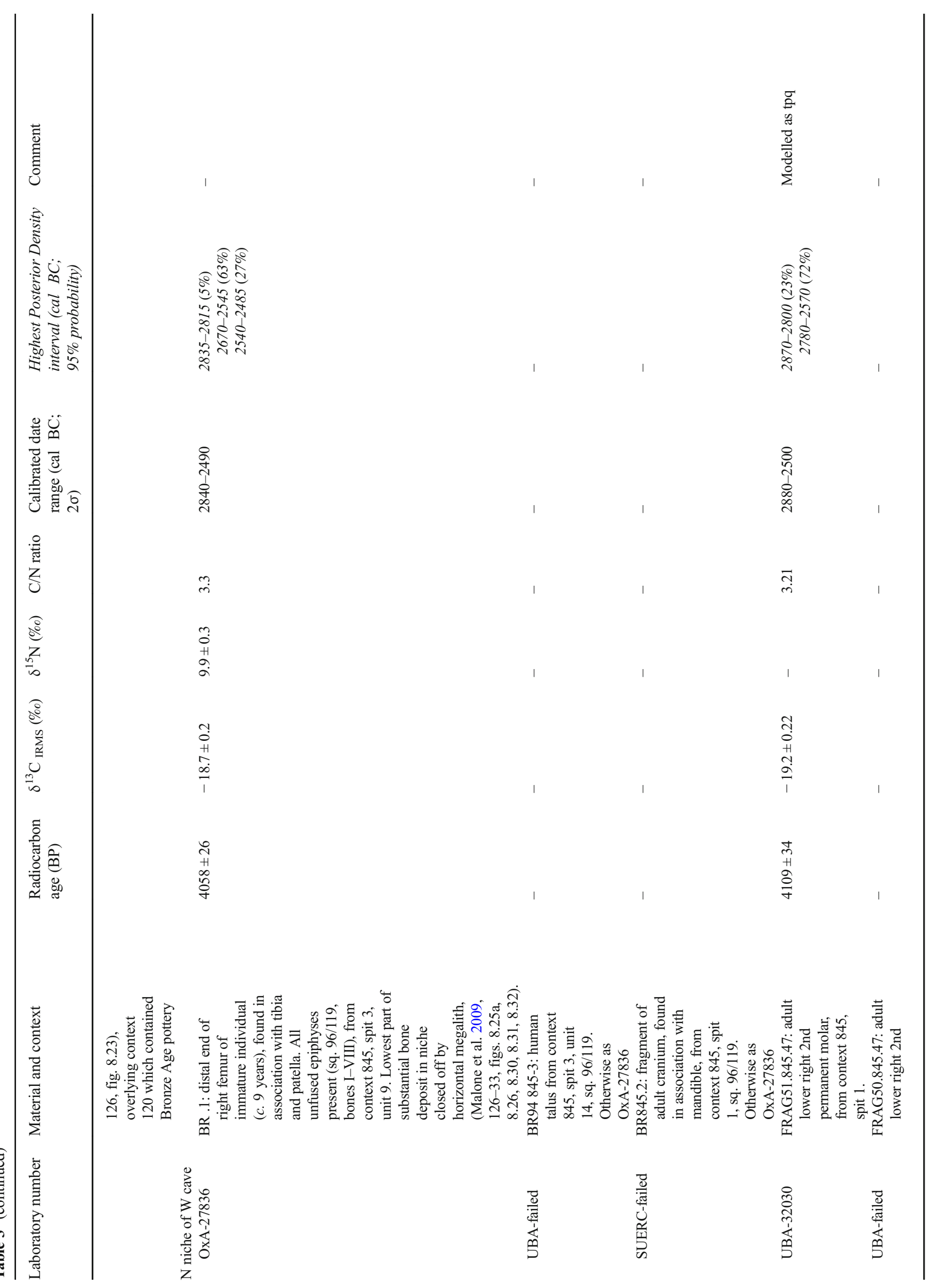




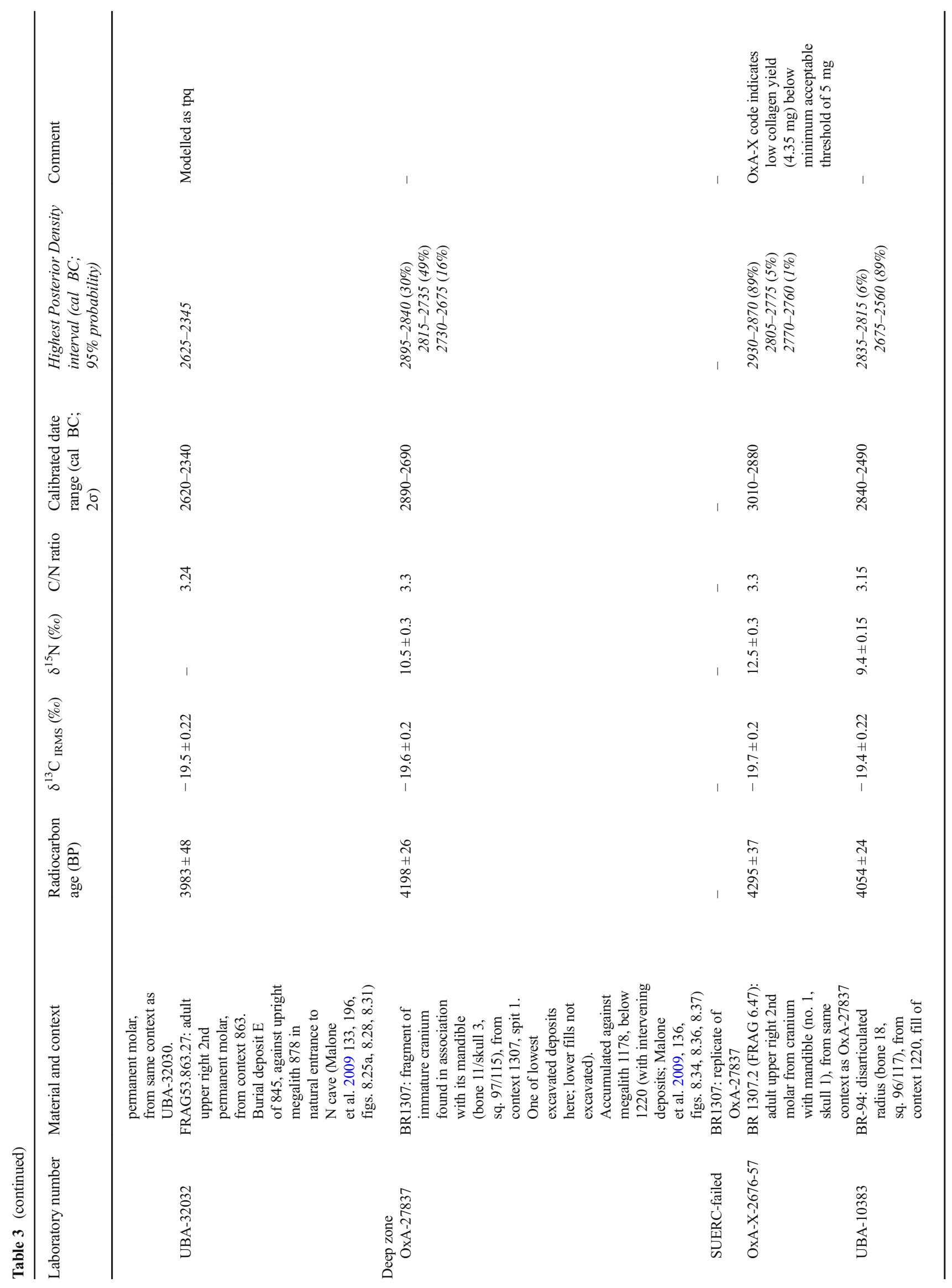




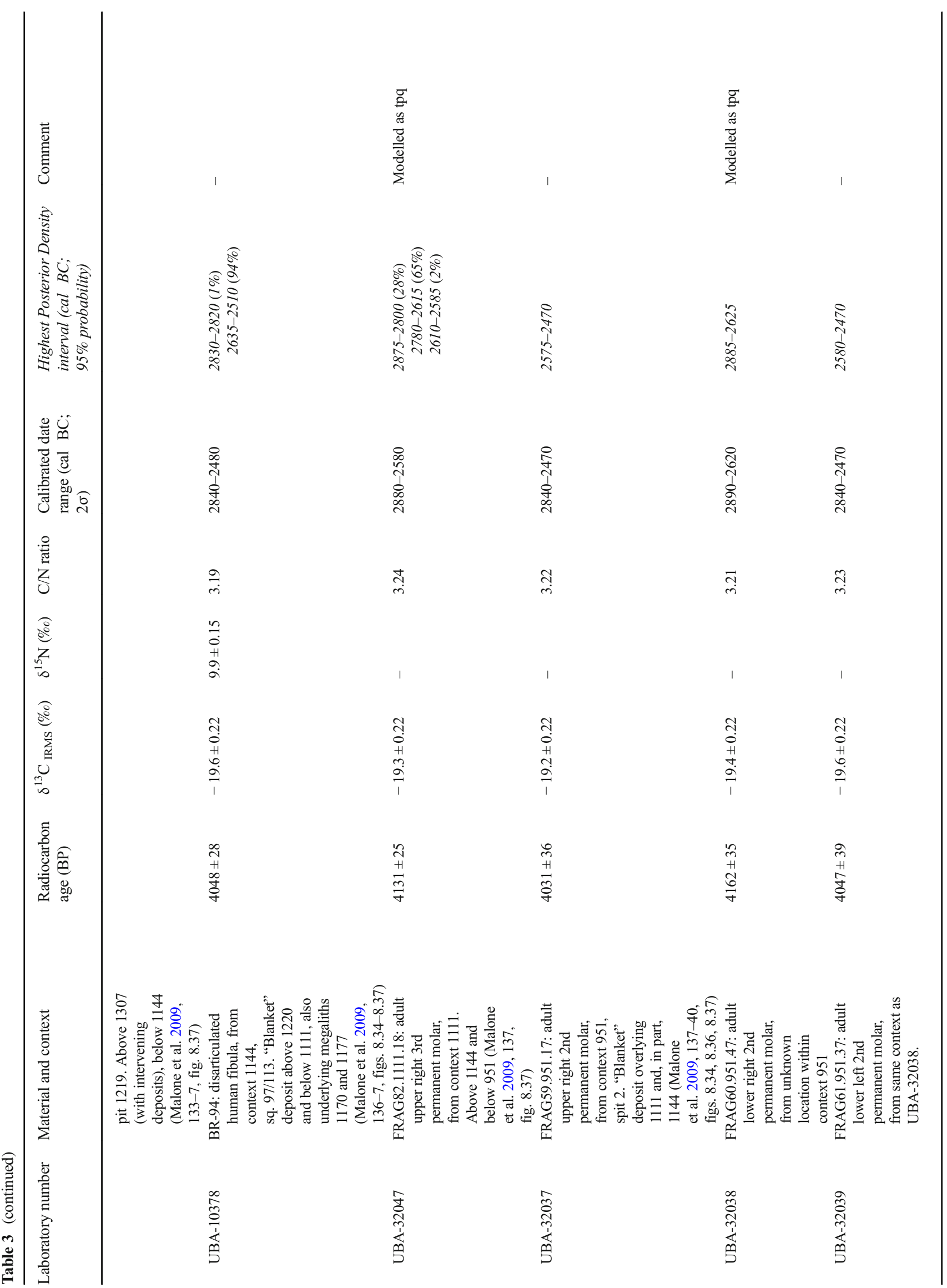




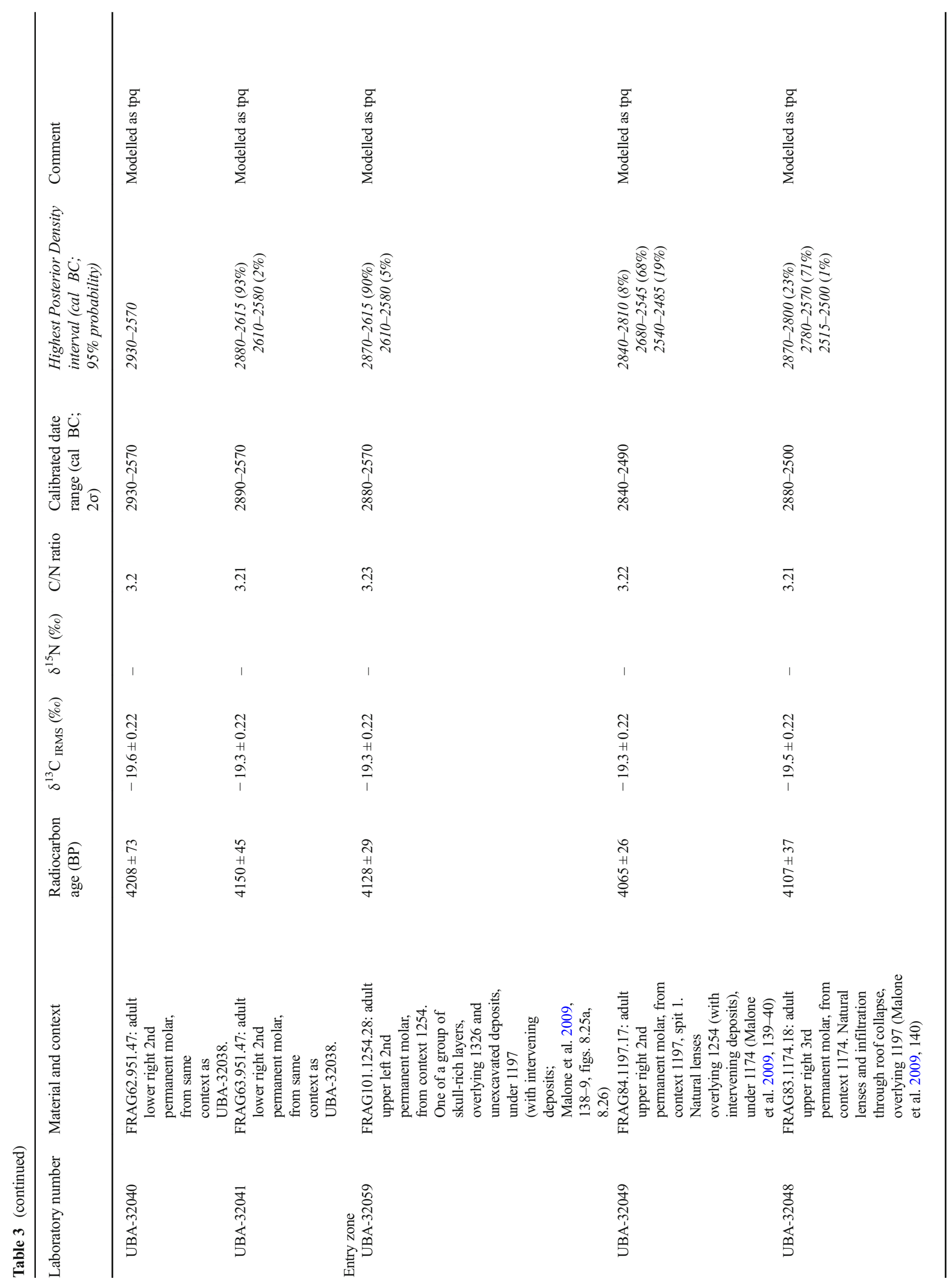




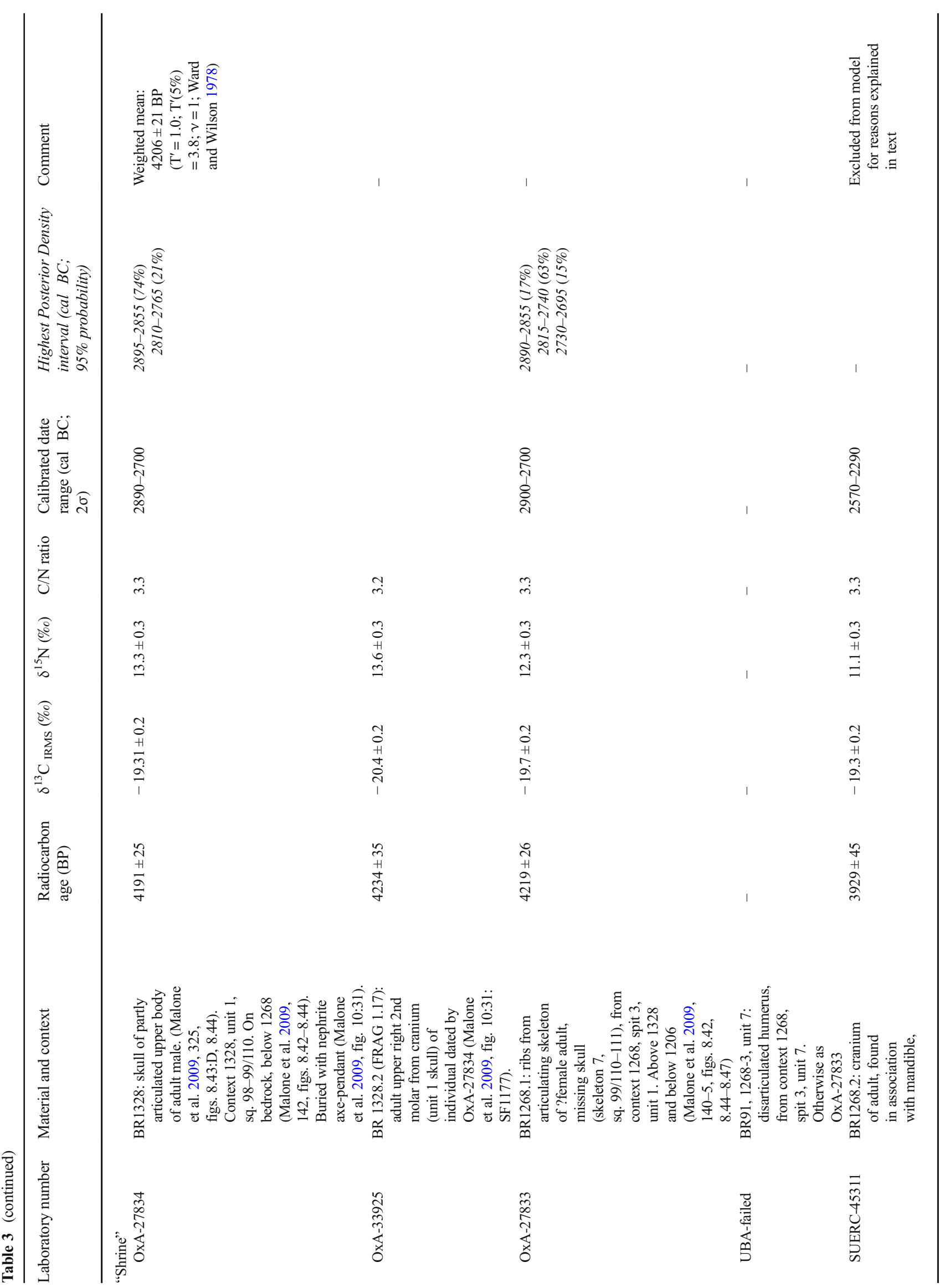




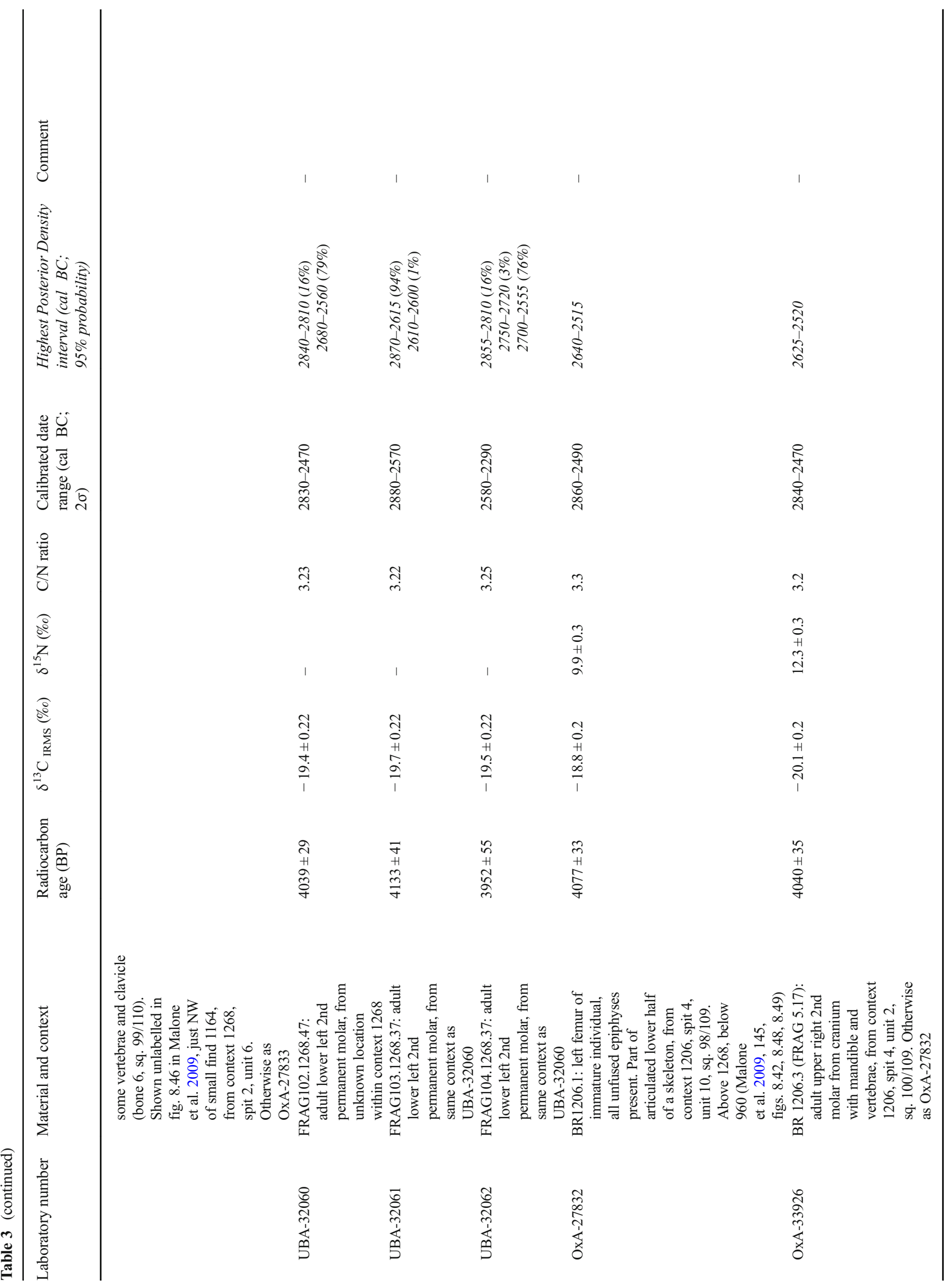




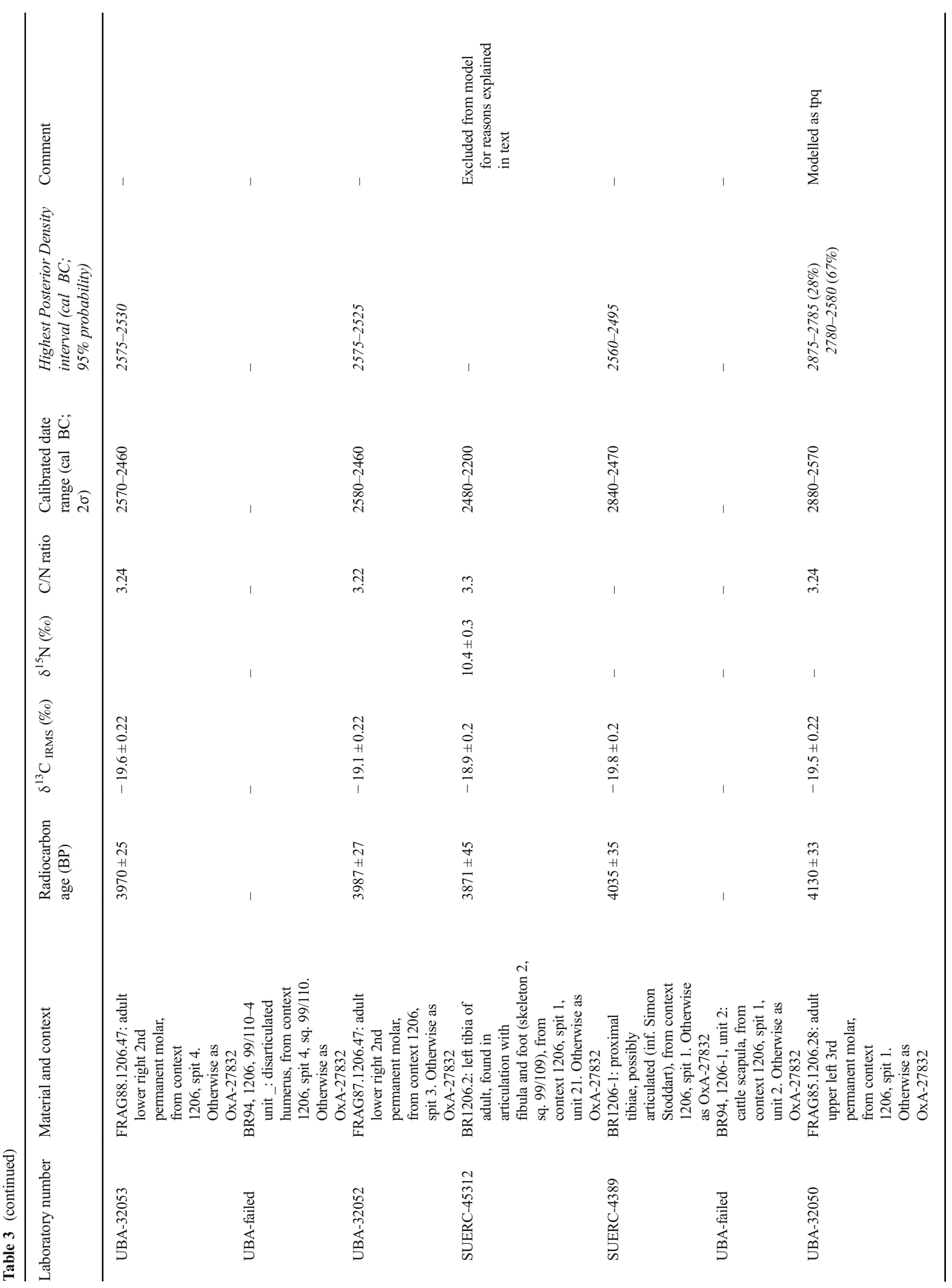




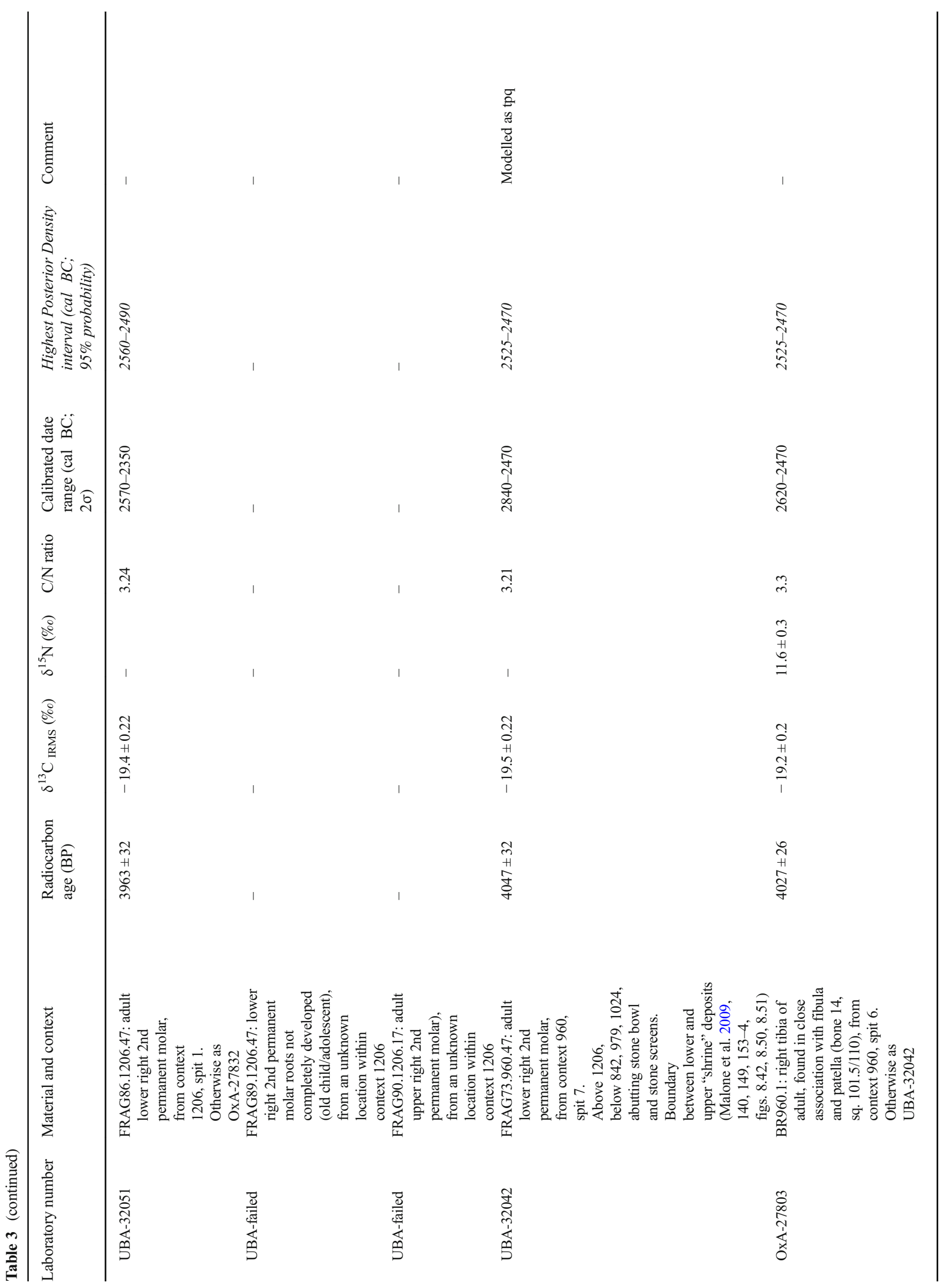




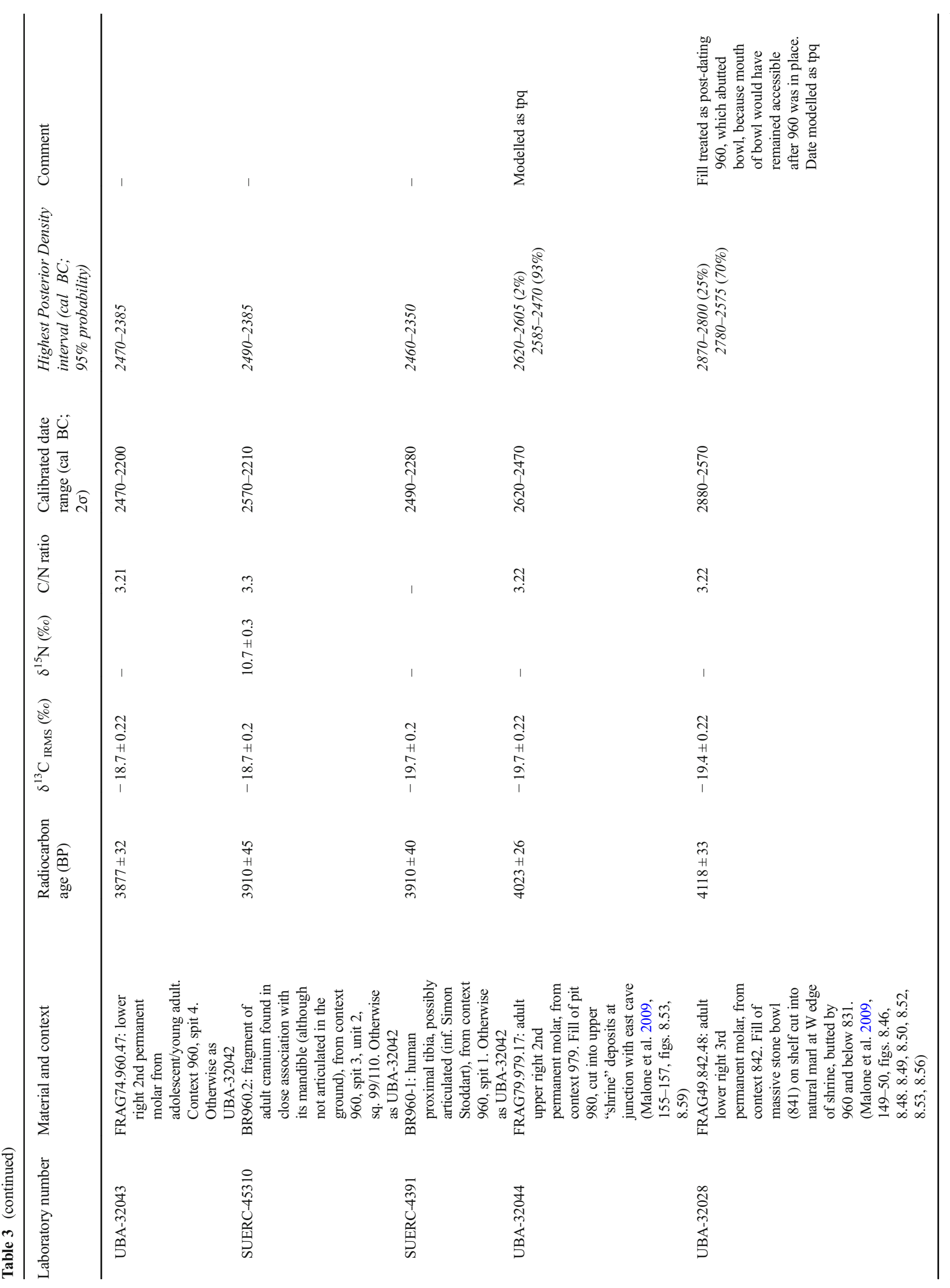




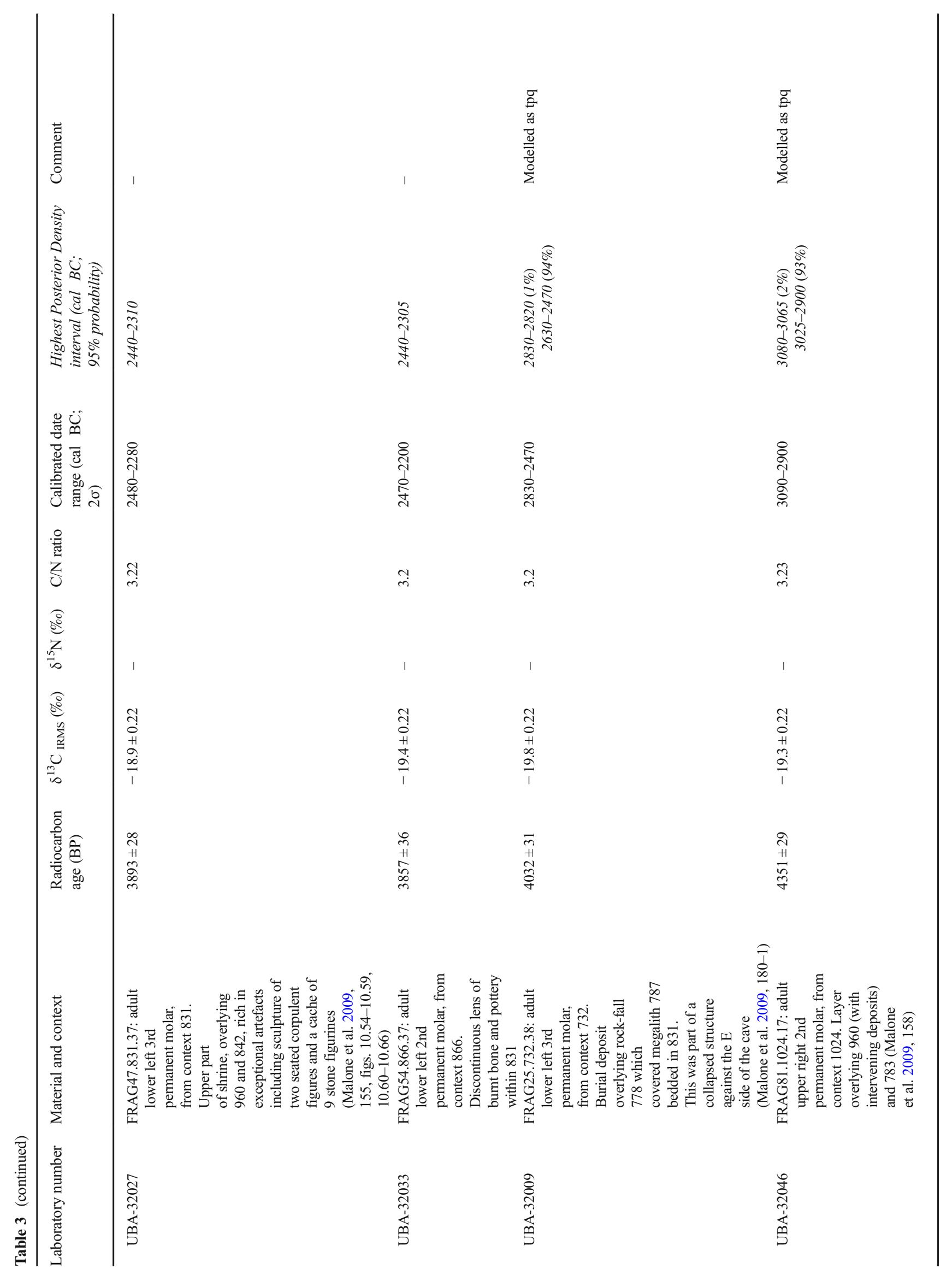




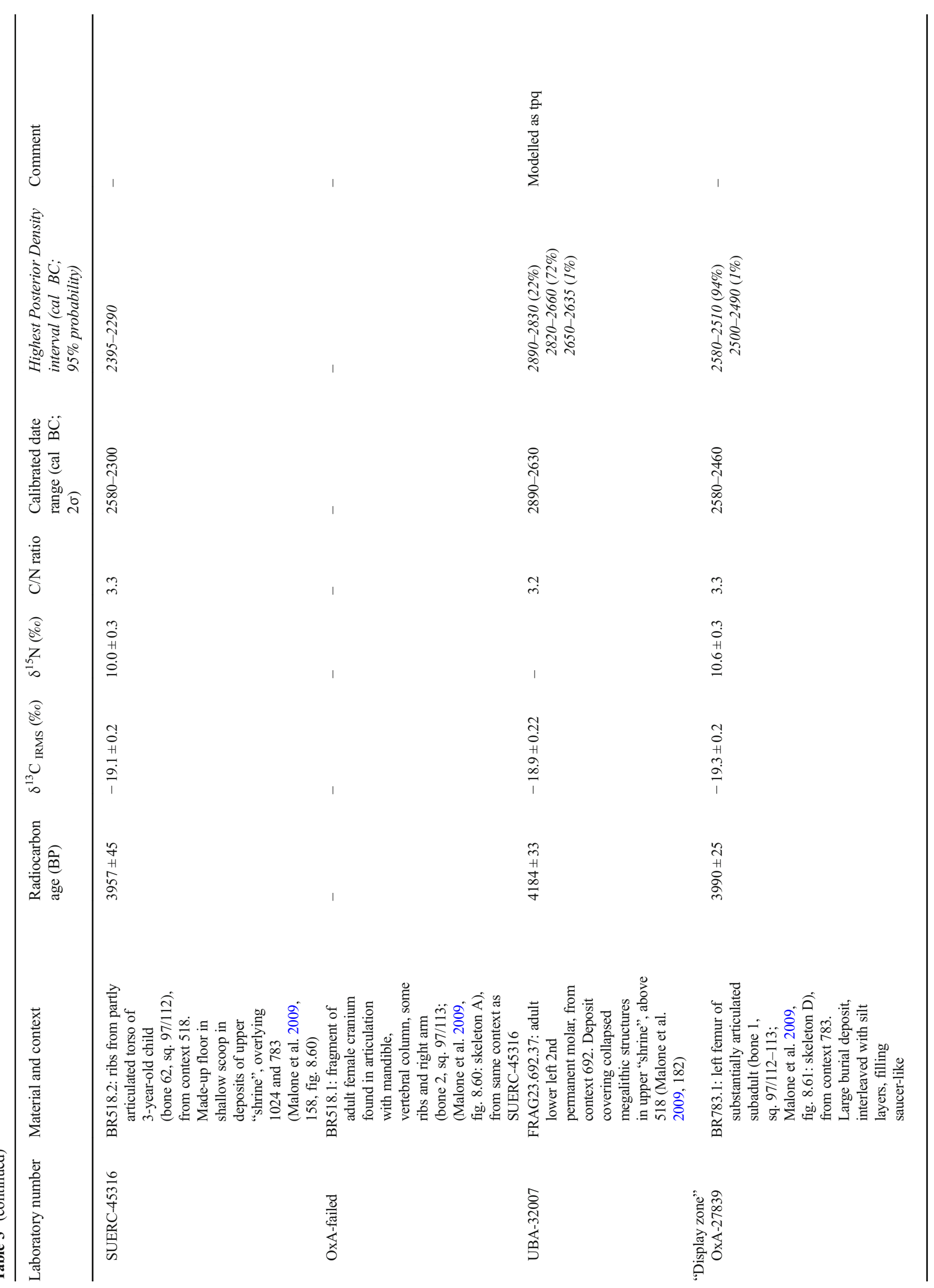




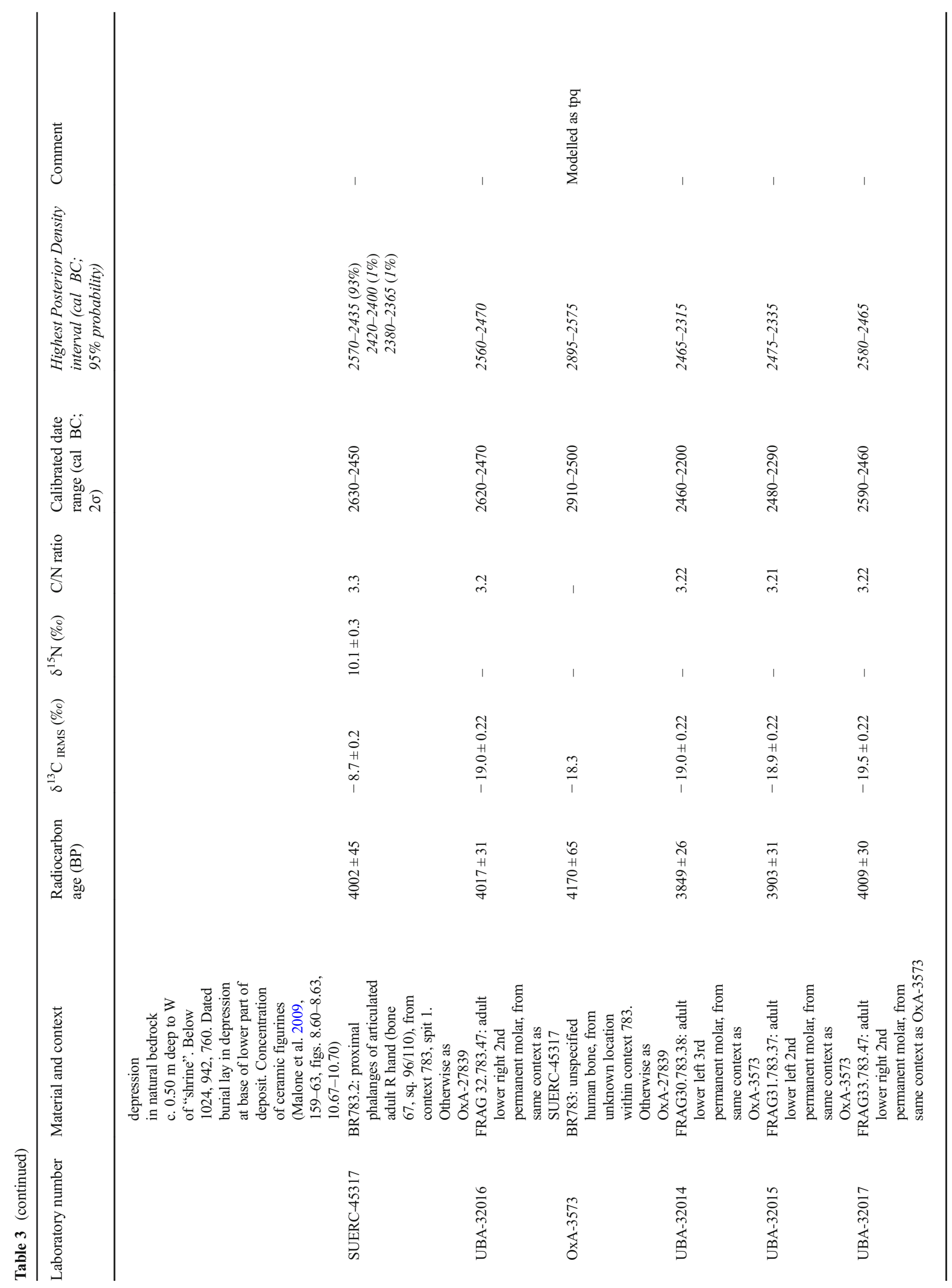




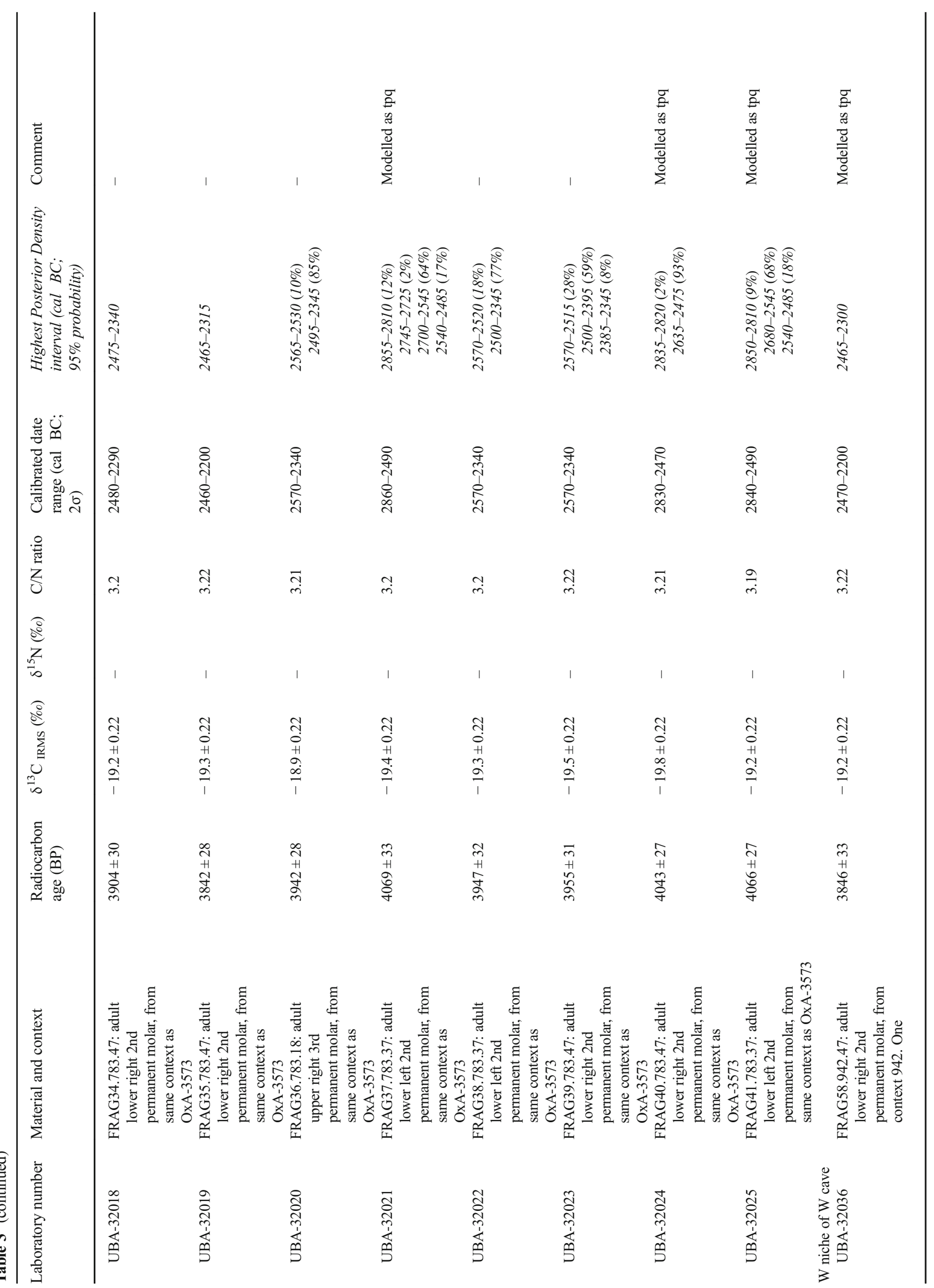




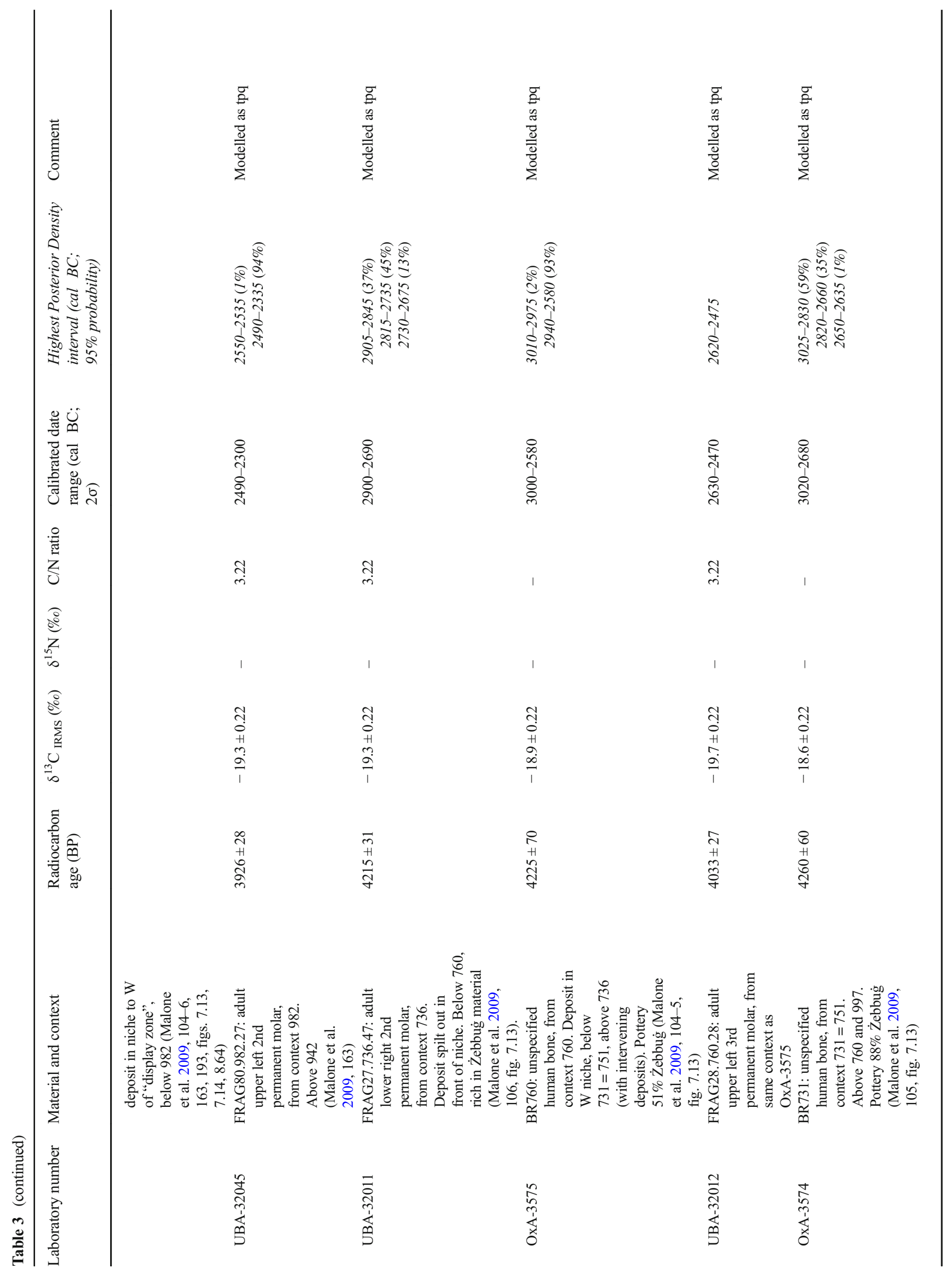




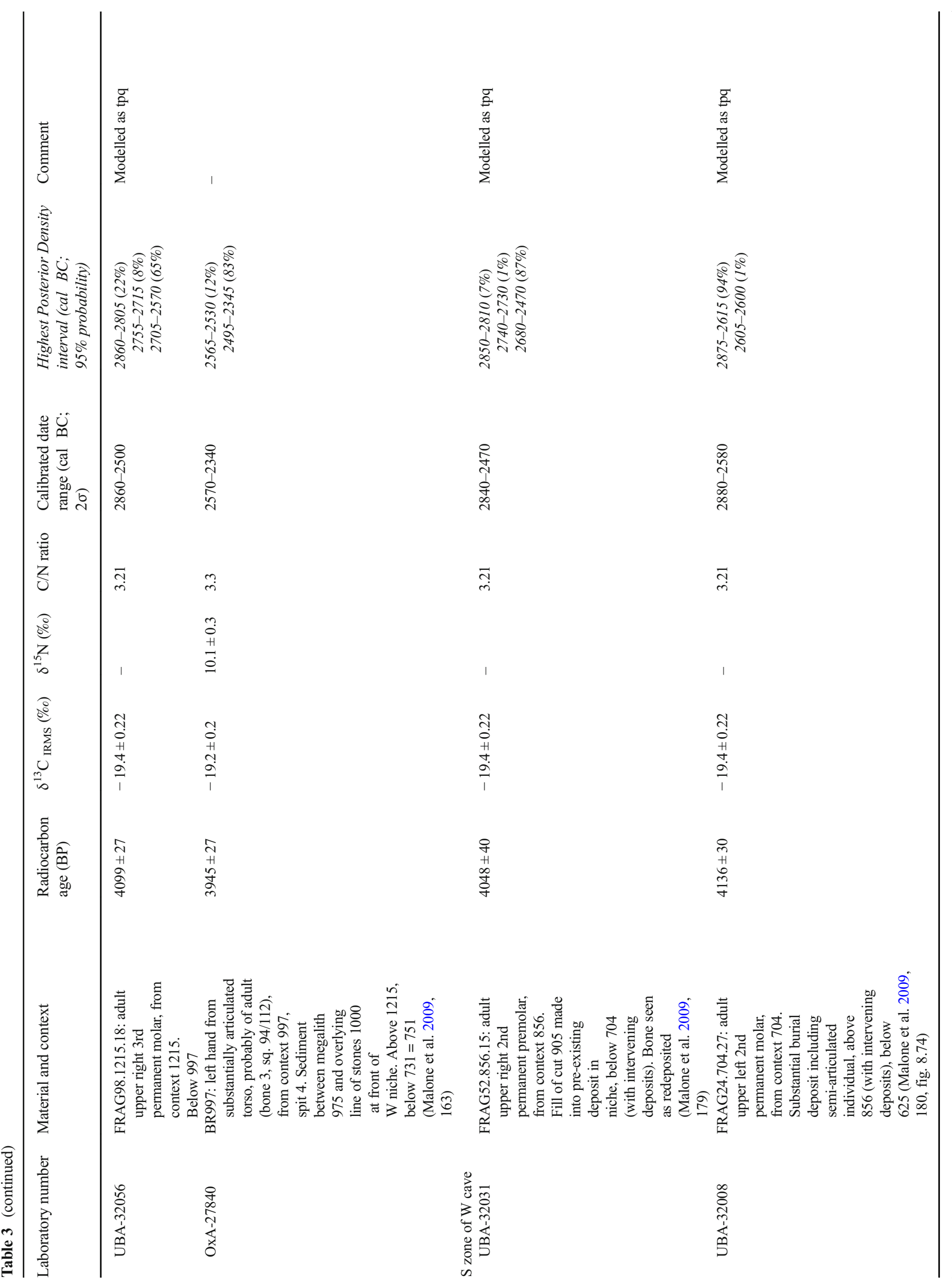




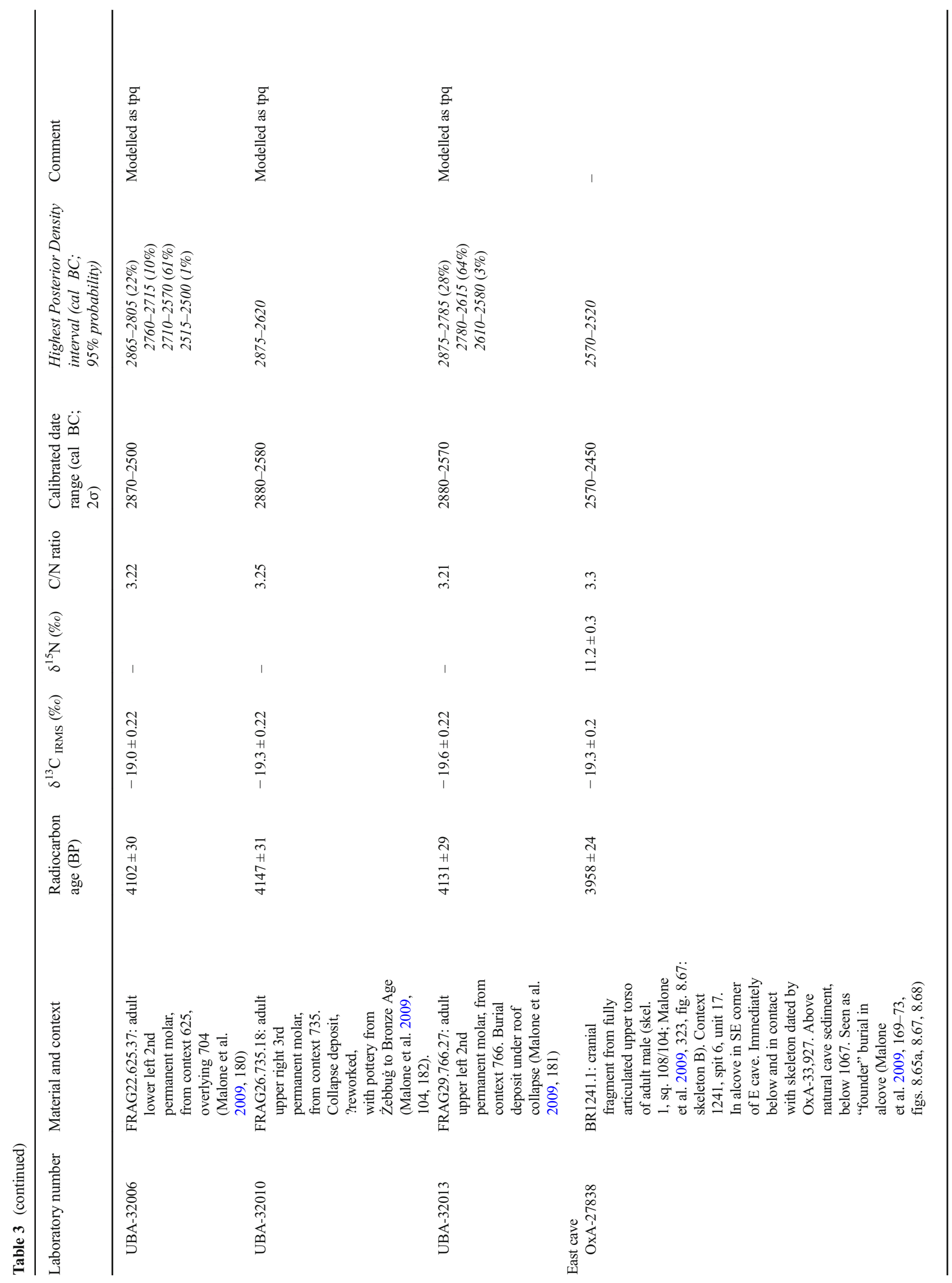




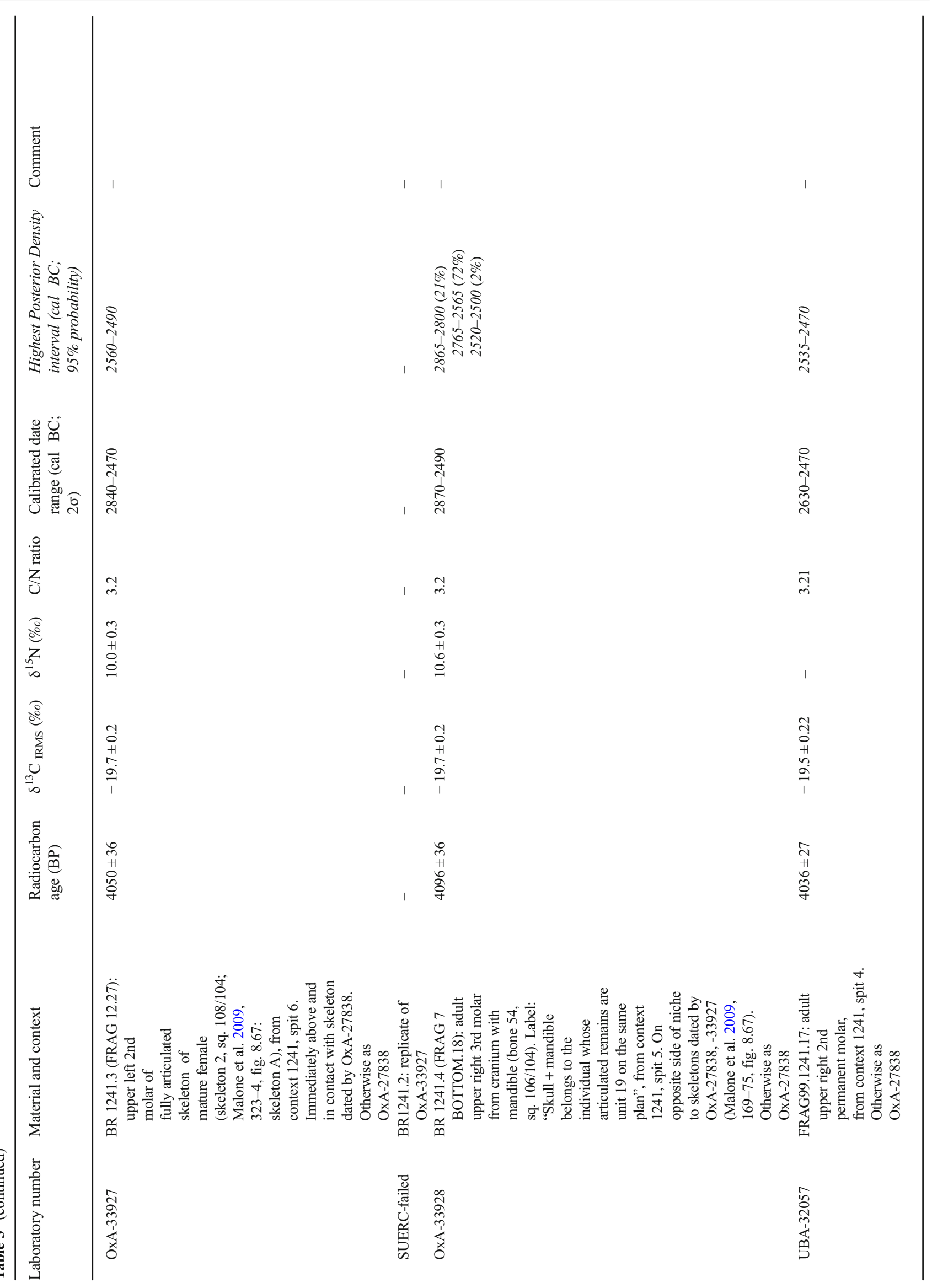




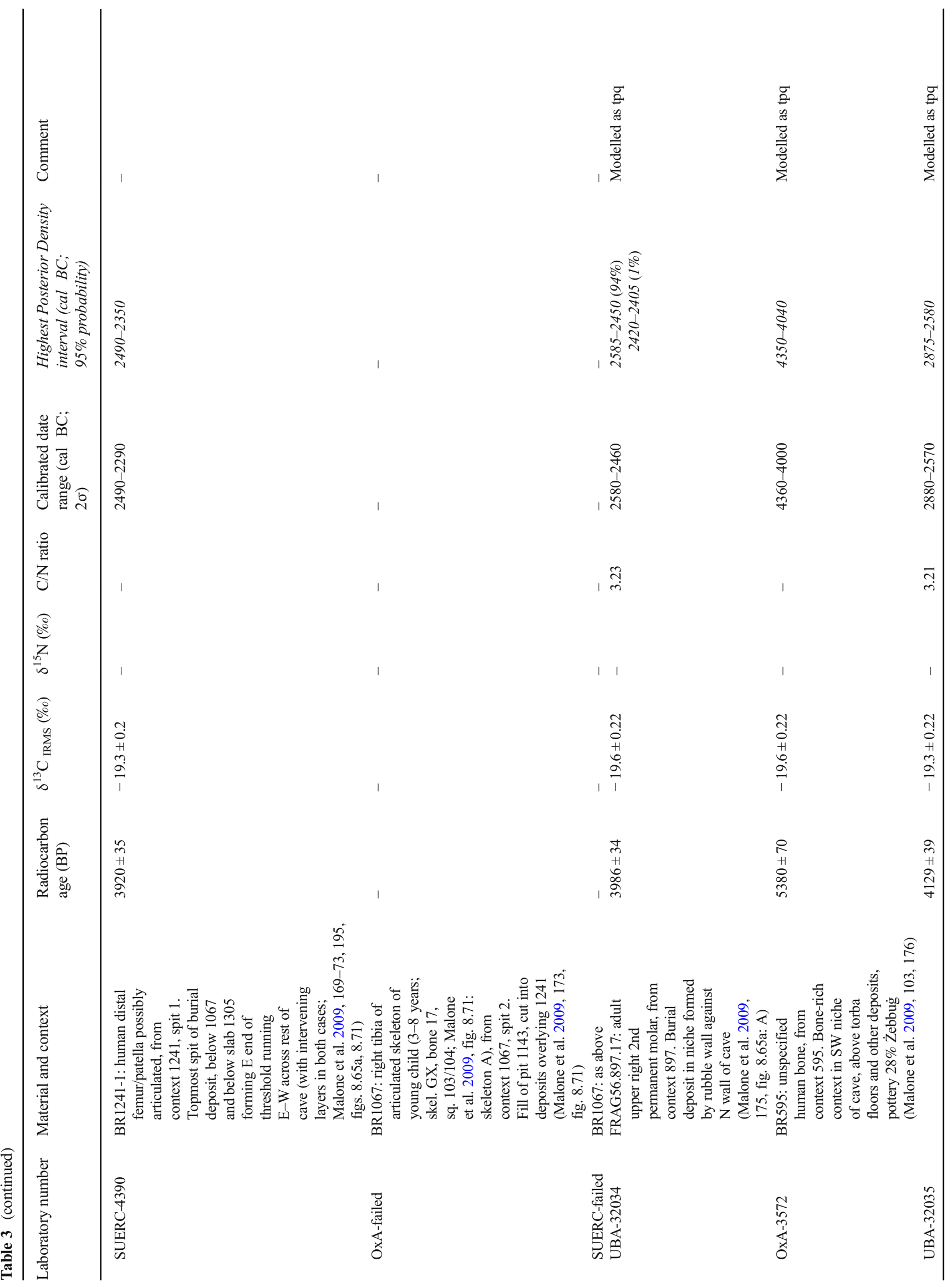




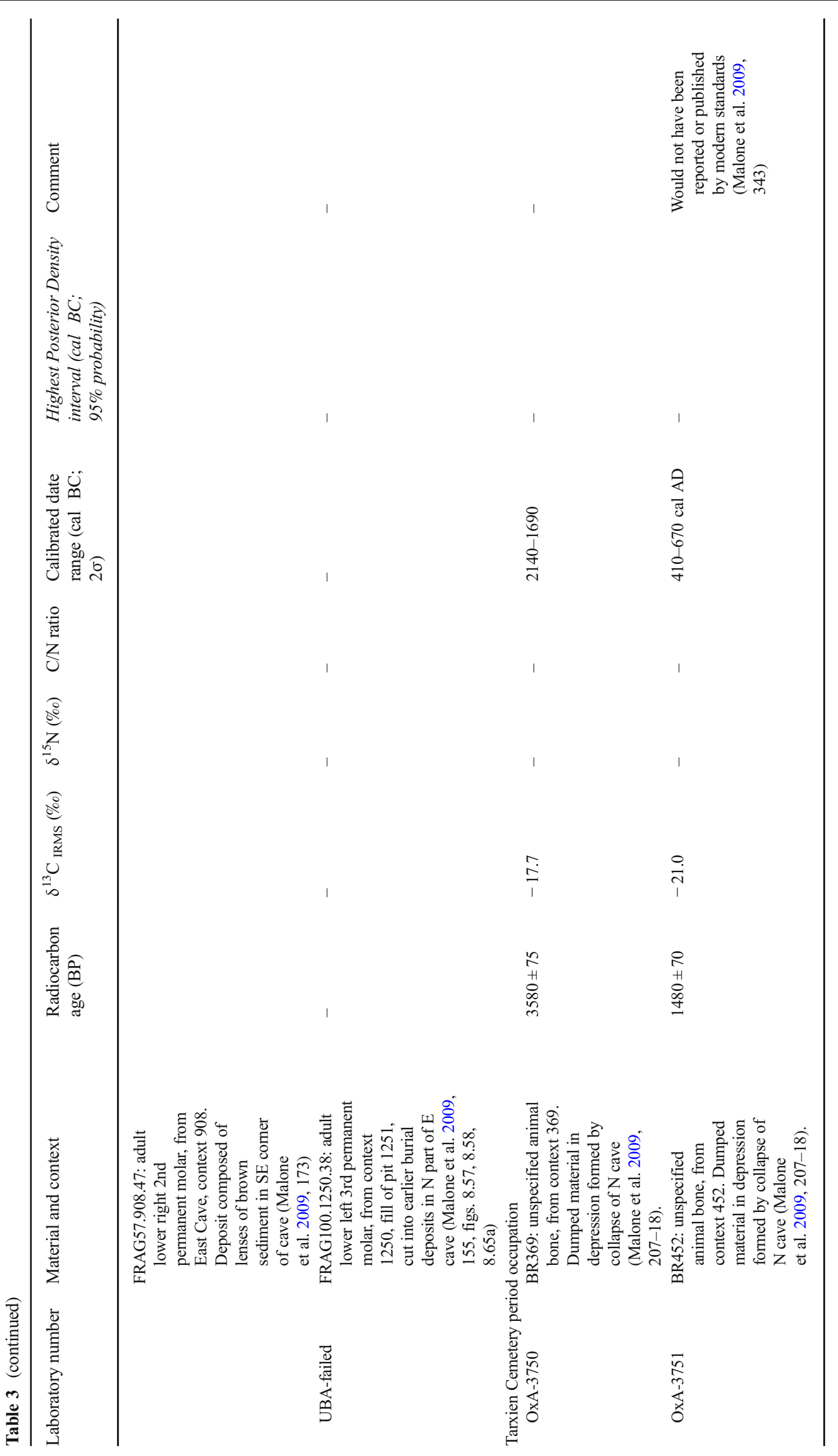


made in the pretreatment of bone samples and in assessing whether collagen preservation is sufficient for accurate dating (Brock et al. 2010, 105, 107; 2007, 190). A review of the preexisting measurements concludes that, of the 14 results reported in 1992-1994, five (OxA-3567, -3568, -3751, -5038, 5039) would not have been dated using current criteria for satisfactory collagen yields, while the remaining nine (OxA$3566,-3569,-3570,-3571$ to -3575 and -3750 ) should be treated with some caution (Malone et al. 2009, 341-3). Four of the first five are accordingly excluded from the models presented here; the fifth (OxA-3751) relates to Tarxien Cemetery period use of the site. Far more rigorous standards obtained, however, by the time the measurements made at Belfast and East Kilbride were undertaken in the early 2000s (Malone et al. 2009, 343-5), and these are taken as reliable.

\section{Chronological modelling}

ToTL's programme of radiocarbon dating for the site has been designed within a Bayesian statistical framework (Buck et al. 1996). The principle behind the Bayesian approach to the interpretation of data is encapsulated by Bayes' theorem (Bayes 1763). It means that new data collected about a problem ("the standardised likelihoods") are analysed in the context of existing experience and knowledge of that problem ("prior beliefs"). The combination of the two permits a new understanding of the problem ("posterior beliefs") which can, in turn, become prior beliefs in a subsequent model. Bayesian analysis brings together archaeological information and radiocarbon information by expressing both as probability density functions, which are also the form of the posterior beliefs.

In the modelling of archaeological chronologies, calibrated radiocarbon dates form the "standardised likelihoods" component of the model and archaeology provides the "prior beliefs", so that the radiocarbon dates are reinterpreted in light of the archaeological information to provide posterior beliefs about the dates. Such estimates will vary with the model(s) employed, and several different models may be constructed based on varying interpretations of the same data (Bayliss et al. 2007, 2016). The purpose of modelling is to progress beyond the dates at which individual samples left the carbon cycle to the dates of the archaeological events associated with those samples.

Prior beliefs fall into the following two main groups: informative and uninformative. Informative prior beliefs employed in modelling dates from archaeological contexts often derive from the stratigraphic relationships between the contexts of samples. An often employed uninformative prior belief is that the samples dated are representative of a more-or-less continuous episode of activity, such as the placing of Tarxien-phase individuals in the tomb, and are spread more or less uniformly through it, without necessarily including the earliest or the latest material generated by it (Buck et al. 1992). This assumption is necessary to constrain the scatter inherent in radiocarbon ages, which would otherwise make episodes of activity appear to start earlier, continue longer and end later than they actually did (Steier and Rom 2000).

The chronological modelling described here has been undertaken using OxCal 4.2 (Bronk Ramsey 1995, 1998, 2009; Bronk Ramsey et al. 2010; Bronk Ramsey and Lee 2013) and the internationally agreed calibration curve for terrestrial samples from the northern hemisphere (IntCal13; Reimer et al. 2013). Once the models have been defined, detailing the radiocarbon results and specifying the known relative ages of the samples, and the probability distributions of individual calibrated results have been calculated, the programme attempts to reconcile these distributions with the prior information by repeatedly sampling each distribution to build up a set of solutions consistent with the model structure. This is done using a random sampling technique (Markov Chain Monte Carlo or MCMC) which generates a representative set of possible combinations of dates. This process produces a posterior probability distribution for each sample's calendar age, which occupies only a part of the calibrated probability distribution. In the illustrations, in this report, the posterior density estimates are shown in solid colour and the calibrated radiocarbon dates from which they have been sampled are shown in outline. In the case of OxA-27803, for example, a simple calibra-

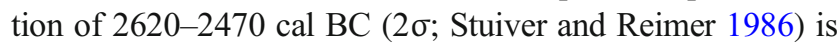
reduced to a Highest Posterior Density Interval of 2525 2470 cal BC (95\% probability; Table 3$)$.

Not all posterior density estimates directly map particular radiocarbon dates. For example, formal estimates can be made of the dates when episodes of activity began and ended (e.g. start "shrine"; Table 5). By calculating the difference between these date estimates, the duration of an episode can be calculated (e.g. use lower "shrine"; Table 4). The difference between the posterior density estimates for the dates of two different events provides an estimate for the interval between them (e.g. end rock-cut tomb/start cave complex; Table 4). This can be partly negative if the distributions for the events in question overlap.

Statistics calculated by $\mathrm{OxCal}$ provide guides to the reliability of a model. One is the individual index of agreement which expresses the consistency of the prior and posterior distributions. If the posterior distribution is situated in a high-probability region of the prior distribution, the index of agreement is high (sometimes 100 or more). If the index of agreement falls below 60 (a threshold value analogous to the $95 \%$ significance level in a $\chi^{2}$ test), the radiocarbon date is regarded as inconsistent with the sample's calendar age. Sometimes, this merely indicates that the radiocarbon result is a statistical outlier (more than two standard deviations from the sample's true radiocarbon age), but a very low index of 
agreement may mean that the sample is redeposited or intrusive (i.e. that its calendar age is different to that implied by its stratigraphic position), or that it is contaminated with exogenous carbon. Another index of agreement, Amodel, is calculated from the individual agreement indices and indicates whether the model as a whole is likely, given the data. In most applications, this too has a threshold value of 60 .

The simple calibrations provided in Table 3 have been calculated by the maximum intercept method (Stuiver and Reimer 1986) and are cited as recommended by Mook (1986): rounded outwards by 10 if the standard deviation is 25 or more, by 5 if it is less than 25 . The probability distributions of calibrated radiocarbon dates shown in outline in the graphs have been calculated using the probability method (Stuiver and Reimer 1993). Highest Posterior Density Intervals output from the models are rounded outwards to five years and are cited in italics to distinguish them from simple calibrated date ranges. The chronological models are defined by the OxCal CQL2 keywords and by the brackets on the lefthand side of the OxCal graphs.

\section{Sample selection}

Samples submitted for the originally published dates were generally single bone fragments, although those for SUERC4389 and -4390 , both from selected skeletons, consisted respectively of proximal tibiae fragments and a distal femur fragment and patella (Malone et al. 2009, 341, table 12.3), suggesting that the first were paired and the second articulated. Samples submitted by FRAGSUS were selected to provide an overview of the chronology of the site and to date particular pathological specimens. They were all loose molars or premolars of adult or sub-adult individuals. Since these teeth were not all of the same kind (Table 3), some could conceivably have come from the same individual, which would not have been possible if, for example, they had all been, for example, lower left third molars.

ToTL's rationale for sample selection has been detailed elsewhere (e.g. Bayliss et al. 2011, 38-42). The aim is to ensure that a sample is contemporary with its context, rather than already old when incorporated into it. For projects employing stratigraphic relationships between deposits as prior information in Bayesian models, this is critical, since the stratigraphy relates to deposits and radiocarbon dating relates to samples from those deposits. If the samples were not freshly deposited in their parent contexts, then the stratigraphic sequence is not the sequence of the dated samples.

In the case of the Xaghra Circle, extensive, probably repeated, reworking and rearrangement of human bone (Malone et al. 2009, 364-6) meant that a disarticulated bone could easily be older than its final context. Preferred samples were, thus, of articulated or articulable human bone from individuals who, although often disturbed or incomplete, would, because they remained articulated, still have been connected by soft tissues when buried, so that they would have reached their final positions soon after death. Two disarticulated samples were submitted with the intention of replicating pre-existing dates, and multiple disarticulated samples were dated from a context which lacked articulated samples so that the most recent would provide a maximum age for the deposit. Priority was given to samples from sequences of deposits, so that the stratigraphic relationships would provide constraint. Simulation models were run to determine the most efficient sampling strategy within each stratigraphic sequence.

In the event, suitable samples were located from the small rock-cut tomb and from the Tarxien period use of the cave complex. The shape of the calibration curve for the initial, early third millennium cal BC part of the Tarxien use of the site is such that the distributions of individual calibrated dates which fall here, even when constrained by the model, are extended and sometimes bimodal, so that the resulting age estimates are less precise than if they had fallen elsewhere on the curve (Fig. 4).

\section{The possibility of dietary offsets}

Diet-induced radiocarbon offsets can occur if a dated individual has taken up carbon from a reservoir not in equilibrium with the terrestrial biosphere (Lanting and van der Plicht 1998). If one of the reservoir sources has an inherent radiocarbon offset - for example, if the dated individual consumed marine fish or freshwater fish from a depleted source - then the bone will take on some proportion of radiocarbon that is not in equilibrium with the atmosphere. This makes the radiocarbon age older than they would be if the individual had consumed a diet consisting of purely terrestrial resources. Such ages, if erroneously calibrated using a purely terrestrial calibration curve, will produce anomalously early radiocarbon dates (Bayliss et al. 2004). No one on the Maltese islands would have been far from the sea. Initial stable isotope analyses of human remains from the site, however, indicated that protein from marine sources would have been insignificant in the diet (Lai et al. 2009; Richards et al. 2001). For present purposes, we, therefore, proceed on the basis that the marine component in the diet of the dated individuals was negligible. We note, however, the wide range of $\delta^{15} \mathrm{~N}$ values currently available $(9.4 \pm 0.15 \%$ o to $13.6 \pm 0.3 \%$; Table 3), which does not preclude the possibility that some individuals may have consumed a larger proportion of marine protein. This issue will be clarified by ongoing work by Tamsin O'Connell, Argyro Nafplioti, Emma Lightfoot and Rowan McLaughlin as part of the FRAGSUS project. 
Table 4 Highest posterior density intervals of durations and intervals (Fig. 10)

\begin{tabular}{lll}
\hline Duration or interval & Years (95\% probability) & Years (68\% probability) \\
\hline Use rock-cut tomb & $45-155(13 \%)$ or $170-505(82 \%)$ & $240-480$ \\
Use N threshold bone pit & $40-275$ & $105-230$ \\
Use surface & $330-600$ & $410-550$ \\
Use lower shrine & $235-300(20 \%)$ or 315-395 (75\%) & $265-270(1 \%)$ or 325-380 (67\%) \\
Use 783 & $130-265$ & $155-230$ \\
Use 1241 & $100-460$ & $125-295(60 \%)$ or 355-395 (8\%) \\
Use cave complex & $515-660$ & $545-620$ \\
End rock-cut tomb/start surface & $160-425$ & $180-300(53 \%)$ or 345-400 (15\%) \\
$\quad$ activity and cave complex & -105 to-65 (4\%) or - 20-60 (71\%) & $-5-45(64 \%)$ or $100-110(4 \%)$ \\
Start 1307/start shrine & or $75-145(20 \%)$ & $175-295$ \\
Start shrine/end N threshold & $80-315$ & $230-240(4 \%)$ or 295-345 (64\%) \\
$\quad$ bone pit & $200-360$ & $50-120$ \\
Start shrine/start 783 & $25-155$ & \\
End 960/end surface activity & & \\
$\quad$ and cave complex & &
\end{tabular}

\section{The model}

Stratigraphic relationships between the contexts from which samples have been dated are shown in Fig. 5. Since there are no stratigraphic relationships between the rock-cut tomb and the cave complex (and activity on the surface), they are modelled as independent bounded phases. Bone samples not specifically recorded as articulated are generally taken to have been disarticulated, like the loose teeth, and are modelled as termini post quos (literally points or dates after which) for their contexts using the After function in OxCal, on the grounds that they could have been redeposited in the deposits from which they were recovered. This function calculates a wedge-shaped distribution which increases in probability as the parent date or group of dates decreases and has a beginning but no end, because it is not known how much later than the sample in question the context may be (Fig. 6). It is these distributions which are active in the models, although they are not visible in the graphs. Results for disarticulated samples are not treated this way when they are statistically consistent with, or later than, measurements on articulated samples from the same contexts and/or when the dates have good agreement with dates on stratigraphically related articulated samples.

In the model for the main, Tarxien, use of the site (Figs. 8, 9, 11, 12, 13 and 17, 18), this procedure results in the treatment of 38 dates as termini post quos. While the samples may have been or, in some cases, clearly were redeposited in the contexts from which they were excavated, they could, at the same time, derive from the funerary use of the complex, especially given that not all of it was excavated, including the deepest and earlier levels, and that there was much movement and manipulation of human bone. For this reason, they are treated as part of the funerary use of the site although not of their final contexts. This is done by modelling them independently in a bounded phase (Fig. 7) and then incorporating the estimated start and end dates from this exercise in the overall period of Tarxien activity on the surface and in the cave complex (Fig. 8: start tpqs, end tpqs). The fifth millennium cal BC date OxA-3572 from context 595 is excluded from this exercise because, if the measurement is accurate, the sample was clearly redeposited and may be contemporary with Żebbug pottery, which made up $28 \%$ of a large predominantly Tarxien assemblage from this context (Malone et al. 2009, 103, 176).

Where there are dates for samples from different spits within a single deposit, adjacent lower spits (for example, 4 and 5) and adjacent upper spits (for example, 1 and 2) are placed in single phases on the grounds that, while spit 4 at one location within the deposit may not have been deposited after spit 5 at another, spits 1 and 2 probably were deposited after spits 4 and 5 . Dates are estimated for the installation of particular structures or other features where these can be related to other parameters in the model (e.g. floor 525; Table 5). These, which are shown in orange in the graphs, are often termini ante quos, notably where it is clear that certain contexts abutted megaliths, but less clear into precisely which deposits those megaliths were inserted because they were left in place, with their bases unexcavated (e.g. taq megalith 1178; Table 5). Some attempt was made to model other archaeological events that could be stratigraphically related to parameters in the model, but these were insufficiently constrained to produce meaningful date estimates; the formal date estimate for the construction of the megalithic threshold which overlay the infilled north threshold bone pit (Malone et al. 2009, 116-18), for example, spans more than 300 years. The dates of many other archaeological events could not be estimated at all as they were not securely related to those deposits that have been dated.

The overall structure of the model is shown in Fig. 8, with its component parts relating to the rock-cut tomb illustrated in 
Fig. 9, and those relating to the main Tarxien use of the site in Figs. 11, 12, 13 and 17, 18. This model has good overall agreement (Amodel: 71).

\section{The rock-cut tomb}

This small structure (Malone et al. 1995, 2009, 95-103) is the oldest dated element of the site. Its age, perhaps combined with the intrusion of modern vine pits, and its shallowness, compared to the cave complex, made for particularly poor collagen preservation and, hence, for failed samples or rejected results. Four of the five pre-existing dates are among those noted previously which would not have been reported or published by modern standards. They are therefore excluded from the model (Fig. 9: OxA-3567?, -3568?, -5038?, -5039?). Six of ten samples submitted by the ToTL project failed for lack of collagen, and a seventh had a collagen yield below the Oxford laboratory's minimum threshold, although other parameters, including the $\mathrm{C}: \mathrm{N}$ ratio, were acceptable (Table 3). Two of the failed samples submitted by the ToTL project were replicates of OxA-5039 and -5039, confirming the unreliability of these dates.

Once unreliable measurements are excluded, there are only two dates from the east chamber. The first is one of 3635 3515 cal BC (65\% probability) or 3430-3375 cal BC $(30 \%$ probability), probably $3600-3550$ cal BC (28\% probability) or 3540-3515 cal BC (19\% probability) or 3415-3380 cal BC ( $21 \%$ probability) for one of a set of articulating subadult upper thoracic vertebrae from context 328 , which lay directly on the chamber floor and was the first in a series of funerary deposits (Fig. 9: OxA-27802; Malone et al. 2009, 99-102, figs. 7.7-7.9). The second (Fig. 9: UBA-32005) is a date for a loose molar from the same context which is statistically consistent with the first, as determined by a chi-squared test (Ward and Wilson 1978; $\mathrm{T}^{\prime}=0.3 ; \mathrm{T}^{\prime}(5 \%)=3.8 ; v=1$ ). These provide a date for the start of deposition in the chamber.

In the west chamber, the single basal funerary deposit, context 276 , yielded one date for a molar from a cranium and mandible found together and, hence, not long out of articulation, if not actually articulated (Fig. 9: OxA-33921). The only other remaining articulated sample failed. A dearth of articulated material from this context prompted the submission of four disarticulated samples on the ground that the most recent of them should be close to the date of the deposit. Two of these dated successfully (Fig. 9: $O x A-33922, O x A-X-2676-49$ ). The more recent of them, $O x A-33922$, is statistically consistent with $O x A-33921\left(\mathrm{~T}^{\prime}=1.3 ; \mathrm{T}^{\prime}(5 \%)=3.8 ; v=1\right)$. Together, these provide the basis for an estimated end for the deposition of human remains in 276 of $3360-3140 \mathrm{cal} B C(95 \%$ probability), probably $3355-3265$ cal BC (53\% probability) or 3235-3195 cal BC (15\% probability; Fig. 9: end 270). The
Fig. 4 30th to 24th century cal BC dates from the Xaghra circle plotted on the IntCal13 calibration curve (Reimer et al. 2013)

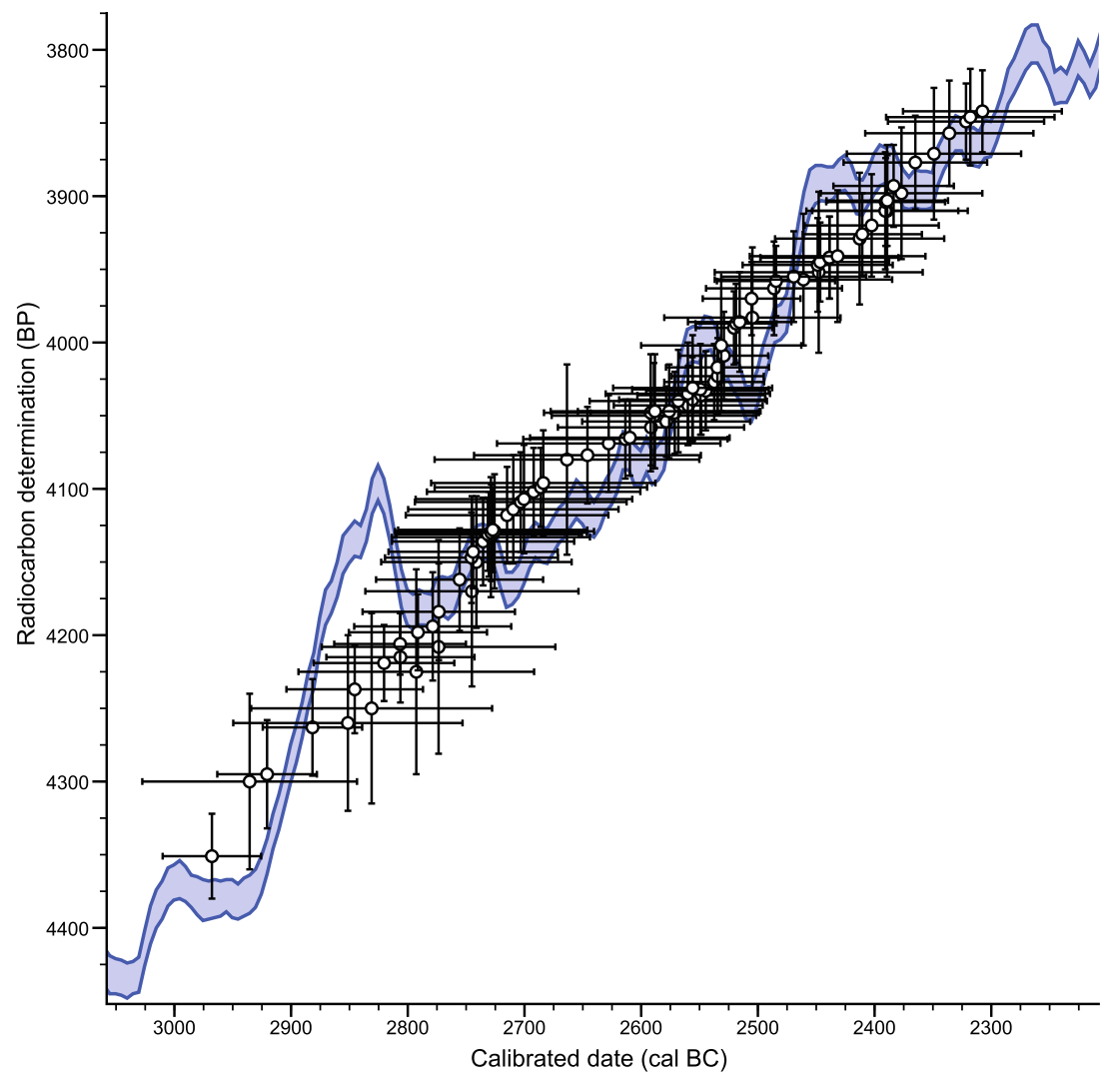




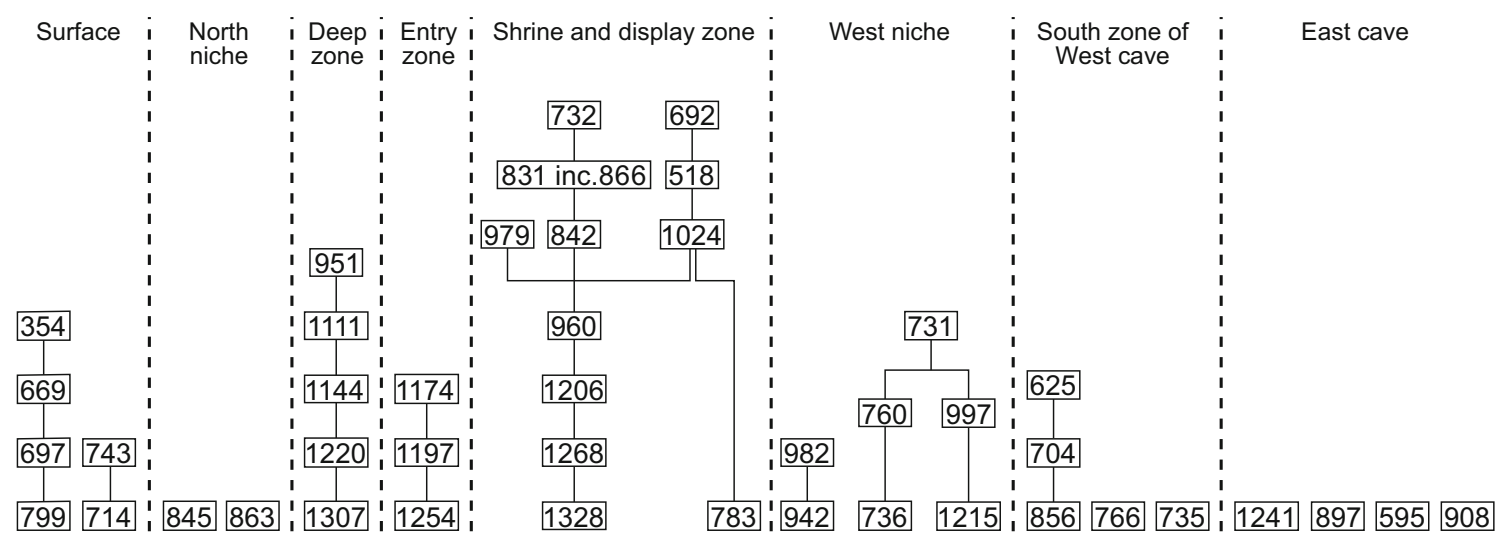

Fig. 5 Matrix of dated contexts. This shows relationships between dated contexts only. Where a context is in the bottom row, this simply means that there is no dated sample stratified below it, not that it is early in the sequence

older date, $O x A-X-2676-49$, may be inaccurate, given its low collagen content, or may reflect an earlier stage of deposition, since time depth is suggested by the movement of bones towards the rear of the chamber during its use (Malone et al. 2009, 98). This possibility is heightened by its statistical consistency with the two results from the basal deposit in the east chamber $\left(T^{\prime}=3.3 ; \mathrm{T}^{\prime}(5 \%)=6.0 ; v=2\right)$. The latest burial in the west chamber, inserted after it had been sealed and re-opened (Malone et al. 2009, 99), yielded a measurement that is statistically consistent with OxA-33921 and -33922 (Fig. 9: OxA$\left.3566 ; \mathrm{T}^{\prime}=2.6 ; \mathrm{T}^{\prime}(5 \%)=6.0 ; v=2\right)$.

After the dates from the tomb had been winnowed, there remained five effective likelihoods (i.e. dates, whether single results or the mean of more than one, that are employed in the model rather than excluded from it). On this basis, burial in the rock-cut tomb would have begun in 3640-3500 cal BC $(73 \%$ probability) or $3465-3385$ cal BC (22\% probability), probably in $3635-3550$ (48\% probability) or $3545-3515$ (17\% probability) or 3425-3410 (3\% probability; Fig. 9: start rockcut tomb). It would have gone out of use in 3355-3260 cal BC (31\% probability) or 3255-3095 cal BC (64\% probability), probably in $3345-3310$ cal BC (13\% probability) or $3295-$ 3285 cal BC (3\% probability) or 3275-3260 cal BC (3\% probability) or 3235-3170 cal BC (29\% probability) or 31653115 cal BC (20\% probability; Fig. 9: end rock-cut tomb), having continued for 50-155 years (13\% probability) or 175-
505 years ( $82 \%$ probability), probably for $240-480$ years ( $68 \%$ probability; Fig. 10: use rock-cut tomb). While most of the pottery in both chambers was Żebbug, Ġgantija material was also present, some of it in context 276, the basal deposit in the west chamber (Malone et al. 2009, 83-4, 228, fig. 6.6), and the dating would accord with this attribution.

\section{The surface area and the cave complex}

After an interval of 160-425 years (95\% probability), probably $180-300$ years (53\% probability) or $345-400$ years $(15 \%$ probability; Fig. 10: end rock-cut tomb/start surface activity and cave complex), Tarxien activity began in the area of the undated circle.

\section{The surface area}

While features and superficial contexts in the surface area contained Żebbug and Ġgantija materials (Malone et al. 2009, 82-5), the dated features fell within the Tarxien period. Samples were obtained from pits at ground level, which seemed, with an undated pit, to form a rough alignment with a megalithic threshold leading to the entrance to the caves (Malone et al. 2009, 116). These were the north threshold

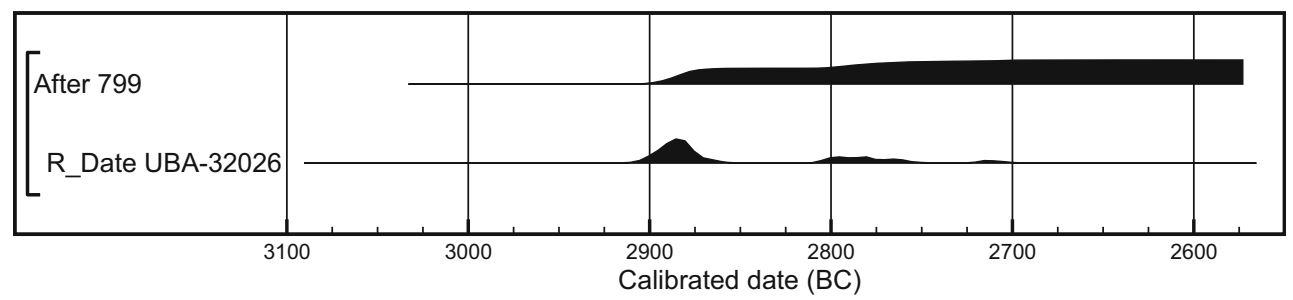

Fig. 6 A calibrated radiocarbon date (UBA-32036; 2915-2855 cal BC (64\% probability) or $2810-2730$ cal BC (27\% probability) or 2725 2700 cal BC (4\% probability; Stuiver and Reimer 1993) and a terminus post quem (799; 2720-cal BC) calculated from it using the After function in OxCal. This second distribution has a beginning but no end: its righthand edge is arbitrarily truncated in the graphic 
Fig. 7 Probability distributions for radiocarbon dates for samples from surface activity and the cave complex which are modelled as termini post quos in the model shown in Figs. 8, 9, 11, 12, 13 and 17,18 . Here, they are modelled as part of a single more-or-less continuous phase of activity for which start and end dates (start tpqs, end tpqs) are estimated.

These are in turn incorporated into the main model (Figs. 8, 9, 11, 12, 13 and 17, 18). OxA-3572 is excluded for reasons explained in the text

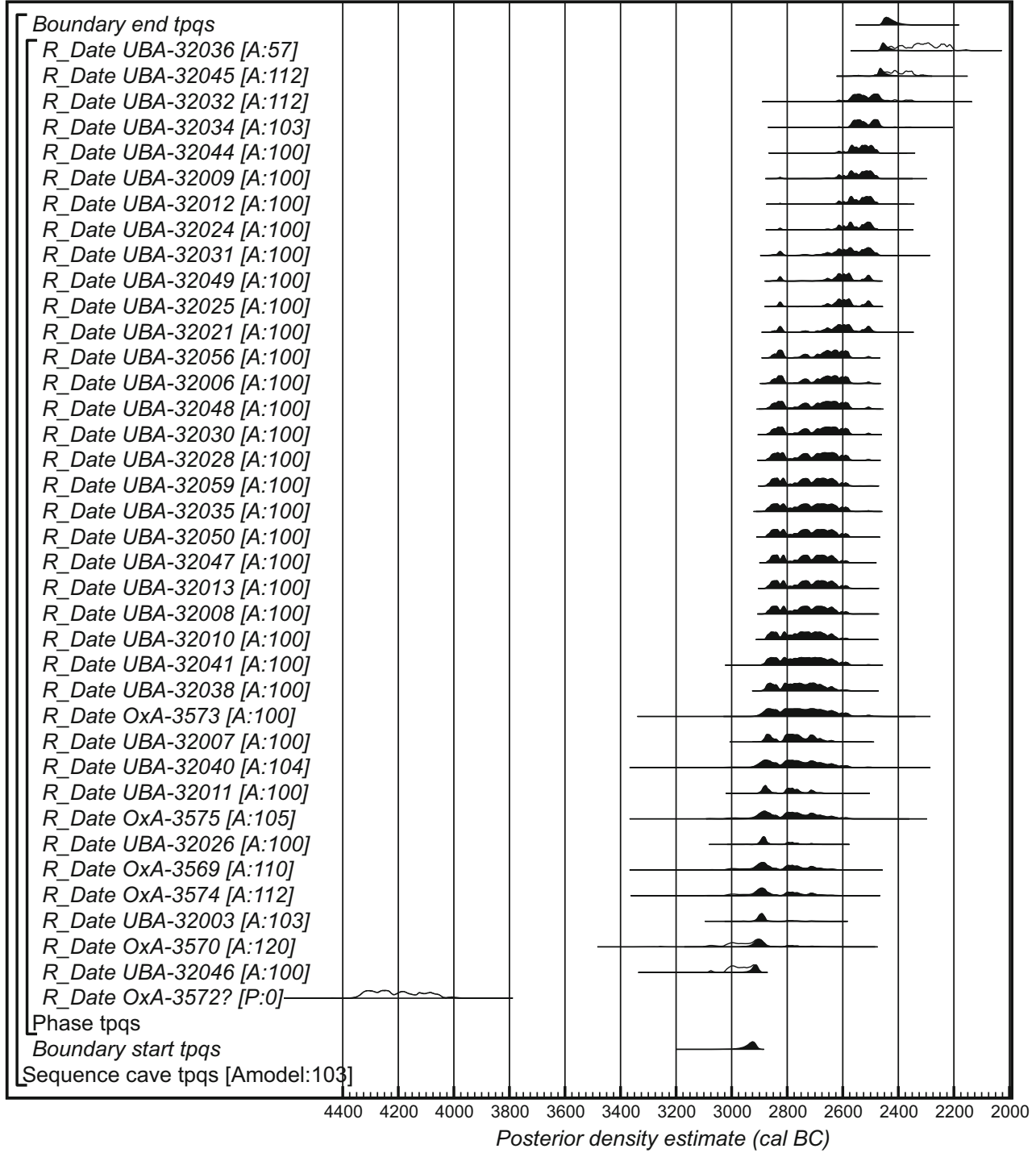

bone pit, at its north end (Malone et al. 2009, fig. 8.6) and the east cave central pits at its south end (Malone et al. 2009, fig. 8.12).

The north threshold bone pit contained a sequence of burial deposits (Malone et al. 2009, figs. 8.3, 8.8). From the first of these, context 799, there are dates for an articulated skeleton (Fig. 11: OxA-3571; Malone et al. 2009, figs. 8.8e, 8.9c) and for a cranium found in articulation with its mandible. The latter is not only more recent than the date for the articulated skeleton, it is also more recent than dates for articulated samples from overlying contexts 697 and 354 and, if included in the model, throws it into poor overall agreement. It is difficult to see how the sample could have been intrusive at the base of a $1.6 \mathrm{~m}$ deep pit. It is excluded from the model as potentially inaccurate (Fig. 11: SUERC-45309?). A date for a loose molar is modelled as a terminus post quem (Fig. 11: UBA-32026). Above 799, the largely disarticulated bones in 697 included a cranium found with its mandible (Fig. 11: OxA-33923, Malone et al. 2009, fig. 8.9e). The sequence is continued by disarticulated samples from 669 and 354 (Malone et al. 2009, fig. 8.9c, 8.9e) both modelled as termini post quos (Fig. 11: OxA-3570, -3569). 354 also yielded two articulated or fitting samples (Fig. 11: OxA-27835, -33924). This deposit immediately preceded cobbling (421) which sealed the pit (Malone et al. 2009, fig. 8.8b).

On the basis of seven effective likelihoods, human remains would have been placed in the pit from $2880-2715 \mathrm{cal} \mathrm{BC}$ (95\% probability), probably from $2870-2785$ cal BC $(67 \%$ probability) or 2780-2770 cal BC (1\% probability; Fig. 11: start $N$ threshold bone pit), to 2745-2570 cal BC $(95 \%$ probability), probably to $2685-2615$ cal BC (54\% probability) or 2610-2580 cal BC (14\% probability; Fig. 11: end $N$ threshold bone pit), over a period of $40-275$ years $(95 \%$ probability), probably over a period of $105-230$ years $(68 \%$ probability; Fig. 10: use $N$ threshold bone pit). The pit was part of a longer sequence of activity. It cut through a torba (limestone plaster) floor laid directly on the soil (context 525, Malone et al. 2009, 112), which has an estimated date of 
Fig. 8 Overall structure of the model. The component sections are shown in Figs. 9, 11, 12, 13 and 17,18 . Prior distributions "start_tpqs" and "end_tpqs" are derived from the model defined in Fig. 7. The model is defined by the OxCal keywords and by the large square brackets on the lefthand sides of Figs. 8, 9, 11, 12, 13 and 17, 18 (Bronk Ramsey 2009)

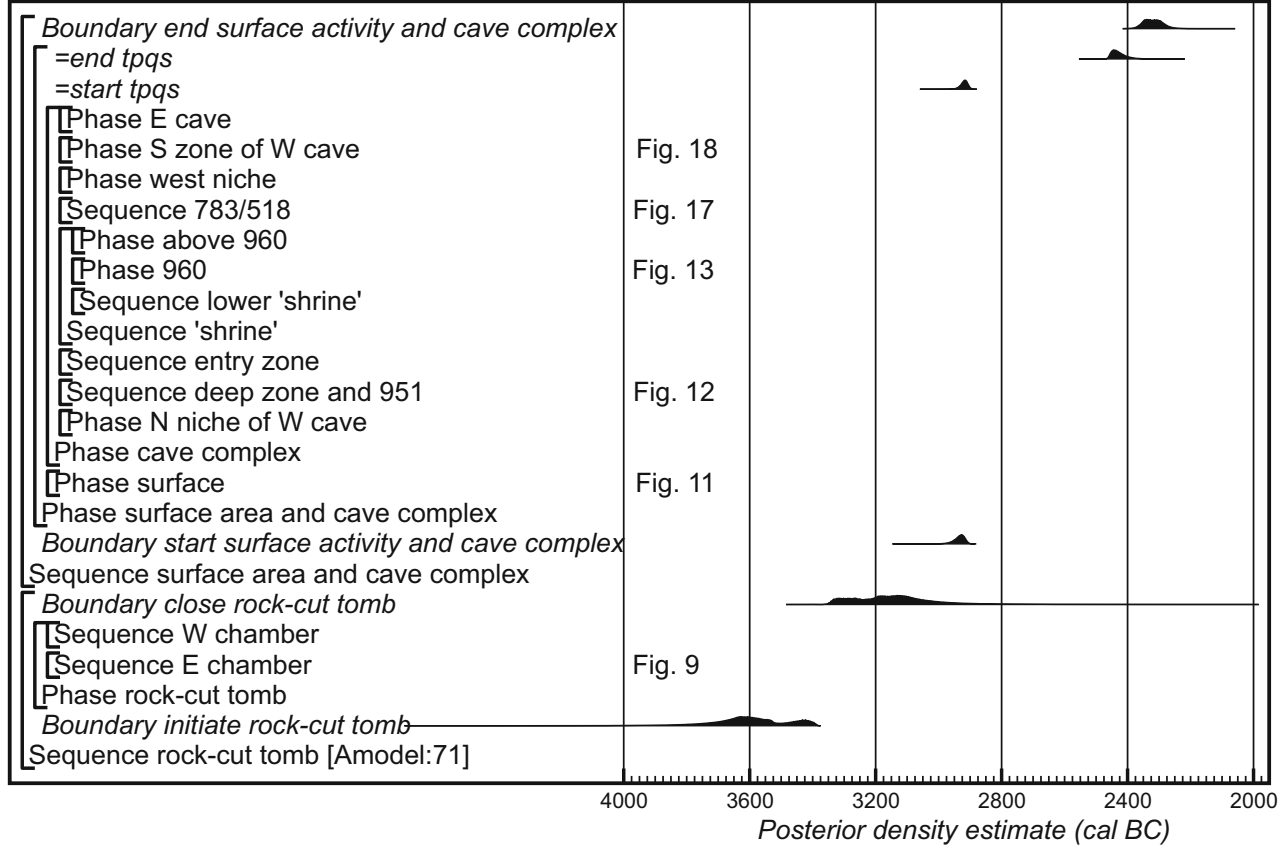

2955-2765 cal BC (95\% probability), probably of 29252835 cal BC (68\% probability; Fig. 11: floor 525). Cobbling which overlay context 354 and sealed the pit was overlain by a slab of the megalithic threshold crossed by those entering the cave (Malone et al. 2009, figs. 8.3-8.6), for the placement of which end $N$ threshold bone pit provides a terminus post quem, probably in the twenty-seventh century cal BC.

Just beyond the south end of the threshold, a collapse of the roof of the east cave had led to the downward slumping of surface deposits, including two successive burial pits, 435 and 437, which retained their stratigraphic relation to each other (Malone et al. 2009, 118-22, figs. 8.10-8.12, 8.14). Context 714 , the basal layer of pit 435 , contained both human and animal bone, the latter including articulated ovicaprid phalanges held together by limestone concretion which yielded a date of 2570-2520 cal BC (20\% probability) or 2500 2395 cal BC (71\% probability) or 2385-2355 cal BC (4\% probability), probably of $2565-2535$ cal $B C(15 \%$ probability) or 2490-2445 cal BC (50\% probability) or 2420-2410 cal BC (3\% probability; Fig. 11: OxA-27687). Context 743 , the basal fill of pit 437 , contained a substantially articulated human hand dated to 2490-2305 (95\% probability), probably to $2470-2455$ cal BC ( $8 \%$ probability) or 2445-2430 cal BC (5\% probability) or 2425-2345 (55\% probability; Fig. 11: SUERC-45318).

These two dates are in good agreement with the stratigraphic sequence. Since they are considerably later than the sequence from the northern threshold bone pit, they also indicate that the digging and filling of pits on the surface occurred over an extended period of 330-600 years (95\% probability), probably of 410-550 years (68\% probability; Fig. 10: use surface).

\section{The cave complex}

Żebbug and Ġgantija pottery was present in parts of the cave complex, evidencing activity before its major monumentalisation in the Tarxien period, although the earlier styles were almost always mixed with Tarxien material (Malone et al. 2009, 82-5, figs. 6.5, 6.7). Saflieni style pottery, seen as a funerary style possibly contemporary with Tarxien, also occurred (Malone et al. 2009, 85-6, 229-31). The complex itself was many times more extensive than the rock-cut tomb and had far deeper and more diverse stratigraphy. The text here broadly follows the order in which elements of the complex are described by Malone et al. (2009, chapter 8). Steps from ground level led to the west cave, the most fully investigated area. Excavation also took place in areas opening off the west cave: the east cave, the roof of which had collapsed, probably towards the end of the Tarxien period; and the north cave (Malone et al. 2009, fig. 8.1).

The north cave remains largely unexplored. Exploration here was confined to a deep sounding near its junction with the west cave (Malone et al. 2009, 126, fig. 8.23) and to investigation of later, Tarxien Cemetery period, occupation deposits in a hollow formed by the collapse of the cave roof (Malone et al. 2009, 207-13). A 30th to twenty-ninth century cal BC date for a molar from a Bronze Age or later upper level in the deep sounding should relate to the Tarxien use of the site but can be only a terminus post quem for its context (Fig. 12: $U B A-32003)$. Two dates previously obtained for samples from Tarxien Cemetery period contexts are not used in the model because they fall much later in time and have dubious stratigraphic integrity (Table 3: OxA-3750, -3751). 
Table 5 Highest posterior density intervals for key parameters (Fig. 19)

\begin{tabular}{|c|c|c|}
\hline Parameter & cal BC (95\% probability) & cal BC (68\% probability) \\
\hline Start rock-cut tomb & $3640-3500(73 \%)$ or $3465-3385(22 \%)$ & $\begin{array}{c}3635-3550(48 \%) \text { or } 3545-3515 \\
(17 \%) \text { or } 3425-3410(3 \%)\end{array}$ \\
\hline End rock-cut tomb & $3355-3260(31 \%)$ or $3255-3095(64 \%)$ & $\begin{array}{l}3345-3310(13 \%) \text { or } 3295-3285 \\
\quad(3 \%) \text { or } 3275-3260(3 \%) \text { or } \\
3235-3170(29 \%) \text { or } 3165-3115 \\
(20 \%)\end{array}$ \\
\hline Start surface activity and cave complex & $2975-2900$ & $2950-2910$ \\
\hline Taq megalith 1178 & $2975-2855$ & $2935-2895$ \\
\hline Start 1307 & $2930-2870(90 \%)$ or $2810-2775(5 \%)$ & $2915-2880$ \\
\hline Floor 525 & $2955-2765$ & $2925-2835$ \\
\hline Start "shrine" & $2895-2855(74 \%)$ or $2810-2765(21 \%)$ & $2890-2860$ \\
\hline Start $N$ threshold bone pit & $2880-2715$ & $2870-2785(67 \%)$ or $2780-2770(1 \%)$ \\
\hline Start 1241 & $\begin{array}{c}2865-2805(21 \%) \text { or } 2760-2715 \\
(10 \%) \text { or } 2710-2535(64 \%)\end{array}$ & $\begin{array}{l}2850-2810(16 \%) \text { or } 2695-2685(1 \%) \\
\quad \text { or } 2680-2575(51 \%)\end{array}$ \\
\hline End $N$ threshold bone pit & $2745-2570$ & $2685-2615(54 \%)$ or $2610-2580(14 \%)$ \\
\hline Start 1206 & $2665-2540$ & $2615-2565$ \\
\hline Start 783 & $2620-2605(2 \%)$ or $2585-2515(93 \%)$ & $2575-2540$ \\
\hline Taq megaliths 1170 and 1177 & $2620-2495$ & $2590-2520$ \\
\hline Taq large standing figure & $2650-2495$ & $2595-2520$ \\
\hline End 1206 & $2555-2490$ & $2540-2510$ \\
\hline $\begin{array}{l}\text { Taq stone bowl 841, screens } 665 \\
\text { and 955/914/915 }\end{array}$ & $2545-2485$ & $2530-2500$ \\
\hline Start 960 & $2530-2475$ & $2520-2490$ \\
\hline End 1241 & $2490-2350$ & $2475-2405$ \\
\hline End 960 & $2460-2350$ & $2445-2385$ \\
\hline End surface & $2490-2305$ & $\begin{array}{l}2470-2455(8 \%) \text { or } 2445-2430(5 \%) \\
\quad \text { or } 2425-2345(55 \%)\end{array}$ \\
\hline Slab 1305 & $2460-2290$ & $2420-2325$ \\
\hline End 783 & $2420-2305$ & $2400-2335$ \\
\hline Taq megalith 787 & $2405-2275$ & $2375-2310$ \\
\hline SUERC-45316 (floor 518) & $2395-2290$ & $2380-2335(54 \%)$ or $2325-2305(14 \%)$ \\
\hline End surface activity and cave complex & $2375-2255$ & $2355-2290$ \\
\hline Start tpqs & $2985-2895$ & $2945-2905$ \\
\hline End tpqs & $2465-2370$ & $2460-2415$ \\
\hline
\end{tabular}

In the north side of the west cave, the north niche, a recess blocked off by a horizontal megalith, contained a substantial deposit of both human and animal bone (context 845); this was put in place over some time, since its accumulation was interrupted by a pit and a silt layer (Malone et al. 2009, 12633). The only successfully dated articulated sample was an immature distal femur fragment found with the tibia, patella and all the relevant unfused epiphyses, from the lowest spit in 845. This provides a date of 2835-2815 (5\% probability) or 2670-2545 (63\% probability) or 2540-2485 cal BC $(27 \%$ probability), probably of 2625-2565 cal BC (49\% probability) or 2525-2495 cal BC (19\% probability) for the start of the deposit (Fig. 12: OxA-27836). This is also a terminus post quem for an overlying burial deposit (context 880). Single dates for loose teeth from 845 and from context 863 , elsewhere in the niche, are modelled as termini post quos for their contexts (Fig. 12: UBA-32030, -32032).

Immediately to the south of this niche was the deepest part of the excavated stratigraphy: the so-called deep zone, reaching to $5 \mathrm{~m}$ below the surface. It was an area of 2.4 by $2.0 \mathrm{~m}$, framed to the north by the megalithic blocking of the niche described above, to the east by another megalith-defined niche, and to the south and west by bedrock. The deposits within it had accumulated on both sides of an upright megalith, the base of which was not reached (Malone et al. 2009, 133-7). Context 1307, the lowest excavated deposit in one of the sequences through the zone (Malone et al. 2009, fig. 8.37) yielded two articulated samples (Fig. 12: $O x A-27837, O x A-X$ 2676-57). Disarticulated samples from 1220, the fill of a pit cut into layers above 1307, and from 1144, a higher, "blanket" 


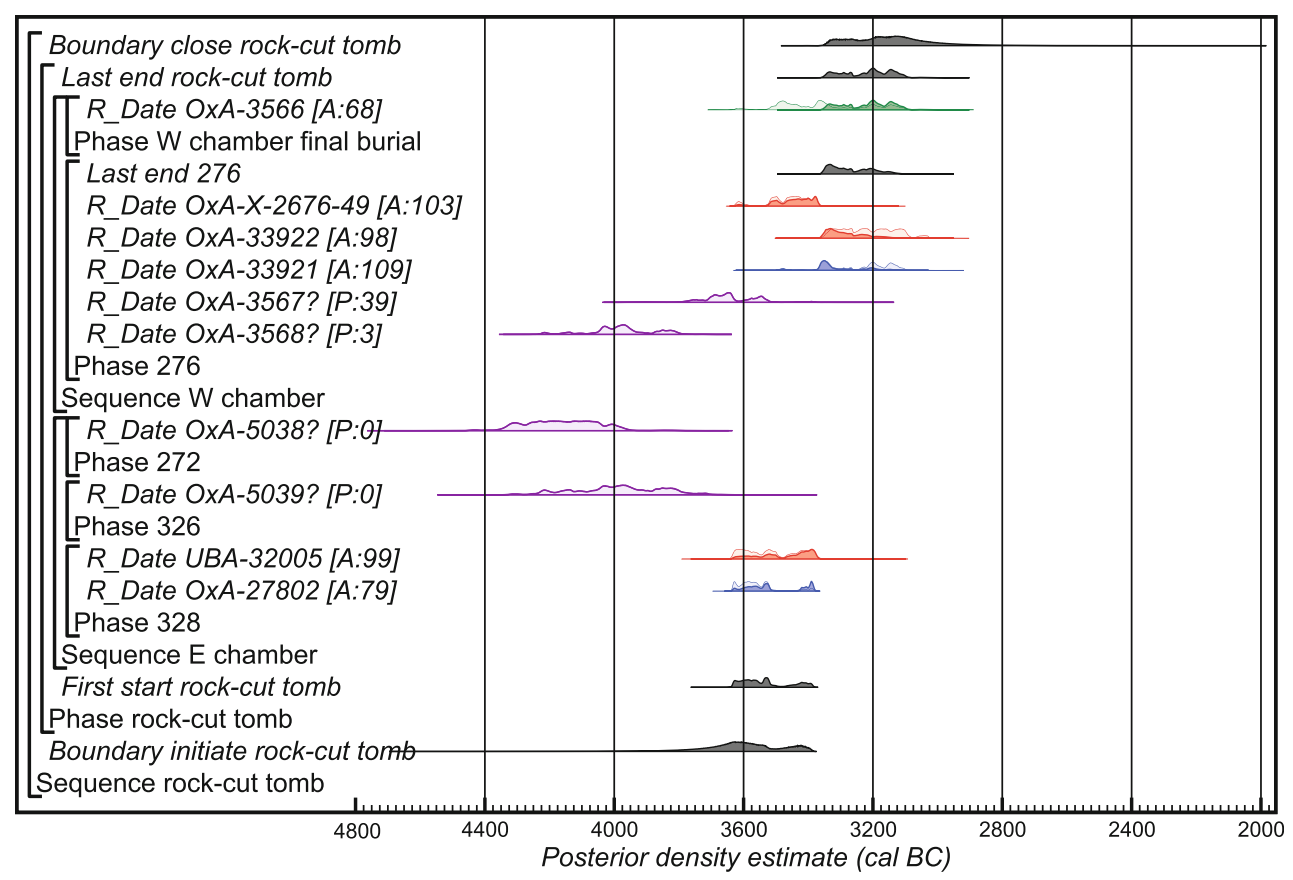

Fig. 9 Probability distributions for radiocarbon dates from the rock-cut tomb (Malone et al. 2009, 95-104). For each date, the total distribution represents the simple radiocarbon date and the solid distribution is derived from and constrained by the model. Other distributions represent parameters estimated by the model, for example "end 276". The model is defined by the OxCal keywords (Bronk Ramsey 2009) and by the large square brackets down the left-hand side of Figs. 8, 9, $11,12,13$ and 17,18 . The numbers in square brackets which follow the

deposit, are compatible with the sequence and are therefore modelled as contemporary with their contexts (Fig. 12: UBA10383, -10378). A date for a loose molar from 1111, above 1144 (Malone et al. 2009, 137, fig. 8.37), is earlier than either of these and is modelled as a terminus post quem (Fig. 12: UBA-32047). Above this again, 951, a "blanket" deposit overlying 1111 and, in part, 1144 (Malone et al. 2009, 137, figs. 8.34, 8.36, 8.37), yielded two dates for loose teeth which are in good agreement with the stratigraphic sequence (Fig. 12: UBA-32037, -32039) and three older dates which are modelled as termini post quos (Fig. 12: UBA-30238, $30240,-30241)$.

The start of deposition of context 1307 can be estimated as 2930-2870 cal BC (90\% probability) or 2810-2775 cal BC (5\% probability), probably as $2915-2880 \mathrm{cal} B C(68 \%$ probability; Fig. 12: start 1307). Deposits in this area extended below this level and must be earlier. These include an upright megalith which was not bottomed and which was abutted by the excavated deposits (Malone et al. 2009, 136, figs. 8.34, 8.36, 8.37). This would have been inserted before an estimated date of 2975-2855 cal BC (95\% probability), probably of 2935-2895 cal BC (68\% probability; Fig. 12: taq megalith 1178). Higher up the sequence, megaliths 1170 and 1177 (Malone et al. 2009, fig. 8.26) were bedded into 1144 and overlain by subsequent deposits (Malone et al. dates, for example "OxA-33921 [A:109]", are individual indices of agreement which express the compatibility of each date with the prior beliefs incorporated in the model. "?" denotes dates excluded from the model for reasons explained in the text; these dates are shown in outline only. Blue denotes articulated or articulating bone samples measured for the ToTL project; green denotes previously measured articulated or articulating bone samples; purple denotes disarticulated bone; red denotes loose molars

2009, 140), as were other megaliths (Malone et al. 2009, fig. 8.38). 1170 and 1177 would have been in place by 2620 2495 cal BC (95\% probability), probably by 2590 2520 cal BC (68\% probability; Fig. 12: taq megaliths 1170 and 1177).

The entry zone between the north part of the west cave and the "shrine" complex (Malone et al. 2009, 137-40) yielded a sequence of dates on three loose molars (Fig. 12: UBA-30259, -32049, -32048). Since their relationships to more securely dated contexts cannot be assessed, they are all modelled as termini post quos.

The "shrine" sequence, against the east wall of the west cave, at the foot of the steps leading from the surface, comprised a series of deposits incorporating burials, megalithic structures and a rich array of artefacts (Malone et al. 2009, fig. 8.42). At the base, context 1328, filling a series of cuts into natural chalky-marl sediment, included three bundles of bone, each from a single individual, and the articulated upper body of an adult male (Malone et al. 2009, 325, fig. 8.43: D). Statistically consistent measurements for replicate samples from this individual provide a date for the start of the sequence (Fig. 13: fig. 8.43: skeleton $\left.D ; \mathrm{T}^{\prime}=1.0 ; \mathrm{T}^{\prime}(5 \%)=3.8 ; v=1\right)$. The first of two articulated samples from two successive spits in the overlying layer, context 1268 (Malone et al. 2009, figs. $8.45,8.46$ ), is in good agreement with the sequence (Fig. 13: 
Fig. 10 Estimated durations and intervals from the model shown in Figs. 8, 9, 11, 12, 13 and 17, 18 (Table 3)

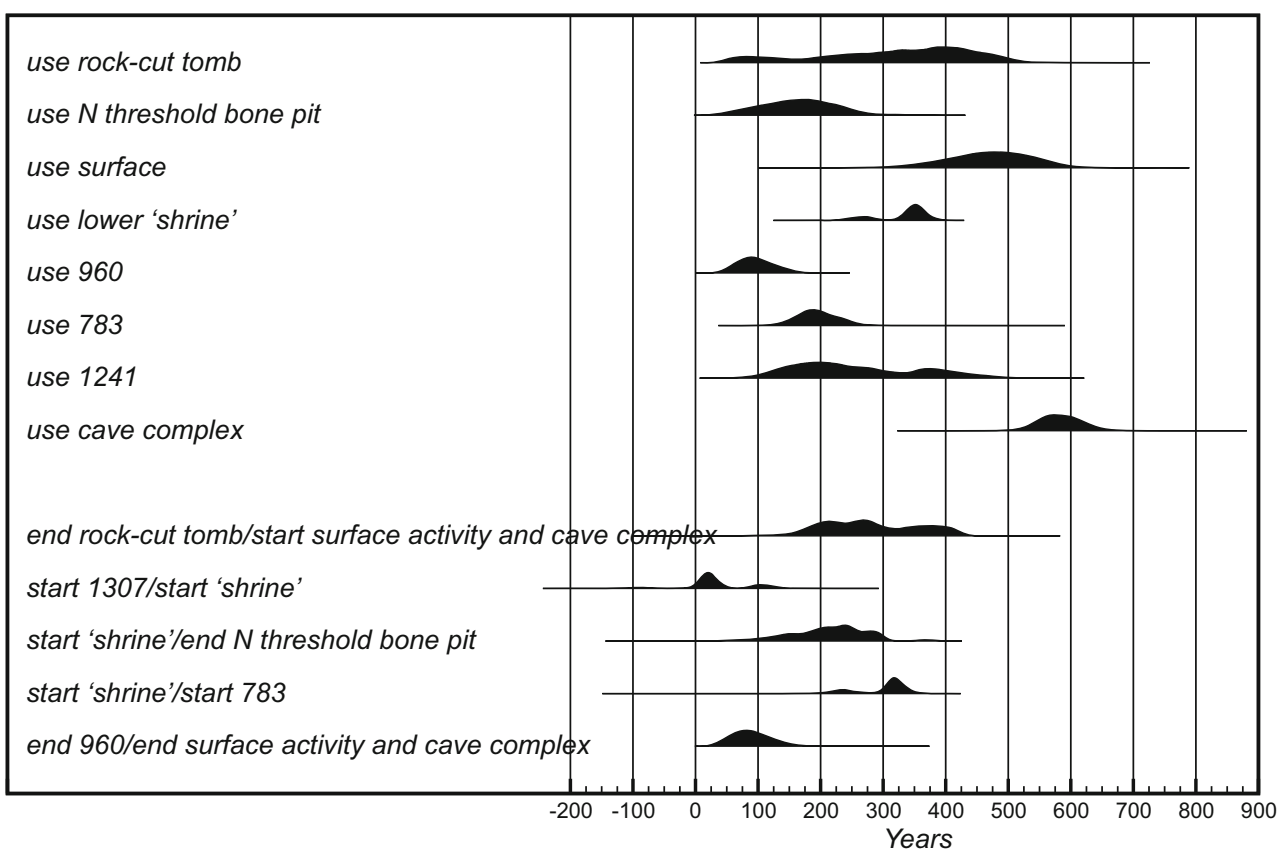

$O x A-27833)$. The second, however, is in poor agreement with the model, being more recent than articulated samples from the overlying layers, contexts 1206 and 960. It is therefore excluded from the model (Fig. 13: SUERC-45311?). Three dates for loose molars are compatible with their stratigraphic position in 1268 and are therefore modelled as contemporary with the context (Fig. 13: UBA-32060 to -32062). Although
$U B A-32062$ has poor individual agreement, this result is more recent than its place in the model would suggest and so is more likely to be a statistical outlier than from a residual sample.

In the lower spits of context 1206 (Malone et al. 2009, figs. $8.48,8.49)$, there are statistically consistent measurements for two articulated samples from spit 4 (Fig. 13: OxA-27832, $\left.33926 ; \mathrm{T}^{\prime}=0.6 ; \mathrm{T}^{\prime}(5 \%)=3.8 ; v=1\right)$. These are also
Fig. 11 Probability distributions for radiocarbon dates from the surface area (Malone et al. 2009, 109-123). "After" denotes that a date has been modelled as a terminus post quem for its context. Orange denotes an estimated date for a structural event. The format is otherwise the same as in Fig. 9

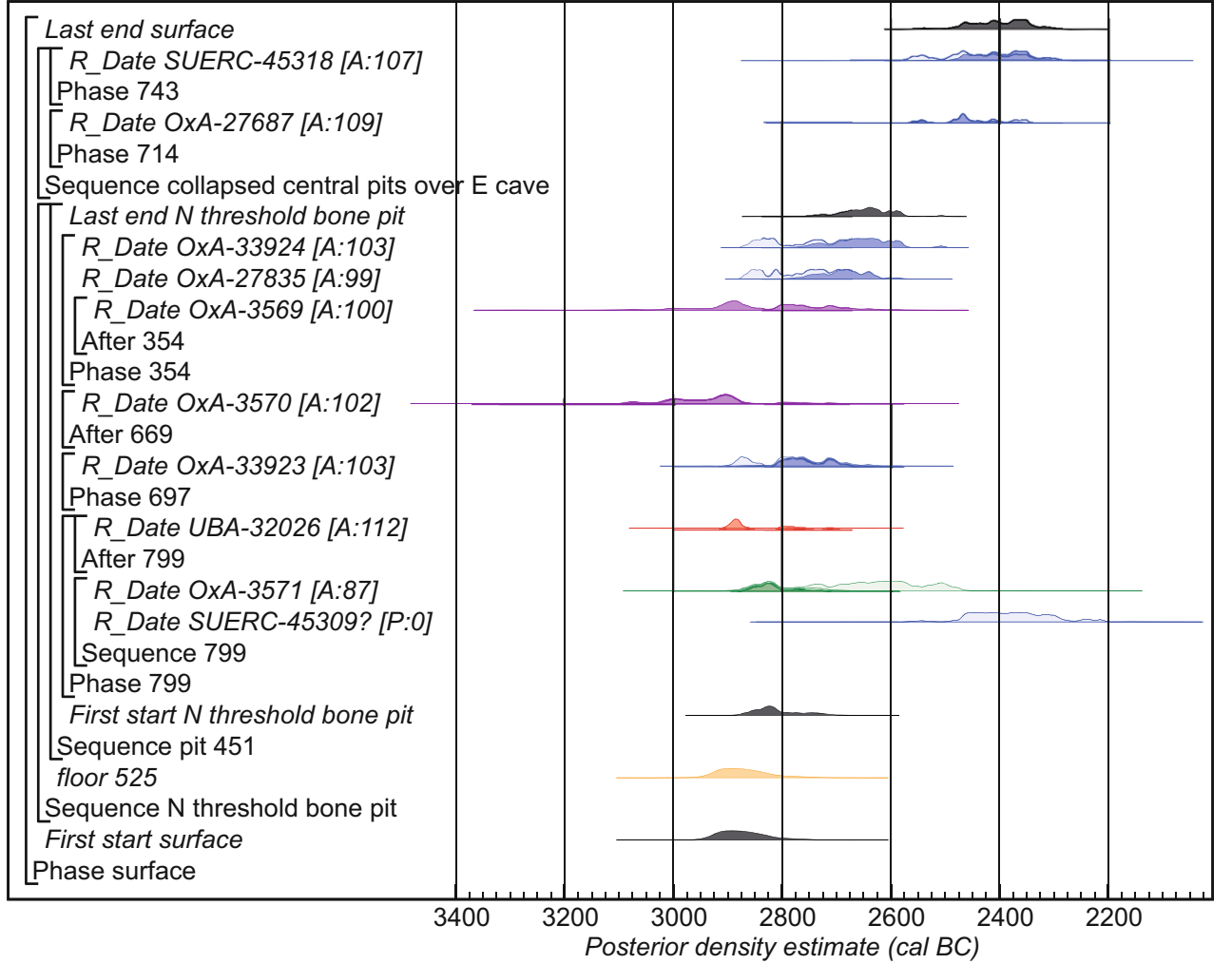


Fig. 12 Probability distributions for radiocarbon dates from context 21 in the north cave and contexts in the north of part of the west cave. "After" denotes that a date has been modelled as a terminus post quem for its context. Orange denotes an estimated date for a structural event. The format is otherwise the same as in Fig. 9

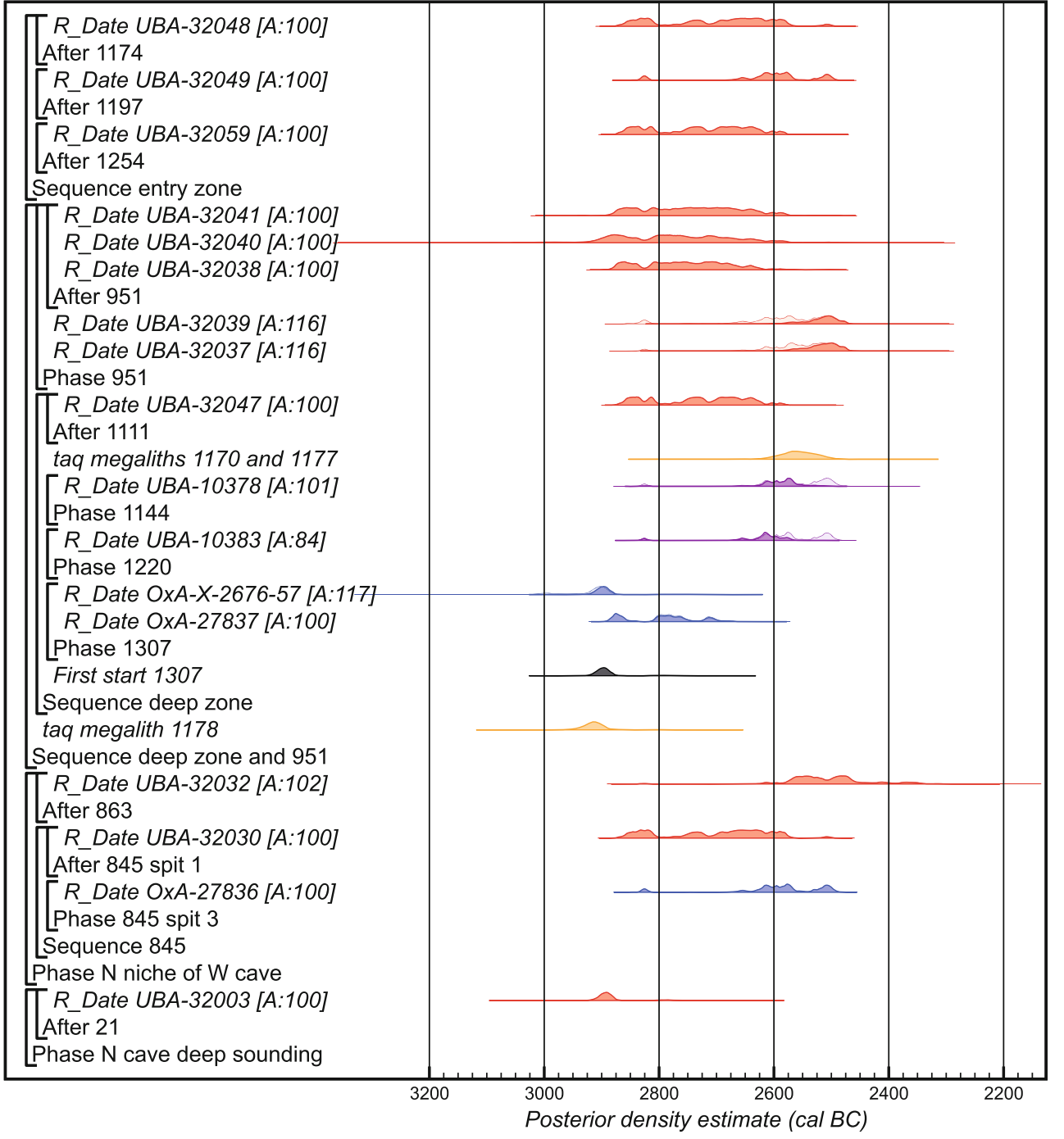

statistically consistent with a determination for an articulated sample from spit 1 (Fig. 13: SUERC-4389; $\mathrm{T}^{\prime}=0.9 ; \mathrm{T}^{\prime}(5 \%)=$ $6.0 ; v=2$ ). A second, articulated sample from spit 1 , however, is so much more recent than other samples both from 1206 and from the overlying layer 960 that it throws the model into poor overall agreement and has been excluded from the model (Fig. 13: SUERC-45312?). It appears that both SUERC45311 and SUERC-45312 are anomalously recent for unknown reasons. Three dates for loose molars are and compatible with their stratigraphic positions in 1206 and are statistically consistent with all the previously mentioned dates from 1206, with the exception of SUERC-45312 $\left(\mathrm{T}^{\prime}=10.7 ; \mathrm{T}\right.$ $'(5 \%)=11.1 ; v=5)$. They are modelled as contemporary with the context (Fig. 13: UBA-32051 to -32053), while an older date on another molar is modelled as a terminus post quem (Fig. 13: UBA-32050).

1206 was the latest of a succession of layers containing articulated or semi-articulated burials as well as disarticulated bones. It was also the earliest dated context to contain part of a large standing skirted stone figure, originally over $0.60 \mathrm{~m}$ high (Fig. 14; Malone et al. 2009, figs. 10.48-52), the dispersed fragments of which were widely scattered, mainly in the "display zone" and west niche (Malone et al. 2009, 283-9, 453, fig. 53). On the premise that it was smashed before 1206 was completely in place, this would have occurred before 2650 2495 cal BC (95\% probability), probably before 2595 2520 cal BC (68\% probability; Fig. 13: taq large standing figure).

On the basis of 12 effective likelihoods, the lower part of the "shrine" sequence would have begun in 2895-2855 cal BC (74\% probability) or 2810-2765 cal BC (21\% probability), probably in 2890-2860 cal BC $(68 \%$ probability; Fig. 13: start "shrine") and ceased in 2555-2490 cal BC (95\% probability), probably in 2540-2510 cal BC (68\% probability; Fig. 13: end $1206)$, having been built up over 235-300 years $(20 \%$ probability) or 315-395 years ( $75 \%$ probability), probably over 265-270 years (1\% probability) or 325-380 years (67\% probability; Fig. 10: use lower "shrine”). 
These lower "shrine" deposits were sealed by "blanket" layer 960, which formed a horizon between them and the upper "shrine" deposits (Malone et al. 2009, 140, 149). In its lower levels, the date for an articulated sample from spit 6 is statistically consistent with another for a loose molar from spit $7\left(\mathrm{~T}^{\prime}=0.2 ; \mathrm{T}^{\prime}(5 \%)=6.0 ; v=2\right.$; Fig. 13: OxA-27803, UBA32050). A date for an articulating sample from spit 3 is consistent with deposition later than the samples from spits 6 and 7 (Fig. 13: SUERC-45310), as is a date for a loose molar from spit 4 (Fig. 13: UBA-32043). The date for a possibly articulated sample from spit 1 (Fig. 13: SUERC-4391) is statistically consistent with SUERC-45310 $\left(\mathrm{T}^{\prime}=0.0 ; \mathrm{T}^{\prime}(5 \%)=6.0 ; \mathrm{v}=2\right)$. On this basis, 960 was deposited between 2530-2475 cal BC (95\% probability), probably $2520-2490 \mathrm{cal} \mathrm{BC}(68 \%$ probability; Fig. 13: start 960$)$ and 2460-2350 cal BC (95\% probability), probably $2445-2385$ cal BC (68\% probability; Fig. 13: end 960).

960 ran up against significant features in the form of a massive stone bowl, $c .1 \mathrm{~m}$ in diameter and $1 \mathrm{~m}$ high, placed on a shelf cut into natural marl at the west edge of the "shrine" area (Malone et al. 2009, 140, 149-55, 264, figs. 8.50, 8.52, 10.36) and of two megalithic screens, one, essentially intact, to the south of the bowl (665; Fig. 15; Malone et al. 2009, $150-4$, figs. 8.53-8.56), the other, partly dismantled, to the east (955/914/915; Malone et al. 2009, 154-5, figs. 8.53, 8.54). While all three were abutted by 960 , it is not clear precisely when the megaliths were inserted because some were not excavated but left in situ. On the premise that the bowl and megaliths were in place before 960 was deposited, it is possible to estimate a terminus ante quem for their installation of 2545-2485 cal BC (95\% probability), probably of 2530-2500 cal BC (68\% probability; Fig. 13: taq stone bowl, screens 665 and 955/914/915).

It was difficult to find suitable samples from the upper "shrine" deposits. Furthermore, most of the dated loose molars from contexts stratified above 960 are older than its estimated end and are therefore modelled as termini post quos (Fig. 13: $U B A-32007,-32009,-32028,-32044,-32046)$. Of these, $U B A-32028$ dates a loose tooth from context 842 , the fill of the massive stone bowl The fill is treated as post-dating 960 because the interior of the bowl would have remained accessible once 960 was in place.

The exceptions are dates for loose molars from context 831, the major upper "shrine" deposit, and from 866, a lens within it. These are statistically consistent with each other $\left(\mathrm{T}^{\prime}=0.6 ; \mathrm{T}^{\prime}(5 \%)=6.0 ; v=2\right)$ and in agreement with their stratigraphic position above 960 (Fig. 13: UBA-32027, 32033). 831 contained a cache of nine stone figurines (Malone et al. 2009, figs. 10.60-10.66) and a statue of two seated corpulent figures on a bed (Fig. 16; Malone et al. 2009, figs. 10.54-10.59) among numerous other artefacts, and was seen as possibly marking the closure of this part of the complex (Malone et al. 2009, 155). A megalith bedded in 831 had formed part of a collapsed structure against the east side of the cave (Malone et al. 2009, $158,180-1)$. It would have been in its final location by 2405-2275 cal BC (95\% probability), probably by 2375 2310 cal BC (68\% probability; Fig. 13: taq megalith 787$)$. A single articulated sample came from context 518, a made-up floor of powdered limestone chips and chalky deposit which overlay parts of the upper "shrine" and also overlay the "display zone" (Malone et al. 2009, 158; Fig. 13: SUERC-45316).

To the west of the "shrine" was the "display zone", a natural depression some $4 \mathrm{~m}$ across filled by up to $0.50 \mathrm{~m}$ of deposit containing human and animal bone and artefacts, including a concentration of ceramic figurines (Malone et al. 2009, 159-63). Samples were dated from an articulated subadult skeleton at the north-east edge of the depression, near the base of the deposit (Malone et al. 2009, fig. 8.61: D), and from an articulated adult right hand in the topmost spit near the south-east edge (Fig. 17: OxA-27839, SUERC-45317). Of 13 disarticulated samples, nine yielded results either statistically consistent with or later than these and are therefore modelled as contemporary with the context (Fig. 17: UBA-32014 to $32020,-32022,-32023)$. The remaining four are older than OxA-27839, which should date from close to the start of the deposition of human remains here, and are hence modelled as termini post quos (Fig. 17: OxA-3573, UBA-32021, -32024, 32025 ). On this basis, 783 would have begun to be deposited in 2620-2605 cal BC (2\% probability) or 2585-2515 cal BC (93\% probability), probably in $2575-2540$ cal BC (68\% probability; Fig. 17: start 783) and would have been built up over a period of 130-265 years (95\% probability), probably over a period of $155-230$ years (68\% probability; Fig. 10: use 783) until 2420-2305 cal BC (95\% probability), probably until 2400-2335 cal BC (68\% probability; Fig. 17: end 783).

To the west side of 783 , its upper parts reached to a niche in the cave side - the west niche - demarcated by successive stone features. The niche and its immediate surroundings contained much Żebbug material, although Ġgantija and Tarxien artefacts were also present (Malone et al. 2009, 83$5,104-6,163$, figs. $7.13,7.14) .760$ and $731=751$ were rich in Żebbug material, although stratified above Tarxien deposits (Malone et al. 2009, fig. 7.13). Many of the relevant contexts consisted of slumped rather than in situ material, so that the nature of the parent contexts is difficult to determine. An articulated sample provides a date for context 997 (Fig. 17: $O x A-27840$ ), which contained a further fragment of the large statue. Otherwise, the remaining dates for disarticulated samples are modelled as termini post quos (Fig. 17: OxA-3574, 3575; UBA-32012, -32036, -32045, -32056, -32011).

In the south zone of the west cave, to the south-west of screen 665, there were further burial deposits (Malone et al. 2009, 178-82, figs. 8.74, 8.75). Three layers (contexts 856, 704 and 625) formed a sequence against the west wall of the 
Fig. 13 Probability distributions for radiocarbon dates from the "shrine" area. "After" denotes that a date has been modelled as a terminus post quem for its context. Orange denotes an estimated date for a structural event. The format is otherwise the same as in Fig. 9

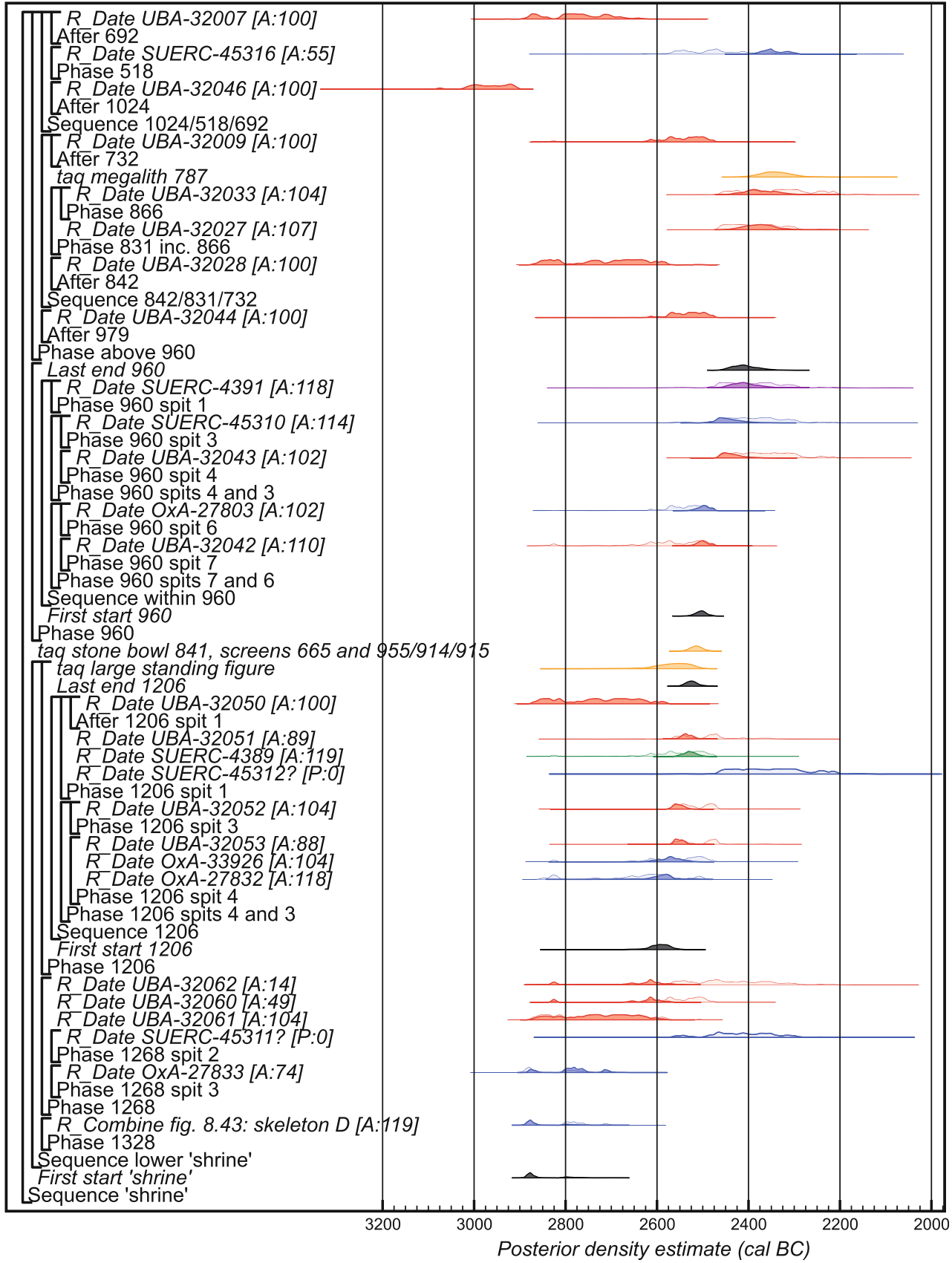

cave. Loose molars from them and from contexts 735 and 766 elsewhere in this area could not be related to any articulated samples and are hence all modelled as termini post quos (Fig. 18: UBA-32006, -32008, 32010, -32013, -32031).

The east cave (Malone et al. 2009, 163-176) was considerably smaller than the west cave, from which it was entered to the south of the "shrine". Augering showed that up to $1 \mathrm{~m}$ of unexcavated deposit remained in this entrance area. Bedrock was, however, reached in some locations, as in the southeastern corner, where sediment filling natural fissures was overlain by context 1241 , a substantial burial deposit, the lower part of which contained several wholly or partly articulated skeletons (Malone et al. 2009, fig. 8.67). The articulated upper body of an adult male, seen as the founder burial of this sequence (Malone et al. 2009, 169, fig. 8.67: B; Fig. 18: OxA27838) was immediately overlain by a more complete female (Malone et al. 2009, 169, fig. 8.67: A; Fig. 18: OxA-33927). Some $2 \mathrm{~m}$ to the west, also in the lower part of the deposit, was another articulated individual (Fig. 18: OxA-33928). An unexcavated area between this and the two previously mentioned samples (Malone et al. 2009, fig. 8.67) makes it impossible to judge whether the spit 5 from which this sample came 


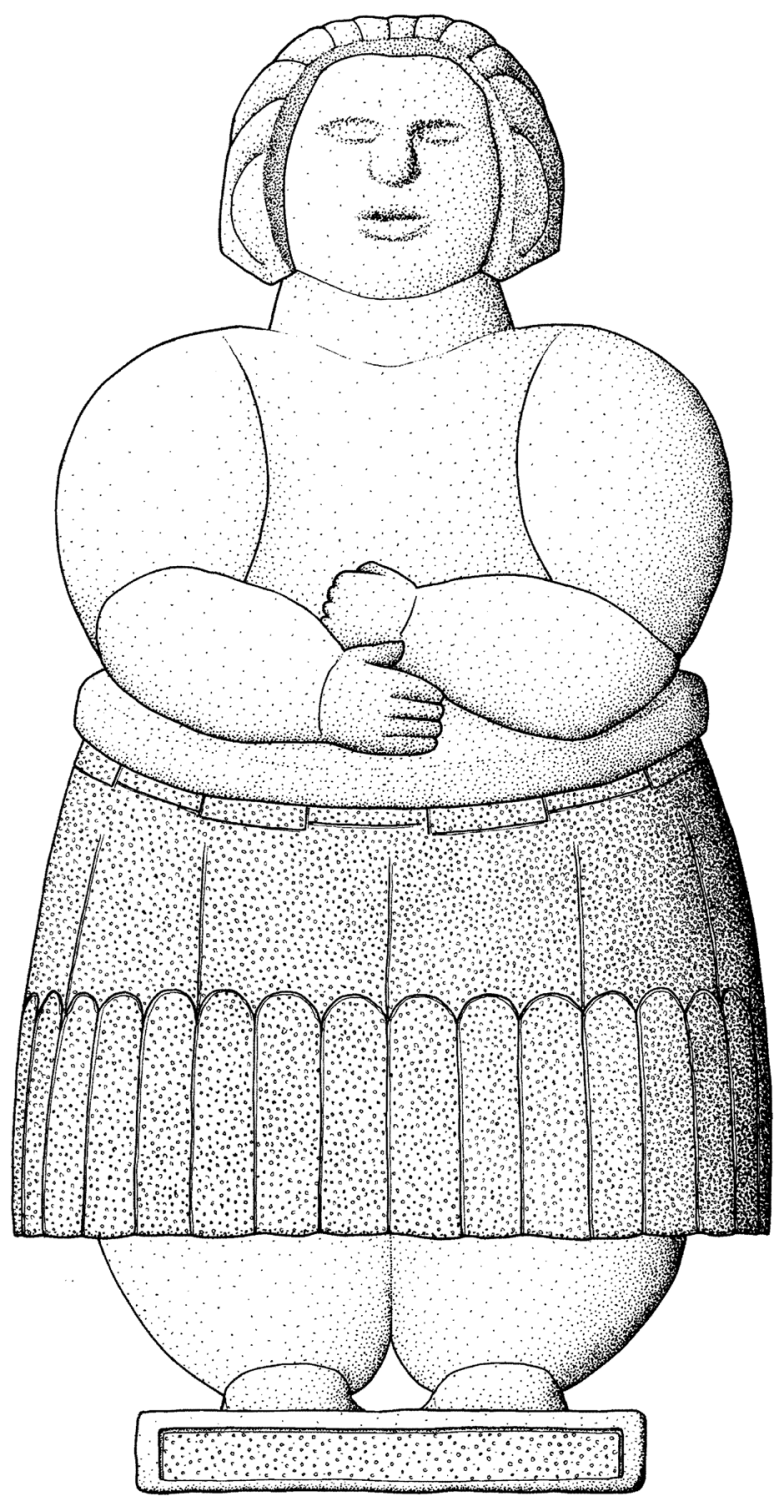

Fig. 14 Reconstruction of a statue originally $c .0 .60 \mathrm{~m}$ high, found in dispersed fragments, one in context 1206 of the lower "shrine", but most in the "display zone" and west niche (Malone et al. 2009, 283-9, 453, figs. 10.48-53). (C) McDonald Institute for Archaeological Research

was above the spit 6 from which the others came; they are therefore modelled as parts of a single phase. Certainly above all three of these was an articulated sample from spit 1, at the top of the deposit (Fig. 18: SUERC-4390). The result on a loose molar from spit 4 is statistically consistent with $O x A$ $33927\left(\mathrm{~T}^{\prime}=0.1 ; \mathrm{T}^{\prime}(5 \%)=3.8 ; v=1\right)$ and is hence modelled as contemporary with the deposit (Fig. 18: UBA-32057).

On this basis, burials would have begun to be made in 1241 in 2865-2805 cal BC (21\% probability) or 2760-2715 cal BC (10\% probability) or $2710-2535$ cal BC (64\% probability), probably in $2850-2810$ (16\% probability) or $2695-$ 2685 cal BC (1\% probability) or 2680-2575 cal BC $(51 \%$ probability; Fig. 18: start 1241) and continued until 24902350 cal BC (95\% probability), probably until 2475

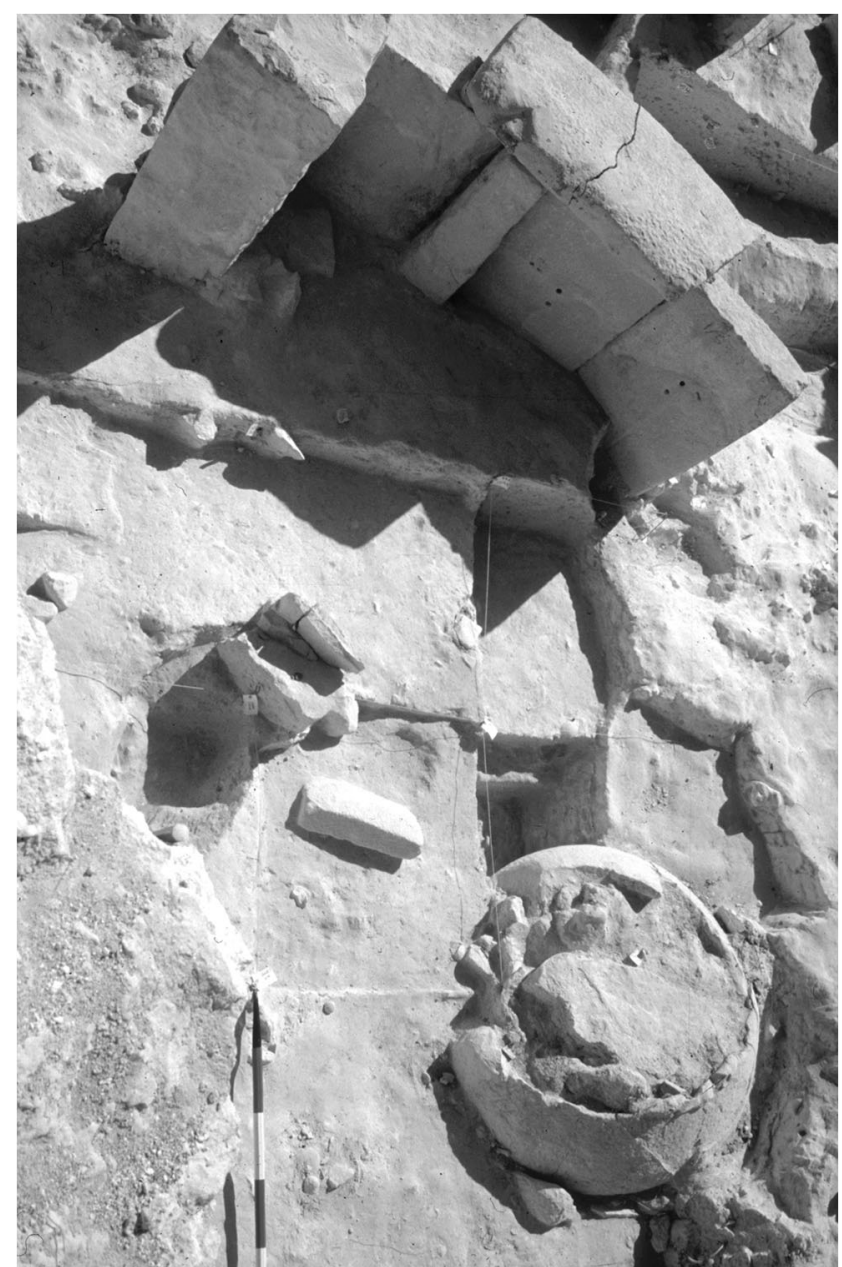

Fig. 15 The southern screen (665) and massive stone bowl (841) from above and north (Malone et al. 2009, fig. 8.56b). (C) McDonald Institute for Archaeological Research

2405 cal BC (68\% probability; Fig. 18: end 1241), over a period of $100-460$ years (95\% probability), probably 130 295 years $(60 \%$ probability) or $355-395$ years ( $8 \%$ probability; Fig. 10: use 1241). 1241 was partly overlain (with intervening layers) by one slab of a threshold running across the east cave (Malone et al. 2009, 169-73, 195, figs. 8.65a, 8.71). The estimated date for this installation is 2460 2290 cal BC (95\% probability), probably $2420-2325$ cal BC (68\% probability; Fig. 18: slab 1305).

Dates for two further loose molars from contexts 897 and 908 in the east cave cannot be related to any measurements on articulated samples and are modelled as termini post quos (Fig. 18: UBA-32034, -32035). A fifth millennium cal BC date for a disarticulated bone from context 595 (Fig. 18: $O x A-3572$ ) corresponds to the presence of Żebbug pottery, which made up $28 \%$ of a large predominantly Tarxien assemblage from this context (Malone et al. 2009, 103, 176). If OxA-3572 is accurate, then at least some of the displaced Żebbug deposits in this area were funerary. 
Fig. 16 Statue of two seated corpulent figures, found facedown and broken in context 831 of the upper "shrine" (Malone et al. 2009, 155, 289-98,

figs. 10.54-10.59). (C) McDonald Institute for Archaeological Research

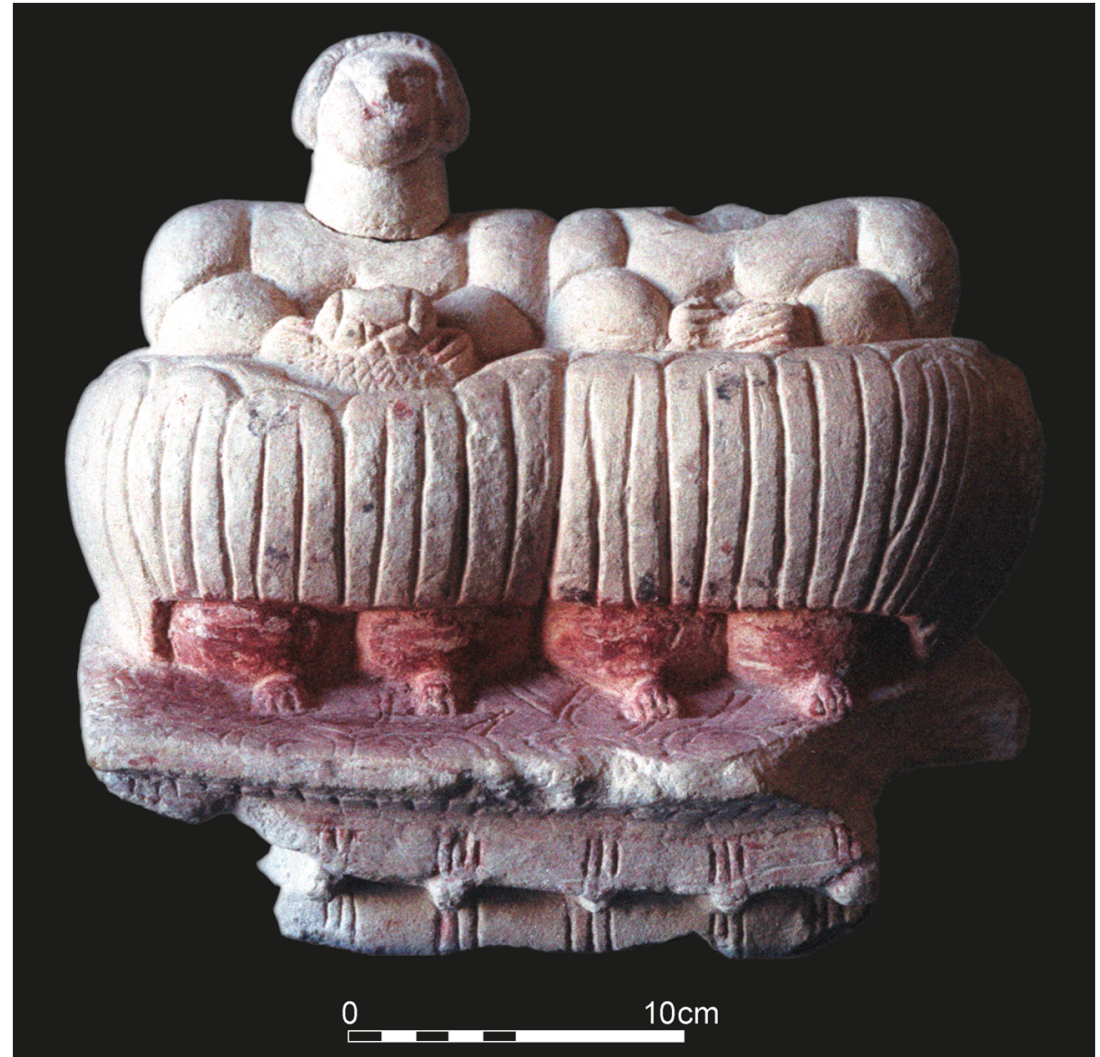

\section{Synthesis (Tables 4, 5, 6, Figs. 10 and 19)}

The rock-cut tomb was originally excavated in 3640 3500 cal BC (73\% probability) or $3465-3385$ cal BC (22\% probability), probably in $3635-3550 \mathrm{cal} B C(48 \%$ probability) or $3545-3515$ cal $\mathrm{BC}$ (17\% probability) or 3425-3410 cal BC (3\% probability; Fig. 19: start rockcut tomb) and continued until 3355-3260 cal BC (31\% probability) or 3255-3095 cal BC (64\% probability), probably until 3345-3310 cal BC (13\% probability) or 3295$3285 \mathrm{cal} \mathrm{BC}$ (3\% probability) or $3275-3260 \mathrm{cal} \mathrm{BC}(3 \%$ probability) or $3235-3170$ cal $B C(29 \%$ probability) or 3165-3115 cal BC (20\% probability; Fig. 19: end rockcut tomb). Large quantities of apparently redeposited Żebbug cultural material may or may not have been accompanied by contemporary human remains, depending on the accuracy of radiocarbon dates which would not now be reported or published (Fig. 9: OxA-3567?, -3568?, 3508?, -3509?). Żebbug pottery, pendants and beads were also found in the cave complex, especially in the west niche (Malone et al. 2009, fig. 6.5). The extent to which these reflect funerary activity is unclear. The only potentially accurate radiocarbon date for human bone is a late 5 th millennium cal $\mathrm{BC}$ one for a sample from a Żebbug-rich context in the east cave (Fig. 18: OxA-3572). All of the samples from the west niche, with its denser concentration of Żebbug material (Malone et al. 2009, figs. 6.5, 7.15), are of Tarxien age (Fig. 17).

$160-425$ years ( $95 \%$ probability), probably $180-300$ years (53\% probability) or $345-400$ years ( $15 \%$ probability) after the last burial in the rock-cut tomb (Fig. 10: end rock-cut tomb/start surface activity and cave complex), the Tarxien use of the site began, in 2975-2900 cal BC (95\% probability), probably in 2950-2910 cal BC (68\% probability; Fig. 19: start surface activity and cave complex).

The earliest dated deposits are in the west cave, where context 1307 in one of the sequences through the deep zone began to form in 2930-2870 cal BC (90\% probability) or 2810-2775 cal BC (5\% probability), probably in 2915 2880 cal BC (68\% probability; Fig. 19: start 1307), by which time an upright megalith was already in place (Malone et al. 2009, 133-7). It is $89 \%$ probable (Table 6) that the start of 1307 pre-dated the start of the sequence in the "shrine" area in 2895-2855 cal BC (74\% probability) or 2810-2765 cal BC ( $21 \%$ probability), probably in $2890-2860 \mathrm{cal}$ BC $(68 \%$ probability; Fig. 19: start "shrine"). It is $82 \%$ probable that the "shrine" was initiated before the north threshold bone pit (Table 6), although there was preceding activity on the surface (e.g. Fig. 19: floor 525).

Burials and artefacts were placed and structures built in the lower "shrine" for 235-300 years (20\% probability) or 315 395 years ( $75 \%$ probability), probably for $265-270$ years $(1 \%$ 
Fig. 17 Probability distributions for radiocarbon dates from "display zone" 783 and the west niche. "After" denotes that a date has been modelled as a terminus post quem for its context. Orange denotes an estimated date for a structural event. The format is otherwise the same as in Fig. 9. SUERC-45316, from context 518 which overlay both 960 and 783 , is cross-referenced, already constrained, from Fig. 13

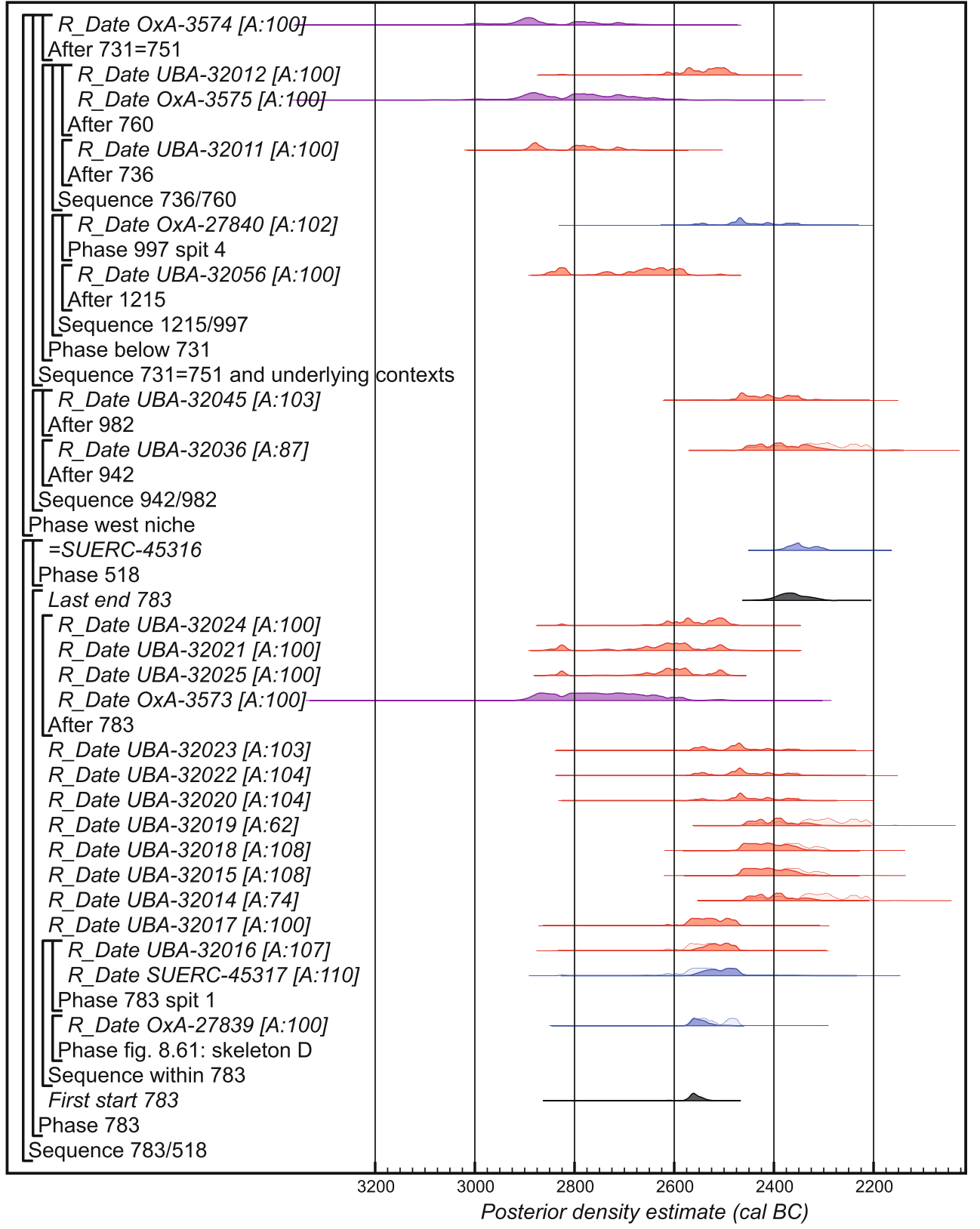

probability) or 325-380 years (67\% probability; Fig. 10: use lower "shrine"). During this period, burial began in context 1241 in a niche in the east cave, in 2865-2805 cal BC $(21 \%$ probability) or $2760-2715$ cal BC (10\% probability) or 2710 2535 cal BC (64\% probability), probably in $2850-2810(16 \%$ probability), or 2695-2685 cal BC (1\% probability) or 2680 2575 cal BC (51\% probability; Fig. 19: start 1241). Also, during this period, the sealing of the north threshold bone pit in 27452570 cal BC (95\% probability), probably in 2685-2615 cal BC (54\% probability) or $2610-2580$ cal BC (14\% probability; Fig. 19: end $N$ threshold bone pit) was followed by the construction of a megalithic threshold on the surface, at least 80 315 years $(95 \%$ probability), probably $175-295$ years $(68 \%$ probability), after the start of the "shrine" sequence (Fig. 10: start "shrine"/end $N$ threshold bone pit). Towards the end of the use of the lower shrine, during the accumulation of context 1206 , the "display zone" began to be used from 26202605 cal BC (2\% probability) or 2585-2515 cal BC $(93 \%$ probability), probably from $2575-2540$ cal BC $(68 \%$ probability; Fig. 19: start 783); megaliths 1170 and 1177 were set up in the area of the deep zone to the north of the shrine; and the large standing figure was broken up. The twenty-sixth century cal BC may also have been the time of major installations, with the final placement of a massive stone bowl and the setting up of the two stone screens. All of these were in place when context 960 began to be deposited in 2530-2475 cal BC $(95 \%$ 
Fig. 18 Probability distributions for radiocarbon dates from the south zone of the west cave and from the east cave. "After" denotes that a date has been modelled as a terminus post quem for its context. Orange denotes an estimated date for a structural event. The format is otherwise the same as in Fig. 9

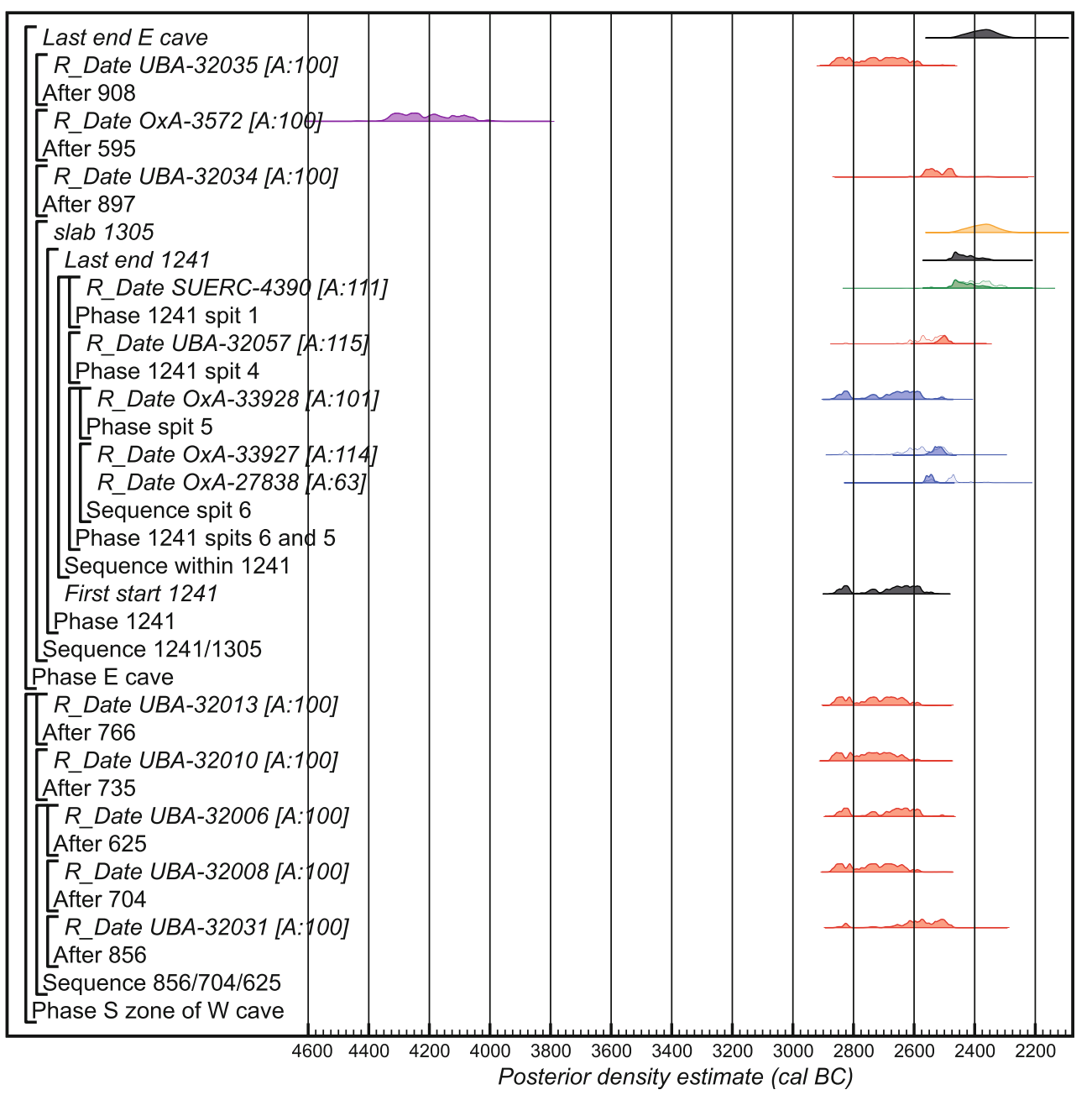

probability), probably in 2520-2490 cal BC (68\% probability; Fig. 19: start 960), but the precise levels at which the screens were inserted remain unclear.

Burial in context 1241 in the east cave came to an end in 2490-2350 cal BC (95\% probability), probably in 24752405 cal BC (68\% probability; Fig. 19: end 1241), and probably during the deposition of 960 (Table 5), to be followed by the construction of a threshold across that cave. Pit-digging on the surface continued into the 25 th or twenty-fourth century cal BC on the evidence of dates for articulated samples from pits above the east cave (Fig. 19: end surface). Closure of the "shrine" would have taken place in the twenty-fourth century cal BC on the evidence of two dates for loose molars from 831 and 866 (Fig. 13: UBA-32027, -32033) and would have been complete by the time floor 518 was laid, for which there is a single date of 2395-2290 cal BC (95\% probability), probably of 2380-2335 (54\% probability) or 2325-2305 cal BC $(14 \%$ probability); Fig. 19: SUERC-45316).

The "display zone" continued to be added to until 2420 2305 cal BC (95\% probability), probably until 24002335 cal BC (68\% probability; Fig. 19: end 783), and some of the dates from the adjacent west niche also indicate activity in the twenty-fourth century cal BC (Fig. 17). The overall Tarxien presence on the site would have ended in 2375 2255 cal BC (95\% probability), probably in $2355-$ 2290 cal BC (68\% probability; Fig. 19: end surface activity and cave complex). This would leave a window for the deposits above 960 in the west cave of 25-155 years $(95 \%$ probability), probably of 50-120 years (68\% probability; Fig. 10: end 960/end surface activity and cave complex), far shorter than the duration of the lower "shrine". The overall Tarxien use of the cave complex would have lasted 515 660 years (95\% probability), probably $545-620$ years $(68 \%$ probability; Fig. 10: use cave complex).

\section{Discussion}

\section{Sequence and phasing: general implications}

The implications of the programme of dating of the Xaghra Circle challenge the traditional notions of chronology for prehistoric Malta. Formerly, the sequence was marked into rigid ceramic episodes (Żebbug, Mgarr, Ġgantija, Saflieni, Tarxien), 
Fig. 19 Summary of key parameters from the model shown in Figs. 8, 9, 11, 12, 13 and 17, 18 (Table 4). Orange denotes an estimated date for a structural event

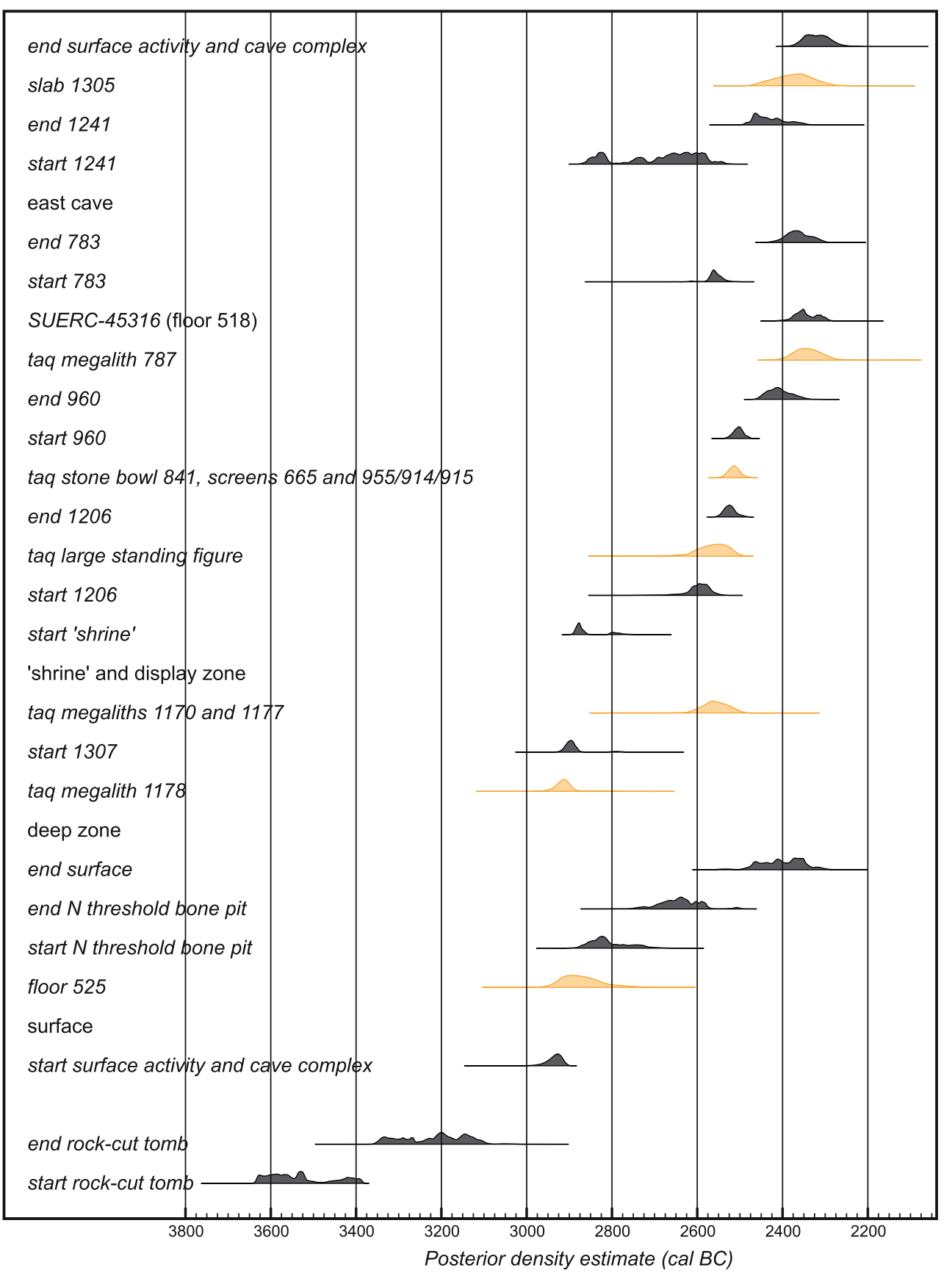

largely based on just one or at best two old (initially uncalibrated) radiocarbon dates, which have been discussed by Trump (2000, 2002, 2004). The record of Xaghra now suggests a more extended, steady and slowly changing cultural sequence where one "phase" slides into the next, highlighting the fact that typochronologies can give an account of prehistory that is not alive to processes of gradual change. The cave complex and the surface area were frequented over a long timespan-perhaps as much as 2000 years, at varying levels of intensity. The character of the earlier phases of that use remains unclear.

The earliest, evidenced by abundant and widespread Żebbug period artefacts (Malone et al. 2009, 62-63), would have occurred in the late fifth or early fourth millennium cal $\mathrm{BC}$, but remains effectively undated here. Whether human remains were introduced to the site from the first is an open question, since, when radiocarbon measurements which would not now be reported or published are disregarded, the only human bone possibly of this period is a single fragment redeposited in a Tarxien period context in the east cave (Fig. 18: OxA-3572), and even this date, measured in the early 1990 s, may be inaccurate, as discussed above. Human remains from the small rock-cut tomb, which in 2009 had seemed to be of Żebbug date, in use from c. 4350 to $c$. 3510 cal BC (Malone et al. 2009, 345); are now placed in 
the 37th to 32 nd centuries cal BC, within the date range conventionally assigned to the Ġgantija phase and corresponding to a small amount of Gंgantija pottery from the tomb, some of it in the lowest deposit in the west chamber (Malone et al. 2009, fig. 6.6). The composition of the assemblage from the tomb may suggest rather conservative mortuary practices, employing ceramic vessels and ornaments of antiquated form, or even of some actual antiquity, instead of the apparently current style. At all events, the Żebbug tradition was clearly significant at the site, on the evidence of both the quantity of material culture present and its deployment in many parts of the cave complex (Malone et al. 2009, 95-107). Also found in the cave complex was a minimal amount of Mgarr pottery, as well as further Ggantija pottery, and Saflieni style pottery (Malone et al. 2009, 83-86). The last of these, largely found on mortuary rather than temple sites, was here always associated with Tarxien and other styles, which led the excavators to question its status as a phase indicator (Malone et al. 2009, 229-31). Within the cave complex, Ǵgantija pottery was, like the Saflieni style, in a minority in Tarxien-dominated deposits.

An interval of at least two centuries separated the Ggantija burials in the rock-cut tomb from the start of the extensive introduction and manipulation of human remains in the cave complex in the Tarxien period (Fig. 10). The lack of any dated human remains from this period suggests that the 32nd to thirtiethcentury uses of the cave complex may been other than funerary. The Tarxien phase is represented by a distinct pottery style that amalgamates many of the stylistic elements of previous phases, and it relates to the latter centuries of the Temple culture, lasting perhaps 500-600 years. This major change went with significant monumentalisation of the caves, in the course of which earlier deposits would have been reworked. This process entailed the importation of large Globigerina limestone blocks, used along with the Coralline limestone of the plateau itself, to create the many megalithic structures within the system. It is possible that the Globigerina blocks came from a demolished temple site, since they generally show evidence for reuse. One candidate for this is nearby Santa Verna, investigated recently as part of the FRAGSUS project, which ceased to be actively used in the Tarxien phase after $c .2900 \mathrm{cal} \mathrm{BC} \mathrm{(McLaughlin} \mathrm{et} \mathrm{al.} \mathrm{in} \mathrm{prep).} \mathrm{In}$ 2009, this phase at the site seemed to run from $c .3000$ to $c$. 2400, possibly c. 2200, cal BC (Malone et al. 2009, 345-6). Its start has now become slightly later than 3000 and its end slightly earlier than 2200 (Fig. 19; Table 5).

\section{The implications of a more detailed site history}

What has changed significantly in the chronology of the Tarxien period is the definition of individual episodes and their relation to each other, even in the absence of stratigraphic relations, in the extended making and re-making of the complex. It is now clear that, for example, the slabs of the threshold on the surface were not laid until probably a couple of 
centuries after use of the "shrine" area had begun (Fig. 10: start "shrine"/end N threshold bone pit) and that the "display zone" came into use 200 or 300 years after the "shrine" area (Fig. 10: start "shrine/start 783") and persisted through major remodellings of the "shrine" area almost to the end of the sequence (Fig. 19: end 783).

A question that remains open is whether the end of the main use of the monument has actually been defined. As modelled, none of the human remains from the Tarxien use of the site need post-date the end of the twenty-fourth century cal BC, some of the latest, both articulated and disarticulated, coming from the upper "shrine" deposits (Fig. 13), the "display zone" and west niche (Fig. 17), the east cave (Fig. 18) and the later of two pits dug into the surface above the east cave (Fig. 11). This poses a problem of interpretation when it comes to the use-life of the site. With all but one of the relevant dates measured on human remains, it is possible that, while these ceased to be introduced to the site around the end of the twenty-fourth century, its Tarxien use, including the manipulation of human bone already present, may have continued after that. Alternatively, the radical transformation which entailed the closure of the "shrine" (Malone et al. 2009, 155) soon after the final depositions in 960 in 2460 2350 cal BC (95\% probability), probably in $2445-2385$ cal BC (68\% probability; Fig. 19: end 960) may have marked the beginning of the end. In this case, the estimated interval of 25 155 years (95\% probability), probably of 50-120 years (68\% probability), between the last deposition in 960 and the end of the Tarxien use of the site (Fig. 10: end 960/end surface activity and cave complex) may have some validity.

Throughout the third millennium cal BC sequence, the deposition and manipulation of human remains were accompanied by the construction, dismantling and moving of megalithic structures and stone objects. The dates estimated for such events here cover only a minority of the documented occurrences. They serve to show, however, that such behaviour persisted from the 30th to the 24th centuries cal BC (Fig. 19: taq megalith 1178, taq megalith 787).

Overall, the history of the Xaghra Circle sees the long development of a distinctive underground setting for the treatment, display and storage of the dead. It and the Hal Saflieni hypogeum on the main island of Malta itself (Pace 2000) are part of the pronounced island identity created in the Temple period. This was not a single act of construction at Xaghra, but a series of elaborations and compartmentalisations enacted over a considerable period of time (the same may be suspected also for the Hal Saflieni hypogeum, but detailed records hardly exist and the human bone has long since been jettisoned). The process of division of space could imply steadily increasing control through time over the treatment of the dead, as certain zones filled up with bones and became inaccessible, and internal megalithic structures were moved or elaborated upon, arbitrated by a community of people for whom funerary rites represented a considerable investment. So, from the detail of the formally modelled chronology for the sequence at the Xaghra Circle, we come back to questions raised at the start of this paper about not only local conditions and the nature of local society, but also the context in which a distinct insular identity, seen against other communities in the central and west Mediterranean, was created. We will look at each of these in turn.

\section{Longevity, sustainability and local conditions}

The longevity issue is the intriguing question here, since how could an apparently dense population, farming quite intensely, have maintained continuity or sustained what seems to be a sufficiently productive environment if constantly engaged in over-production? What we have in Malta from the start of the Żebbug phase to the end of the Temple culture is apparent continuity, with indications that the population retained good health and nutrition, and that the soil quality of the islands was exceptionally good, although gradually in decline in the third millennium cal BC. The temples seem to act as central places in the landscape, and perhaps were homes for elites or storehouses for the community; it is difficult to choose between these options. The megalithic buildings (as containers of cultural and economic material) perhaps formed the stabilising focal point in a dispersed society. They seem to have linked people, agricultural products, food, and ritual together over an immense time range, growing ever more complex in the third millennium cal BC. The flamboyance of art and architecture appears to reach a relatively short-lived flourish in the last centuries, perhaps between c. 2800-2400 cal BC.

Clearly also the prehistoric people of Malta understood how to manage the relatively marginal environment, with its marked seasonal aridity, wind, erosion, lack of dense vegetation or tree-cover and limitations of size, in a manner that was sustainable. The small scale of the Maltese islands (barely more than $316 \mathrm{~km}^{2}$ ) demanded an intensive regime of crop rotation, soil management and stock control which probably ensured a degree of economic continuity and stability over the Tarxien period. Animal husbandry was carefully controlled, with minimal numbers of mature stock kept over the dry summer months, and most animals killed when immature (Malone et al. 2018). Milk production may be one explanation for the numbers of mature, even old, female cattle and sheep bones, and sieves and the abundance of pottery vessels might account for cheese making. Milking cows, however, require up to 701 of water per day in summer, and in Malta, with very little available water (cf. Grima 2016), it seems that the ratio of typical stocking was one or two cows to about 12 sheep/goat. Pig is also represented at similar ratios to the cattle (Malone et al. in press). In the artistic representations, in contrast, bulls appear to be rather significant (e.g. Evans 1971, plates 32-5), but possibly this reflected the rarity of mature beasts and their great value in feasting, with their capacity to feed an entire community. 
Malta and Gozo, small though they are, evidently maintained a relatively stable, economically viable economic system that in turn enabled the putatively crowded island community to survive over centuries. Such stability on small islands is perhaps rare (see Broodbank 2013); in a different, non-Mediterranean, context, other ToTL modelling has indicated a period on the Orkney Islands of busy monument construction and settlement aggregation from the later fourth millennium cal BC, before some kind of decline in the earlier part of the third millennium (Bayliss et al. 2017). The new dating for the Xaghra Circle provides important insight into a phenomenon of longevity and sustainability, which if pottery, in combination with the informal inspection of radiocarbon dates on potentially residual samples, were taken to indicate chronology, would appear to be very different. This insight enables a renewed discussion of social complexity in the case of later Neolithic Malta.

\section{The nature of island society}

At a general level, the role of monuments in the social fabric of later Neolithic Malta has been subject to many interpretations, ranging from providing goddess-focused rituals or formalised religion of some kind, to acting as vehicles for the display of chiefly power. A less dramatic and perhaps more grounded explanation - as suggested by Malone (2018) - is the possibility that the so-called temple structures formed communal "club" houses for formalised, ritualised feasting (see Flannery and Marcus 2012 for further references). Where records or evidence survive, the structures contain remarkable quantities of pottery, animal bone, fire pits, huge communal stone or ceramic cooking/ serving vessels, tethering places for animals, altars and display areas, usually organised to maximise public viewing and participation. The likelihood is that food and feast were focused within and around the monuments (Malone 2018) and that these events were communal and happened quite frequently over long periods of time. Such events might well have put stress on both people and their environment, demanding additional food production to meet the expectations of a doubtless competitive society. But whether this society was tribal or chiefly in its organisation is extremely difficult to determine. In the early days of more explicit modelling of social formations and development, Renfrew (1973) saw the monument building process as one that required centralised - even chiefly — organisation, associated with the emergence of a permanent class of person who oversaw rituals associated with the monuments: a "priesthood". Since then, of course, social formations which have been labelled as chiefdoms have been recognised to be extremely diverse (summarised in Flannery and Marcus 2012), and there are many other situations and ways in which aggrandisers can be seen to operate in what have been called "transegalitarian" societies, but without achieving permanent social control (Flannery and Marcus 2012; Hayden 1995, 2001).
In Malta, with so many temple groups with locally derived, easily quarried and moveable stone, perhaps the temple structures were communal foci rather than centres of power (see also Skeates 2010, 146). Certainly the earlier temple elements were smaller and less complex that those that are perhaps more reliably late in the Tarxien sequence. This is demonstrable at Mnajdra and Hagiar Qim, and indeed at Tarxien, where increasingly elaborate structures were built beside each other and sometimes in direct stratigraphic superposition (Evans 1971, 101-3, 135-8). These late sites seem to reflect greater levels of sophistication, artistic embellishment, deeper hidden zones, and more formalisation and symbolism, perhaps in turn linked to increased social hierarchy or stress. The dietary data that are currently under analysis within FRAGSUS will confirm, for example, if the later skeletal material does indicate reduced levels of meat. Certainly, initial findings imply that cereal/terrestrial foods became more dominant with less and less meat consumed (cf. Richards et al. 2001). Pollen and geoarchaeological evidence too is suggesting climatic fluctuations throughout the third millennium, increasing drought episodes and fewer trees, all of which implies that environmental changes impacted on the productivity, seasonality and the social cohesion of Neolithic Maltese communities. Stress could be marked in various ways, but one that is little evidenced is interpersonal conflict, since exhaustive re-examination of the skeletal material from the Xaghra Circle has identified only a few cases of trauma which may have resulted from violence (Mercieca Spiteri 2016). The archaeological record too contains almost no arrowheads, other than prestige ones crafted in obsidian, further suggesting that social cohesion was maintained in ways other than by force or violence. Perhaps, rather, it was formalised ritual and public gatherings at so-called temple structures that provided such cohesion.

These remain very general assertions and possibilities. A detailed and precise sequence for temple development is sorely lacking; so, the chronology of the Xaghra Circle cannot yet be inserted into a pattern of wider development. However, its more refined chronology already provokes further possible implications, comparisons and contrasts. It seems likely that with a start date a little after $3000 \mathrm{cal} \mathrm{BC}$, the Xaghra Circle joined a landscape that already had some temple structures. It added an elaboration of the underground element already present in the rock-cut tombs. In turn, as argued above, that underground setting was increasingly divided and embellished through the span of Tarxien use. This development perhaps completed the creation of a tiered cosmology, which can be read across the hypogea and temple structures as a whole (Malone and Stoddart 2011). That notion, however, suggests a very ordered and uniform set of beliefs and practices. If the so-called temples were as much communal foci for gathering and feasting as displays of power, as suggested above, could it be that the underground settings of the Xaghra Circle and the Hal Saflieni hypogeum were concerned with ever tighter control of the dead? There could have been a longer trajectory in 
which, first, rock-cut tombs began to mark an interest in recognising and recording group descent, and then later, elaborated underground settings manipulated the dead, in considerable numbers, as part of a complex negotiation with the world of ancestors and spirits. There is no need to separate the temples and the underground settings entirely; many kinds of representation and symbolic artefacts are found at both, but whereas the temple structures can be argued to have a public face, virtually all of the significant features at the Xaghra Circle and the Hal Saflieni hypogeum were underground. If there were social control and secret knowledge in these underground features, they were concealed.

\section{The regional setting, connectivity and difference}

The temple structures and the underground settings together created a distinct island identity in the Temple period on Malta. It seems implausible that this was simply the result of isolation or insularity, given the earlier connections between Malta and elsewhere in the central Mediterranean and the ease of reaching the archipelago (Grima 2001; Robb 2001). After all, Malta was culturally connected with its nearest neighbours from the very start of human occupation in the mid-sixth millennium cal BC (settlers very plausibly deriving from communities of Impressed Ware/Stentinello and early painted pottery users, spread across eastern Sicily and southern Calabria), and this trend continued over the succeeding millennia. The new dating of the Xaghra Circle prompts a brief review of other kinds of community in the central and west Mediterranean as a possible means to understand the nature of Maltese distinctiveness in the Temple period and, through comparisons, to gain further insight into the nature of society on Malta at this time. We will touch very briefly here on just three examplesSicily, peninsular Italy and southern Iberia.

Sicily contrasts with Malta at the most basic level, with its vast, ecologically varied environments which supported Neolithic-Eneolithic cultures that seem to have been mostly dispersed, perhaps largely pastoral, and with little indication of socio-economic intensity. The ceramic record suggests quite close connections earlier in the sequence (despite the limitation of a paucity of well dated sites in Sicily). The later Sicilian Neolithic (locally described as Eneolithic) ceramic sequence starts with the San Cono-Piano Notaro, Conca D'Oro, Serraferlicchio-Chiusazza-Conzo-Petralia and Piano Conte pottery styles, that tally closely with Żebbug on Malta in stylistic terms. Of these the Serraferlicchio is represented, for example, in earlier fourth millennium contexts at Casa Oasi già Sollima near Troina (Ashley et al. 2007). The San Cono-Piano Notaro style has recent dates from several Sicilian sites spanning between $c$. 3700-3300 cal BC (Speciale 2011). Some ceramic styles travel further, especially Piano Conte that is found in Sicily and Calabria, and perhaps tallies with Mgarr-Ġgantija in Malta. The widespread use on Sicily of rock-cut tombs for collective burial is another point in common. However, by the third millennium cal BC, the cultural identity of Malta appears to be quite distinct from SicilianCalabrian material and practices. On Malta, the temple structures and elaborate and sophisticated material culture emerged. The later Eneolithic Sicilian ceramic styles in the mid-third millennium cal BC (Malpasso and Sant'Ippolito) do have some broad stylistic correspondence with Maltese pottery of the preceding millennium, hinting at an origin common to both cultural groups. Although absolute dates for the later Eneolithic period in Sicily and Calabria are still limited in number, the phases range from c. 2700 to 2300 cal BC (Giannitrapani and Ianni 2011; Giannitrapani 2013) and are replaced with early Bronze Age occupation at much the same time as on Malta, in the final two to three centuries of the third millennium cal BC.

So set against just the nearest major neighbour of Sicily, the distinctive Temple period developments on Malta could be seen as the creation of mainly local difference. Wider comparisons, however, may suggest more complex factors at work. In peninsular Italy as a whole, John Robb $(2007,337)$ has identified a broad Copper Age and earlier Bronze Age phase from the mid-fourth to the mid-second millennium characterised by genealogical relatedness and heterarchy, but with, compared to earlier times, "more personalised expression with potentially prominent individuals thought of as apical ancestors of genealogical relations ... and the emergence of [a] more clearly expressed dichotomy of gendered prestige". Metals and decorated stelae are widespread markers of this system. While there are some elements potentially in common, this offers a very different scenario to that seen in Malta, where the absence or concealment of individual differentiation is striking, and where virtually no copper has been recorded. In southern Iberia, the early Copper Age, by convention dated from the late fourth to the mid-third millennium cal BC (Chapman 2008), sees a further series of striking changes, including settlement aggregation, the elaboration of tomb architecture, the development of early copper metallurgy, and the flourishing of exchange or other networks which brought in exotic goods, including Iberian variscite, Sicilian amber, ostrich eggs and both African and Asian ivory (Schuhmacher et al. 2009; Cruz Berrocal et al. 2013; Fernández Flores et al. 2016). There was much variation across southern Iberia, and there has been much debate about the scale and intensity of social differentiation (Cruz Berrocal et al. 2013). As just one example, at Valencina de la Concepción in south-west Spain, where another ToTL dating programme has been carried (García Sanjuán et al. 2018), showy burials in mud-vaulted tholos tombs, such as Montelirio (Fernández Flores et al. 2016), are probably confined to a relatively short horizon within the longer span of the complex, to the 29th and earlier 28th centuries cal BC. Connections, ostentation and differentiation by individuals 
and small groups can all be demonstrated, but these were seemingly not maintained for long.

Given the very wide geographical reach of the networks which took artefacts and materials into southern Iberia in its early Copper Age, it seems very implausible that communities on Malta were unaware of what was going on in the central and western Mediterranean as a whole, and it is against that wider world that distinctive Maltese identity was probably created. Taking a cue from the suggested character of the temple structures, the initial emphasis may have been on the reinforcement of locally important values of cooperation and consensus, against a wider tide of differentiation and accumulation. Whether that was maintained throughout the sequence of the Temple period is open to question, with the possibilities noted above of elaboration and increased control through the span of use of the Xaghra Circle, and also of the suggested trend in temple structures mooted above towards greater architectural subdivision and concealment through time. But even allowing for these developments, there was nothing on Malta similar to the changes seen in peninsular Italy and southern Iberia, and elsewhere.

\section{Endings}

Despite earlier sustainability, it is thought that during the final centuries or even decades of the Xaghra Circle, a sustained environmental decline was underway, potentially leading to rapid erosion and soil degradation (French et al. 2018). At the same time the demise of the Tarxien Culture occurred in terms of burial tradition, temple building and pottery production. The current conclusion (and this is under debate) is that a climatic downturn, possibly aridity (cf. deMenocal 2001), led to landscape change and degradation, and the human inhabitants ceased to do what they had done for many previous centuries, a longevity shown by the Bayesian modelling at Xaghra. Environmental evidence from Malta suggests continuing trends towards aridity (French et al. 2018) and an abrupt decline in cereal pollen around $2300 \mathrm{cal} \mathrm{BC} \mathrm{(Carroll} \mathrm{et} \mathrm{al.} \mathrm{2012),} \mathrm{and} \mathrm{this}$ economic change coincides with the stylistic contrast between Tarxien and Tarxien Cemetery pottery, which points to a clean cultural break (Trump 1976, 2004). It is important to note that all these environmental and archaeological events occurred around a century before the widespread change in climate marked by the so-called " $4.2 \mathrm{k}$ event", which played some role in the cultural and demographic dynamics of other contemporary Mediterranean societies (e.g. Blanco-González et al. 2018). It is also true that the development of Bayesian chronologies in archaeology presents a new challenge for palaeoenvironmental studies, as the palynological events described by Carroll et al. (2012) are not as precisely dated as the archaeology. On-going work by the FRAGSUS project is aimed at addressing this issue. In any case, alternative explanations of the process which led to the abandonment of the temples and its associated culture are possible. There were expanding Bronze Age movements around the Mediterranean in the final two centuries of the third millennium cal BC (e.g. Broodbank 2013, 345-55). Cazzella and Recchia $(2006,2015)$ have speculated that the introduction of particular exotic pottery to Malta (Thermi ware) is a strong indicator of external interactions with the east Mediterranean at this time, but it is not particularly widespread in the Maltese islands and was not identified at Xaghra (Trump et al. 2009). The Tarxien Cemetery culture appeared in the islands shortly after burial at Xaghra came to an end at 2375-2255 cal BC (95\% probability, Fig. 19: end surface activity and cave complex), although precisely when is unknown (Malone et al. 2009). At Xaghra, there is evidence for the presence of the Tarxien Cemetery culture in the form of settlement debris rather than burial, but not occurring until after $2000 \mathrm{cal} \mathrm{BC}$, and, therefore, not necessarily constituting evidence of continuity (Malone et al. 2009). However, a degree of overlap between the cultures has been suggested for some sites (for example at Ġgantija: Evans 1971, 180; see also Skeates 2010, 108-15) and this phenomenon has also been confirmed by the FRAGSUS project during recent excavations at Tac Cawla on Gozo, with continuity in occupation shown by distinctive Thermi or early Tarxien Cemetery culture ceramics (Malone et al. 2016). The refined chronology for the Xaghra Circle helps in many ways to define when the Temple period ended, but there is still much to do with respect to establishing a similarly robust chronology for the Early Bronze Age. That said, the insight into the final centuries of the Xaghra site, made possible with Bayesian modelling and constraining dates for structural elements in the burial complex in particular, potentially provides new understanding of the process of cultural transition in this case. Rather than decades or centuries of decline, we see instead a pattern of sustained or even intensifying activity, with renewed investment in the site made in the form of megaliths and other features during its final phases of use. Nothing in the spread of dates suggests that the events of change or collapse after the turn of the 24th and 23rd centuries cal $\mathrm{BC}$ could have been forecast by a pre-existing trend, which brings us one step closer to the "lived experience" of the patterns we see in the archaeological data where a long-lived and rich cultural tradition was rather abruptly put aside.

Acknowledgements The Times of Their Lives (www.totl.eu) was funded by an Advanced Investigator Grant (295412) from the European Research Council and led by Alasdair Whittle and Alex Bayliss. Fragility and Sustainability in Restricted Island Environments (FRAGSUS: www.qub.ac.uk/sites/FRAGSUS) was funded by an Advanced Investigator Grant (35372) from the European Research Council and led by Caroline Malone. Dani Hofmann did much of the original groundwork for this part of the ToTL project, and she and Seren Griffiths helped with sample collection on Malta. Kirsty Harding helped with the figures. We acknowledge Heritage Malta and the Superintendence of Cultural Heritage (Malta) for permission to undertake the analyses presented here. The FRAGSUS project acknowledges the 
support of Paula Reimer and the staff of ${ }^{14}$ Chrono Centre, Queen's University Belfast, particularly Stephen Hoper, Jim McDonald and Michelle Thompson. For their very helpful insight into Maltese palaeoenvironments and palaeoeconomies, we thank all our FRAGSUS project colleagues, especially Michelle Farrell, Katrin Fenech, Rory Flood, Charles French, Chris Hunt, Finbar McCormick, Patrick Schembri, Jay Stock and Nicholas Vella.

OpenAccessThis article is distributed under the terms of the Creative Commons Attribution 4.0 International License (http://creativecommons.org/ licenses/by/4.0/), which permits unrestricted use, distribution, and reproduction in any medium, provided you give appropriate credit to the original author(s) and the source, provide a link to the Creative Commons license, and indicate if changes were made.

Publisher's note Springer Nature remains neutral with regard to jurisdictional claims in published maps and institutional affiliations.

\section{References}

Ashley S, Bending J, Cook G, Corrado A, Malone C, Pettitt P, Puglisi D, Redhouse D, Stoddart S (2007) The resources of an upland community in the fourth millennium BC. In: Fitzjohn M (ed) Uplands of Sicily and Calabria. Accordia Research Centre, University of London, London, pp 59-80

Bayes TR (1763) An essay towards solving a problem in the doctrine of chances. Philos Trans R Soc 53:370-418

Bayliss A, Bronk Ramsey C, van der Plicht J, Whittle A (2007) Bradshaw and Bayes: towards a timetable for the Neolithic. CAJ 17.1(Supplement):1-28

Bayliss A, Marshall P, Richards C, Whittle A (2017) Islands of history: the Late Neolithic timescape of Orkney. Antiquity 91:1171-1188

Bayliss A, Shepherd Popescu E, Beavan-Athfield N, Bronk Ramsey C, Cook GT, Locker A (2004) The potential significance of dietary offsets for the interpretation of radiocarbon dates: an archaeologically significant example from medieval Norwich. J Archaeol Sci 431: 563-575

Bayliss A, van der Plicht J, Bronk Ramsey C, McCormac G, Healy F, Whittle A (2011) Towards generational time-scales: the quantitative interpretation of archaeological chronologies. In: Whittle A, Healy F, Bayliss A (eds) Gathering time: dating the Early Neolithic enclosures of southern Britain and Ireland. Oxbow Books, Oxford, pp 1660

Bayliss A, Whittle A (2015) Uncertain on principle: combining lines of archaeological evidence to create chronologies. In: Chapman R, Wylie A (eds) Material evidence: learning from archaeological practice. Routledge, London, pp 213-242

Bayliss A, Beavan N, Hamilton D, Köhler K, Nyerges ÉÁ, Bronk Ramsey C, Dunbar E, Fecher M, Goslar T, Kromer B, Reimer P, Bánffy E, Marton T, Oross K, Osztás A, Zalai-Gaál I, Whittle A (2016) Peopling the past: creating a site biography in the Hungarian Neolithic. BRGK 94:23-91

Blanco-González A, Lillios K, López-Sáez JA, Drake BL (2018) Cultural, demographic and environmental dynamics of the Copper and Early Bronze Age in Iberia (3300-1500 BC): towards an interregional multiproxy comparison at the time of the $4.2 \mathrm{ky} \mathrm{BP}$ event. J World Prehist 31:1-79

Brock F, Bronk Ramsey C, Higham T (2007) Quality assurance of ultrafiltered bone dating. Radiocarbon 49:187-192

Brock F, Higham T, Ditchfield P, Bronk Ramsey C (2010) Current pretreatment methods for AMS radiocarbon dating at the Oxford Radiocarbon Accelerator Unit (ORAU). Radiocarbon 52:103-112
Bronk Ramsey C (1995) Radiocarbon calibration and analysis of stratigraphy. Radiocarbon 36:425-430

Bronk Ramsey C (1998) Probability and dating. Radiocarbon 40:461474

Bronk Ramsey C (2009) Bayesian analysis of radiocarbon dates. Radiocarbon 51:337-360

Bronk Ramsey C, Dee M, Lee S, Nakagawa T, Staff RA (2010) Developments in the calibration and modelling of radiocarbon dates. Radiocarbon 52:953-961

Bronk Ramsey C, Higham T, Leach P (2004) Towards high-precision AMS: progress and limitations. Radiocarbon 46:17-24

Bronk Ramsey C, Lee S (2013) Recent and planned developments of the program OxCal. Radiocarbon 55:720-730

Broodbank C (2013) The making of the middle sea: a history of the Mediterranean from the beginning to the emergence of the classical world. Thames and Hudson, London

Buck CE, Litton CD, Smith AFM (1992) Calibration of radiocarbon results pertaining to related archaeological events. J Archaeol Sci 19:497-512

Buck CE, Cavanagh WG, Litton CD (1996) Bayesian approach to interpreting archaeological data. Wiley, Chichester

Carroll FA, Hunt CO, Schembri PJ, Bonanno A (2012) Holocene climate change, vegetation history and human impact in the Central Mediterranean: evidence from the Maltese Islands. Quat Sci Rev 52:24-40

Cazzella A, Moscoloni M (2004-2005) Gli sviluppi culturali del III e II millennio a.C. a Tas Silg: analisi preliminare dei materiali dagli scavi 1963-70 e della loro distribuzione spaziale. Scienze dell'Antichità Storia Archeologia Antropologia 12:263-284

Cazzella A, Recchia G (2006) L'area sacra megalitica di Ta Silg (Malta): nuova elementi per lo studio dei modelli architettonici e delle practice cultuali. Scienze dell'Antichità Storia Archeologia Antropologia 13:689-699

Cazzella A, Recchia G (2015) The early Bronze Age in the Maltese Islands. In: Tanasi D, Vella NC (eds) The late prehistory of Malta: essays on Borg in-Nadur and other sites. Archaeopress, Oxford, pp $141-159$

Chapman R (2008) Producing inequalities: regional sequences in later prehistoric southern Spain. J World Prehist 21:195-260

Cruz Berrocal M, García Sanjuán L, Gilman A (eds) (2013) The prehistory of Iberia: debating early social stratification and the state. Routledge, New York, pp 119-140

Dee M, Bronk Ramsey C (2000) Refinement of graphite target production at ORAU. Nucl Inst Methods Phys Res B 172:449-453

deMenocal PB (2001) Cultural responses to climate change during the Late Holocene. Science 292:667-673

Dunbar E, Cook GT, Naysmith P, Tripney BG, Xu S (2016) AMS ${ }^{14} \mathrm{C}$ dating at the Scottish Universities Environmental Research Centre (SUERC) radiocarbon dating laboratory. Radiocarbon 58:9-23

Evans JD (1953) The prehistoric culture sequence of the Maltese Islands. Proc Prehist Soc 19:41-94

Evans JD (1971) The prehistoric antiquities of the Maltese islands. Athlone Press, London

Fernández Flores Á, García Sanjuán L, Díaz-Zorita Bonilla M (2016) Montelirio: un gran monumento megalítico de la Edad del Cobre. Junta de Andalucía, Sevilla

Flannery K, Marcus J (2012) The creation of inequality: how our prehistoric ancestors set the stage for monarchy, slavery and empire. Harvard University Press, Cambridge

French C, Taylor S, McLaughlin TR, Cresswell A, Kinnaird T, Sanderson D, Stoddart S, Malone C (2018) A Neolithic palaeo-catena for the Xaghra Upper Coralline plateau landscape of Gozo, and its implications for past soil development and land use. Catena 171:337-358

García Sanjuán L, Vargas Jiménez JM, Cáceres Puro L, Costa Caramé ME, Díaz-Guardamino-Uribe M, Díaz-Zorita Bonilla M, Fernández Flores A, Hurtado Pérez V, López Aldana PM, Méndez Izquierdo E, 
Pajuelo Pando A, Rodríguez Vidal J, Wheatley D, Bronk Ramsey C, Dunbar E, Delgado-Huertas A, Mora González A, Bayliss A, Beavan N, Hamilton D, Whittle A (2018) Assembling the dead, gathering the living: radiocarbon dating and Bayesian modelling for Copper Age Valencina de la Concepción (Sevilla, Spain). J World Prehist 31(2):179-313

Giannitrapani E, Ianni F (2011) Le Tarde età del Rame nelle Sicilia central. In: Genick CD, Curci A (eds) Atti della XLIII Riunione Scientifica IIPP, Età del Rame in Italia (Bologna 2008). Alma Mater Studiorum Università di Bologna, Dipartimento di Archeologia, Bologna, pp 271-278

Giannitrapani E (2013) Cronologia assoluta della tarda età del rame nella Sicilia central. In: Cocchi Genik D (ed) Chronologia assoluta e relative dell'età del rame in Italia, Atti dell'Incontro di Studi Università di Verona, 25 giugno 2013. QuiEdit, Verona, pp 190-191

Gillespie R, Hedges REM, White NR (1983) The Oxford radiocarbon accelerator facility. Radiocarbon 25:729-737

Grima R (2001) An iconography of insularity: a cosmological interpretation of some images and spaces in the Late Neolithic temples of Malta. Papers from the Institute of Archaeology 12:48-65

Grima R (2003) Image, order and place in Late Neolithic Malta. In: Wilkins JB, Herring E (eds) Inhabiting symbols: symbol and image in the ancient Mediterranean. Accordia Research Centre, University of London, London, pp 29-41

Grima R (2008) Landscape, territories, and the life-histories of monuments in Temple period Malta. J Mediterr Archaeol 21:35-56

Grima R (2016) Water, geomythology and cosmology in late Neolithic Malta. Accordia Research Papers 14:27-48

Hayden B (1995) Pathways to power: principles for creating socioeconomic inequalities. In: Price TD, Feinman GM (eds) Foundations of social inequality. Plenum Press, New York and London, pp 15-86

Hayden B (2001) Richman, poorman, beggarman, chief: the dynamics of social inequality. In: Feinman GM, Price TD (eds) Archaeology at the millennium: a sourcebook. Kluwer Academic/Plenum Publishers, New York, pp 231-272

Hedges REM (1981) Radiocarbon dating with an accelerator: review and preview. Archaeometry 23:1-18

Hedges REM, Bronk CR, Housley RA (1989) The Oxford accelerator mass spectrometry facility: technical developments in routine dating. Archaeometry 31:99-114

Hedges REM, Humm MJ, Foreman J, van Klinken GJ, Bronk CR (1992) Developments in sample combustion to carbon dioxide, and in the Oxford AMS carbon dioxide ion source system. Radiocarbon 34: 306-311

Hedges REM, Law IA (1989) The radiocarbon dating of bone. Appl Geochem 4:249-253

Lai L, O'Connell T, Tykot RH (2009) Diet and environment in Maltese prehistory: results and potentials of a stable isotopic perspective on the Circle. In: Malone C, Stoddart S, Bonanno A, Trump D (eds) Mortuary customs in prehistoric Malta: excavations at the Brochtorff Circle at Xaghra (1987-94). McDonald Institute for Archaeological Research, Cambridge, pp 335-340

Lanting JN, van der Plicht J (1998) Reservoir effects and apparent ages. J Ir Archaeol 9:151-165

Law I A, Hedges R E M (1989) A semi-automated bone pretreatment system and the pretreatment of older and contaminated samples. In: Long A, Kra R S, Srdoc D (eds) Proceedings of the 13th International ${ }^{14} \mathrm{C}$ Conference, Radiocarbon 31(3): 247-53

Longin R (1971) New method of collagen extraction for radiocarbon dating. Nature 230:241-242

Malone C (2018) Manipulating the bones: eating and augury in the Maltese temples. In: Renfrew C, Morley I, Boyd M (eds) Ritual, play and belief in evolution and early human societies. Cambridge University Press, Cambridge, pp 187-207

Malone C, Brogan C, McLaughlin TR, Stoddart S (2016) Small island sustainability and a case study for Malta. In: Cazzella A, Guidi A,
Nomi F (eds) Ubi minor... Le isole minori del Mediterraneo centrale dal Neolitico ai primi contatti coloniali, Scienze dell'Antichità 22.2. Sapienza Università di Roma, Rome, pp 403-416

Malone C, McCormick F, McLaughlin TR, Stoddart S (in press) Megaliths, people and palaeoeconomics in Neolithic Malta. In: Muller J, Hinz M (eds) Megaliths, societies, landscapes: early monumentality and social differentiation in Neolithic Europe. Frühe Monumentalität und Soziale Differenzierung, Institut für Ur- und Frühgeschichte in Kiel, Dr. Rudolf Habelt Verlag, Bonn

Malone C, McLaughlin R, Mercieca-Spiteri B, Parkinson E, Power R, Stock J, Stoddart S, Thompson J (2018) The social implications of death in prehistoric Malta. In: Schmitt A, Déderix S, Driessen J, Crevecoeur I (eds) Gathered in death. Presses Universitaires de Louvain, Louvain-la-Neuve, Aegis Archéologie du Monde Minoen, pp 128-142

Malone C, Stoddart S, Bonanno A, Gouder T, Trump D (1995) Mortuary ritual of 4th millennium BC Malta: the Żebbug period chambered tomb from the Brochtorff circle at Xaghra (Gozo). Proc Prehist Soc 61:303-345

Malone C, Stoddart S (2011) Maltese prehistoric religion. In: Insoll T (ed) The Oxford handbook of the archaeology of ritual and religion. Oxford University Press, Oxford, pp 758-774

Malone C, Stoddart S, Bonanno A, Trump D (eds) (2009) Mortuary customs in prehistoric Malta: excavations at the Brochtorff Circle at Xaghra (1987-94). McDonald Institute for Archaeological Research, Cambridge

McLaughlin TR, Malone C, French C, Stoddart S, Brogan C, Parkinson E, Armstrong S (in prep) Excavations at Santa Verna. In: Malone C, McLaughlin TR, Stoddart S (eds) Excavations of Maltese prehistory. (FRAGSUS Project Monograph II.). McDonald Institute for Archaeological Research, Cambridge

Mercieca Spiteri B (2016) Re-examining the prehistoric human remains from the Xaghra Circle. In: Sultana S, Vella G (eds) Tesserae: the heritage Malta bulletin, vol issue 3. Midsea Books, Malta, pp 58-67

Mifsud A, Mifsud S (1997) Dossier Malta: evidence for the Magdalenian. Proprint, Malta

Mook WG (1986) Business meeting: recommendations/resolutions adopted by the twelfth international radiocarbon conference. Radiocarbon 28:799

Pace A (2000) The fal Saflieni hypogeum: 4000 BC-2000 AD. National Museum of Archaeology and Museums Department, Malta

Pace A (2002) The Maltese Bronze Age. In: Cilia D (ed) Malta before history. Miranda, Malta, pp 211-227

Reimer PJ, Bard E, Bayliss A, Beck JW, Blackwell PG, Bronk Ramsey C, Buck CE, Cheng H, Edwards RL, Friedrich M, Grootes PM, Guilderson TP, Haflidason H, Hajdas I, Hatté C, Heaton TJ, Hoffmann DL, Hogg AG, Hughen KA, Kaiser KF, Kromer B, Manning SW, Niu M, Reimer RW, Richards DA, Scott EM, Southon JR, Staff RA, Turney CSM, van der Plicht J (2013) Intcal 13 and marine 13 radiocarbon age calibration curves $0-50,000$ years cal BP. Radiocarbon 55:1869-1887

Reimer P, Hoper S, McDonald J, Reimer R, Svyatko S, Thompson M (2015) Laboratory protocols used for AMS radiocarbon dating at the ${ }^{14}$ CHRONO Centre, The Queen's University, Belfast. In: English Heritage research report 5-2015. English Heritage, Portsmouth

Renfrew AC (1973) Before civilization: the radiocarbon revolution and prehistoric Europe. Jonathan Cape, London

Richards MP, Hedges REM, Walton I, Stoddart S, Malone C (2001) Neolithic diet at the Brochtorff Circle, Malta. Eur J Archaeol 2: 253-262

Robb J (2001) Island identities: ritual, travel, and the creation of difference in Neolithic Malta. Eur J Archaeol 4:175-202

Robb J (2007) The ancient Mediterranean village: agency, material culture, and social change in Neolithic Italy. University Press Cambridge, Cambridge 
Sayle KL, Cook GT, Ascough PL, Gestsdóttir H, Hamilton WD, McGovern TH (2014) Utilization of $\delta^{13} \mathrm{C}, \delta^{15} \mathrm{~N}$, and $\delta^{34} \mathrm{~S}$ analyses to understand ${ }^{14} \mathrm{C}$ dating anomalies within a Late Viking Age community in Northeast Iceland. Radiocarbon 56:811-821

Schuhmacher TX, Cardoso JL, Benerjee A (2009) Sourcing African ivory in chalcolithic Portugal. Antiquity 83:983-997

Scott EM (2003) The third international radiocarbon intercomparison (TIRI) and the fourth international radiocarbon intercomparison (FIRI) 1990-2002: results, analyses, and conclusions. Radiocarbon 45:135-150

Scott EM, Cook GT, Naysmith P, Bryant C, O’Donnell D (2007) A report on phase 1 of the 5 th international radiocarbon intercomparison (VIRI). Radiocarbon 49:409-426

Scott EM, Cook GT, Naysmith P (2010) A report on phase 2 of the fifth international radiocarbon intercomparison (VIRI). Radiocarbon 52: $846-858$

Skeates R (2010) An archaeology of the senses: prehistoric Malta. Oxford University Press, Oxford

Slota PJ Jr, Jull AJT, Linick TW, Toolin LJ (1987) Preparation of small samples for ${ }^{14} \mathrm{C}$ accelerator targets by catalytic reduction of $\mathrm{CO}$. Radiocarbon 29:303-306

Speciale C (2011) La facies di San Cono-Piano Notaro-Grotta Zubbia nel quadro delle relazioni con l'Egeo nel primo Eneolitico siciliano. In: Cocchi Genick D, Curci A (eds) Atti della XLIII Riunione Scientifica IIPP. Età del Rame in Italia. (Bologna 2008). Alma Mater Studiorum Università di Bologna, Dipartimento di Archeologia, Bologna, pp 489-493

Steier P, Rom W (2000) The use of Bayesian statistics for 14C dates of chronologically ordered samples: a critical analysis. Radiocarbon 42:183-198

Stoddart S, Bonanno A, Gouder T, Malone C, Trump DH (1993) Cult in an island society: prehistoric Malta in the Tarxien period. Camb Archaeol J 3:3-19

Stuiver M, Polach HA (1977) Reporting of ${ }^{14} \mathrm{C}$ data. Radiocarbon 19: $355-363$
Stuiver M, Reimer PJ (1986) A computer program for radiocarbon age calculation. Radiocarbon 28:1022-1030

Stuiver M, Reimer PJ (1993) Extended ${ }^{14} \mathrm{C}$ data base and revised CALIB $3.0{ }^{14} \mathrm{C}$ age calibration program. Radiocarbon $35: 215-230$

The Times of Malta (2009) 5000-year-old tombs under study in Kercem. Published 10 October, 2009

Trump D (1966) Skorba: excavations carried out on behalf of the National Museum of Malta, 1961-1963. Society of Antiquaries, London

Trump DH (1976) The collapse of the Maltese temples. In: de G SG, Longworth I, Wilson KE (eds) Problems in economic and social archaeology. Duckworth, London, pp 605-610

Trump DH (2000) Malta: an archaeological guide. Progress Press, Valletta

Trump DH (2002) Malta: prehistory and temples. Midsea Books, Malta

Trump DH (2004) Dating Malta's prehistory. In: Cilia D (ed) Malta before history. Miranda, Malta, pp 230-242

Trump D, Stoddart S, Malone C (2009) The pottery. In: Malone C, Stoddart S, Bonanno A, Trump D (eds) Mortuary customs in prehistoric Malta: excavations at the Brochtorff Circle at Xaghra (1987-94). McDonald Institute for Archaeological Research, Cambridge, pp 220-242

Vandeputte K, Moens L, Dams R (1996) Improved sealed-tube combustion of organic samples to $\mathrm{CO}_{2}$ for stable isotope analysis, radiocarbon dating and percent carbon determinations. Anal Lett 29:27612773

Vella C (2016) Constructions of consensus: monument building and the fourth to first millennium BC in the central Mediterranean islands. J Mediterr Archaeol 29:225-245

Ward GK, Wilson SR (1978) Procedures for comparing and combining radiocarbon age determinations: a critique. Archaeometry 20:19-31

$\mathrm{Xu} \mathrm{S}$, Anderson R, Bryant C, Cook GT, Dougans A, Freeman S, Naysmith P, Schnable C, Scott AEM (2004) Capabilities of the new SUERC 5MV AMS facility for ${ }^{14} \mathrm{C}$ dating. Radiocarbon 46 : $59-64$ 